. 
STREAMGAGING CABLEWAYS

By C. RUSSELL WAGNER

U.S. GEOLOGICAL SURVEY

Open-File Report 91-84

Stennis Space Center, Mississippi 


\section{U.S. DEPARTMENT OF THE INTERIOR \\ MANUEL LUJAN, JR., Secretary \\ U.S. GEOLOGICAL SURVEY \\ Dallas L. Peck, Director}

For additional information, write to:

Office of Surface Water Water Resources Division U.S. Geological Survey Stennis Space Center, MS 39529
Copies of this report can be purchased from:

U.S. Geological Survey Books and Open-File Reports sect Federal Center, Box 25425 Denver, Colorado 80225 


\section{PREFACE}

This document was prepared to serve as a "user friendly" design guide for construction of streamgaging cableways. It supersedes Circular 17, prepared by C.H. Pierce in 1947.

Many individuals contributed to the development of this report. The following U.S. Geological Survey personnel served as a technical review board: C.W. Boning, E.D. Cobb, A.C. Condes, H.C. Gunter, G.C. Gravlee, E.F. Hubbard, L.L. Hubbard and R.R. Shields.

Engineering design was by D.L. Cote and G. Garic under the supervision of J.E. Bowie of Sverdrup Technologies, Inc.

The entire report was reviewed by S.G. Bonasso, an international consultant in tramway structures, of Alpha Associates. 



\section{CONTENTS}

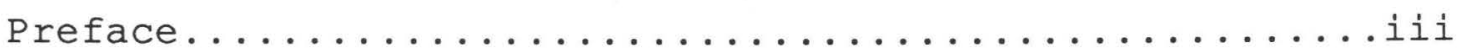

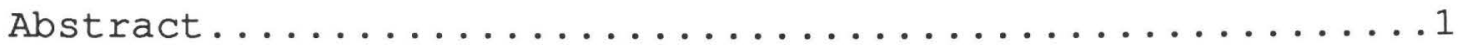

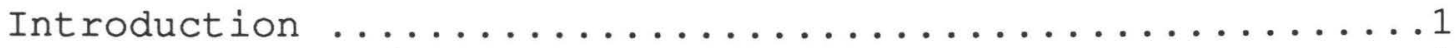

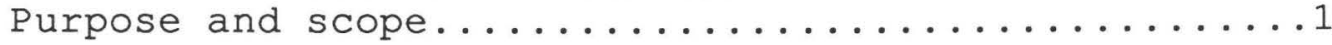

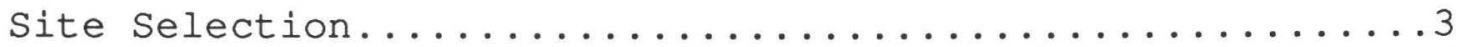

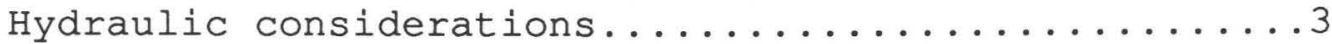

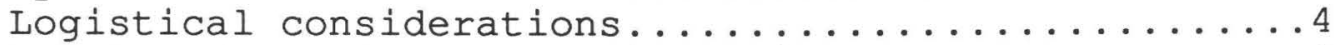

Legal and regulatory considerations..............

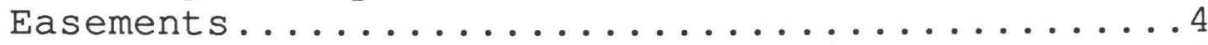

U.S. Army Corps of Engineers requirements.....4 Federal Aviation Administration

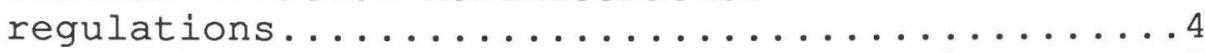

Other state and local laws and regulations:....5

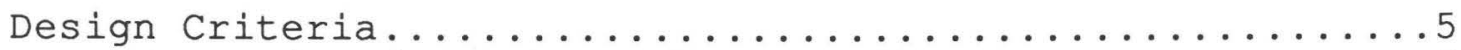

Determination of the 100 -year flood stage..........5

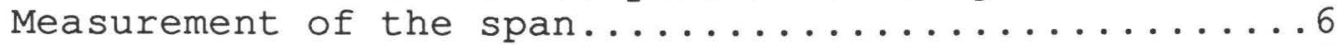

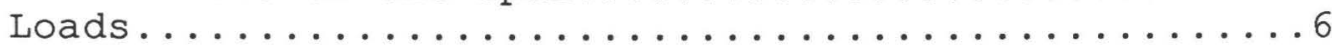

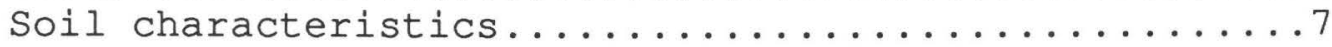

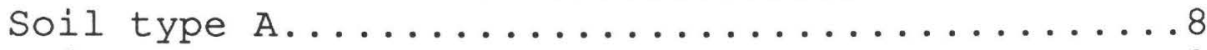

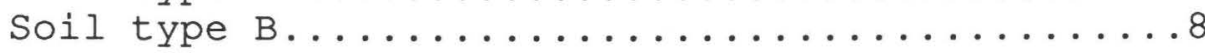

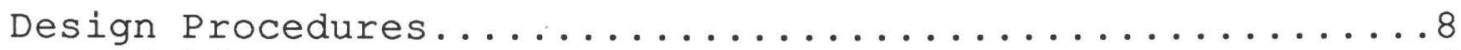

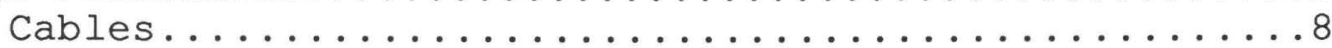

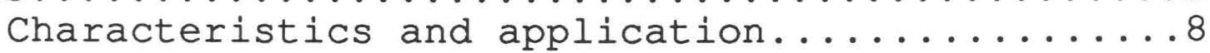

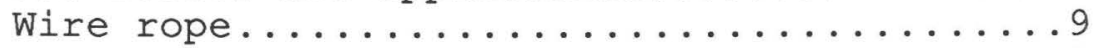

Tramway or structural strand..........10

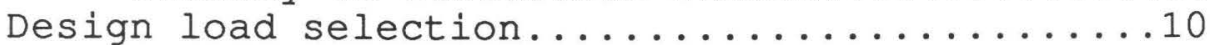

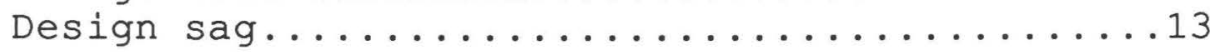

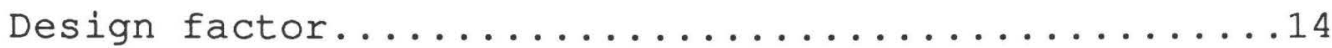

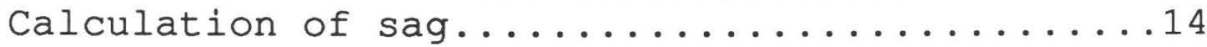

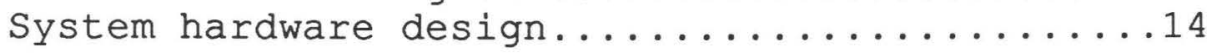

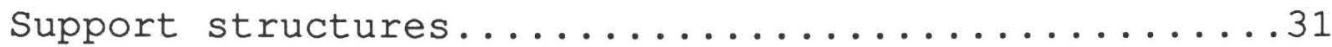

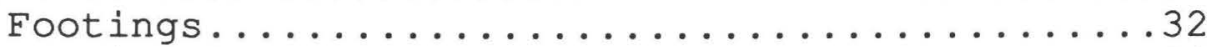

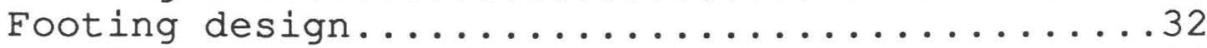

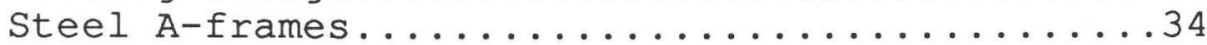

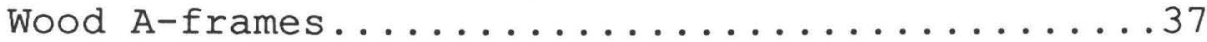

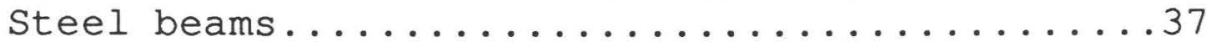

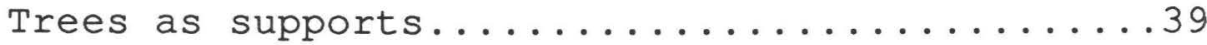

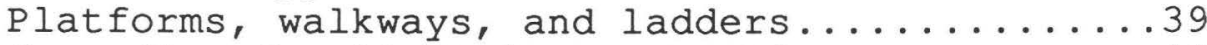

Grounding for lightning protection..........40

Anchorages............................ 41

Concrete mass anchors...............41

Hillside anchors.................42

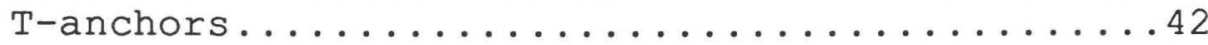




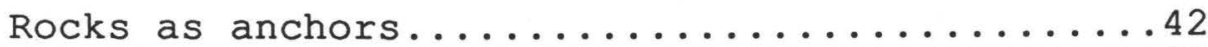

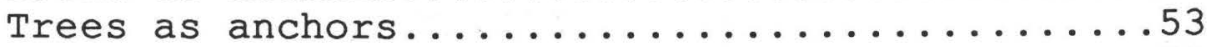

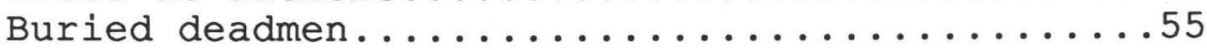

Aircraft warning devices..................56

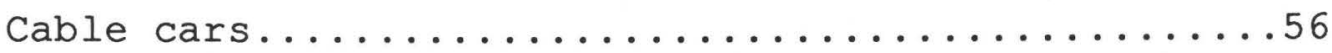

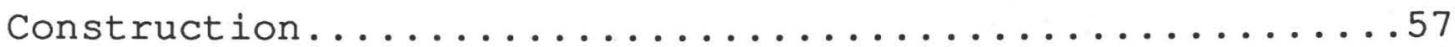

Excavating for anchors and support structures.....57

Preparing concrete for anchors and support

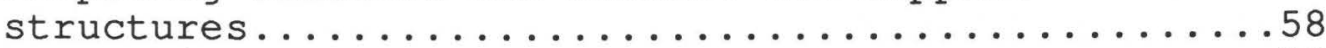

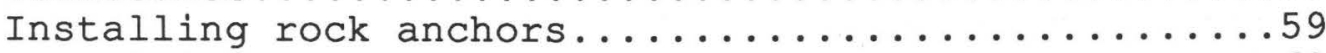

Installing tree supports or anchors..........6. 60

Erecting A-frames and cable...............60

Installing grounds....................65

Grounding rods...................65

Wire grounds.....................66

Cableways conforming to Circular 17 specifications......66

Documentation..........................66

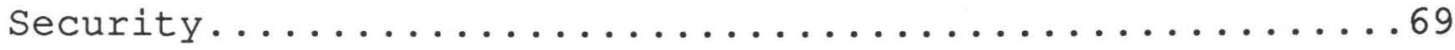

Inspection and Maintenance..................69

Anchors and footings.....................70

Main cable supports....................70

Main cable...........................

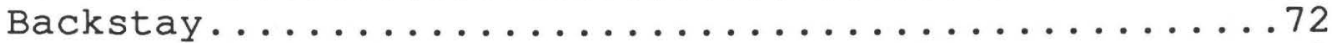

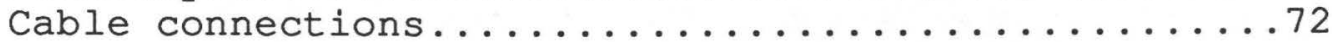

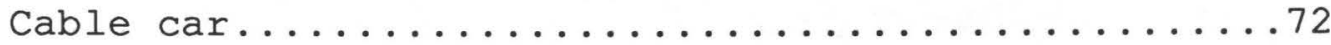

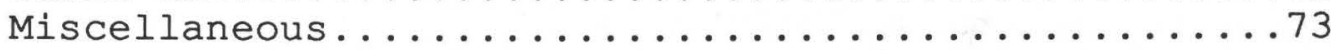

Selected References.......................74

Glossary...........................

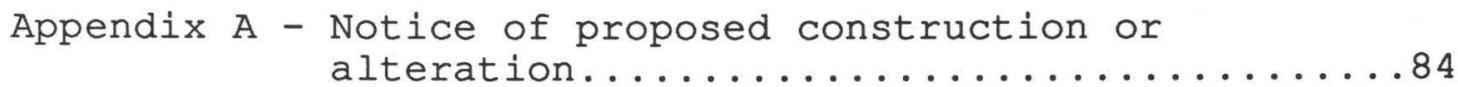

Appendix B - Cableway design summary............. 86

Appendix C - Painting and preservation guidelines......88 


\section{ILLUSTRATIONS}

Figures 1-2. Sketches showing:

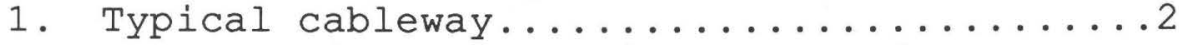

2. Construction of (A) wire rope and

(B) structural strand...............12

Figures 3-14. Sag diagrams and selection guides for:

3. $6 \times 19$ IWRC extra improved plow steel wire rope and cable-car load of

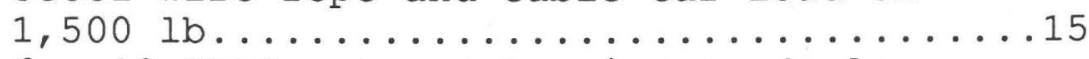

4. $6 \times 19$ IWRC extra extra improved plow steel wire rope and cable-car load of

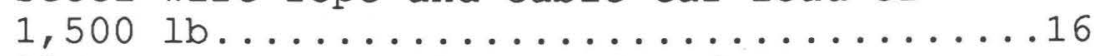

5. Class A structural strand and cable-car load of $1,5001 b \ldots \ldots \ldots \ldots$

6. $6 \times 19$ IWRC extra improved plow steel wire rope and cable-car load of

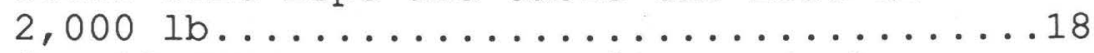

7. $6 \times 19$ IWRC extra extra improved plow steel wire rope and cable-car load of

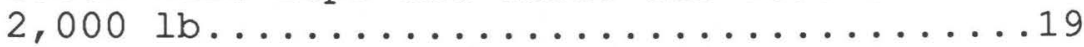

8. Class A structural strand and cable-car load of 2,000 1b............20

9. $6 \times 19$ IWRC extra improved plow steel wire rope and cable-car load of

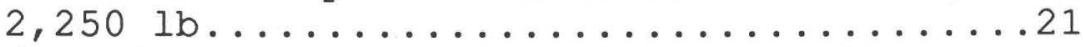

10. $6 \times 19$ IWRC extra extra improved plow steel wire rope and cable-car load of

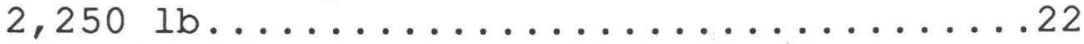

11. Class A structural strand and cable-car load of $2,2501 \mathrm{~b} \ldots \ldots \ldots \ldots . \ldots 23$

12. $6 \times 19$ IWRC extra improved plow steel wire rope and cable-car load of

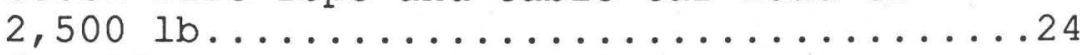

13. 6 × 19 IWRC extra extra improved plow steel wire rope and cable-car load of

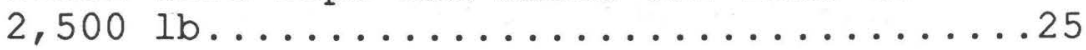

14. Class A structural strand and cable-car load of $2,5001 b \ldots \ldots \ldots \ldots$

\section{Figures 15-35. Sketches showing:}

15. How to measure (or caliper) a wire rope...27

16. Various dimensions of a sheave and the use of a groove gage..............27

17. Cross-section sketches illustrating three sheave-groove conditions...................28

18. Typical cast iron cable saddle block.....28

19. U-bar and bearing block....................

20. Single and combined footing reinforcing

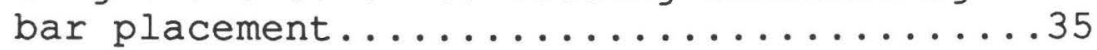

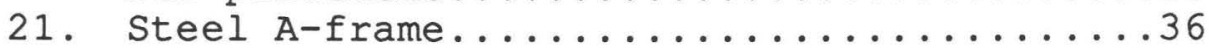




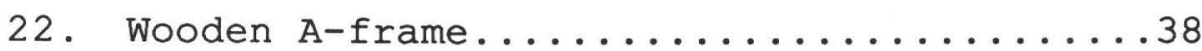

23. Anchorage for cableway positioned at $30^{\circ} .43$

24. Anchorage for cableway positioned at $45^{\circ} .44$

25. Sidehill anchorage for 10,000-pound working load...................46

26. Sidehill anchorage for 15,000-pound working load...................47

27. Sidehill anchorage for 20,000-pound working load....................48

28. Sidehill anchorage for 25,000-pound working load....................49

29. Sidehill anchorage for 30,000-pound working load......................50

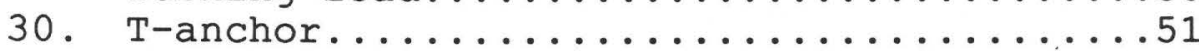

31. Vertical rock anchor................54

32. Horizontal rock anchor ...............55

33. Wire-rope seizing technique and final product....................61

34. Hammer-type cable cutter...........62

35. Correct way to attach cable clips.......63

Figures 36-37. Diagrams showing:

36. Sag diagram for improved plow-steel

6 × 7 wire rope (cable).............67

37. Sag diagram for extra high strength tramway track strand of various diameters...................68

TABLES

Table 1. Strength comparison for various cable materials......................11

2. Hardware component sizes..............29

3 . Bearing areas of footings..................

4. Anchorages for $35^{\circ}$ and $45^{\circ}$ cables.......45

5. T-anchor dimensions..............52

6. Recommended number of clips, torque, and dead-end turnback for wire rope......64 


\section{CONVERSION FACTORS}

\section{Multiply}

inch (in.)

foot (ft)

square foot ( $\left.f t^{2}\right)$

cubic foot $\left(\mathrm{ft}^{3}\right)$

cubic yard $\left(\mathrm{yd}^{3}\right)$

pound, avoirdupois

pound, force (lbf)

foot-pound (ft.lb)

pound per square

inch $\left(1 \mathrm{~b} / \mathrm{in}^{2}\right)$

pound per cubic

foot $\left(1 \mathrm{~b} / \mathrm{ft} \mathrm{t}^{3}\right)$
By

25.4

0.3048

0.09294

0.02832

0.7646

0.4536

4.4482

1. 3558

6.895

16.01846

\section{To obtain}

millimeter (mm)

meter (m)

square meter $\left(\mathrm{m}^{2}\right)$

cubic meter $\left(\mathrm{m}^{3}\right)$

cubic meter $\left(\mathrm{m}^{3}\right)$

kilogram $(\mathrm{kg})$

newton (N)

newton meter $(\mathrm{N}-\mathrm{m})$

kilopascal (kPa)

kilogram per cubic meter $\left(\mathrm{kg} / \mathrm{m}^{3}\right)$ 



\title{
STREAMGAGING CABLEWAYS
}

\author{
By C. Russell Wagner
}

\section{ABSTRACT}

This manual provides a series of standard designs for streamgaging cableways used by the U.S. Geological Survey (USGS). It also provides helpful information on construction, inspection, and maintenance of cableways. Users of design recommendations are cautioned to follow sound engineering practice in selection of system components for a specific site. Accepted industry standards are referenced to facilitate procurement of materials where appropriate.

\section{INTRODUCTION}

Cableways have been used for many decades by the U.S. Geological Survey (USGS) and other organizations involved in the measurement of streamflow and collection of water-quality samples. In 1988 the Survey operated approximately 1,600 cableways. Properly constructed and maintained cableways are dependable and convenient platforms for obtaining water resources data. Highway bridges are becoming more dangerous due to high vehicle use, and some jurisdictions are either banning their use as a measuring platform or requiring prohibitive traffic control measures. The use of cableways eliminates the need for USGS personnel to work from dangerous highway bridges. Cableways also allow the selection of sites that offer optimum hydraulic characteristics for measuring stream discharge.

\section{Purpose and Scope}

The purpose of this manual is to establish guidelines for the design, construction, inspection, and maintenance of streamgaging cableways for use with manned cable cars. A typical cableway is shown in figure 1. Remote, bankoperated cableways are frequently used in Europe but have not been popular in the United States. Discussion of bankoperated cableways is not included in this report.

This manual provides design criteria for structures with a clear span of 1,000 ft or less and support heights of $30 \mathrm{ft}$ or less. These criteria are applicable to the majority of USGS structures. The USGS has built a few structures that have spans approaching 2,000 ft with support towers as high as $100 \mathrm{ft}$. Should future cableways be required that exceed the guidelines provided herein, it is strongly recommended that an experienced structural civil engineering organization, familiar with tramway structures, prepare complete sitespecific design and construction specifications. 


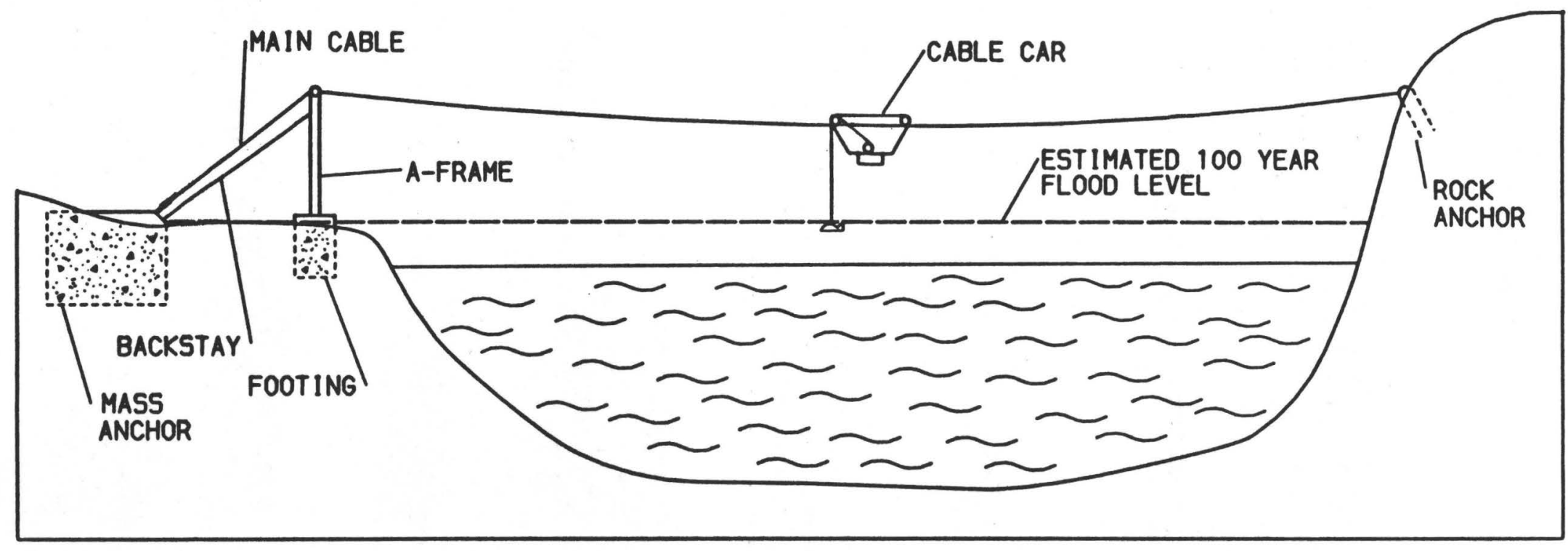

Figure 1.--Typical cableway. 
This manual is intended for use by USGS personnel with limited structural design experience. Careful adherence to design, construction, inspection, and maintenance guidelines covered in this manual should result in a safe and serviceable structure.

\begin{abstract}
WARNING
This document deals with people and machines working together. When this occurs, SAFETY, the freedom from, or limitation of, risk and danger, is of paramount importance. A cableway system is an embodiment of basic physical laws. It deals with high levels of energy, during both construction and operation. Therefore, IMPROPER construction techniques, maintenance, and $(o r)$ interpretation of the information contained in this document can result in serious injury or loss of life. Users of this document are cautioned to use the information contained herein only with the assistance and guidance of experienced engineers, technicians, construction and maintenance personnel, and trained inspectors.
\end{abstract}

\title{
SITE SELECTION
}

\section{Hydraulic Considerations}

The selection of the site for a cableway is based primarily on the hydraulic conditions of the river and the alignment and formation of the river banks. For current-meter measurements, the direction and pattern of the stream flow and the possible effect on the accuracy of the velocity observation are of major importance. Ideally, the channel should be straight at the place of measurement and the river should be flowing smoothly, without eddies or cross-currents. It is desirable that the flow be confined to one channel at all stages; sites having overflow or diversions into old channels should be avoided if possible. Particles of drift in surface flotation should move in parallel straight lines and in a direction that is normal to the axis of the cableway. The section should be free of large rocks and boulders that cause turbulence, and the bottom should be as smooth as possible. Observation of conditions at various stages of the river, particularly at medium and high stages, before selecting a site is recommended. Reconnaissance by low-flying aircraft or boat can assist in locating good cableway sites, especially on larger rivers. 


\section{Logistical Considerations}

Accessibility is an important consideration in the siting of a cableway. A site must be reasonably convenient for the field person, who must use the structure on a frequent basis. Because most cableways will be used for making high-flow measurements, access to the site at high-water conditions is a necessity. A river stage for the 100-year flood should be estimated to determine accessibility under such conditions. A structure that is inaccessible will not serve the intended purpose.

An exception to these guidelines may be made in those situations where a cableway will be used for medium stages only and where high-water measurements will be made from highway bridges or by other means.

\section{Legal and Regulatory Considerations}

Attention is needed to ensure that all easements are obtained from landowners and others and that applicable permits are obtained from appropriate federal, state, or local agencies, prior to cableway construction.

\section{Easements}

Many cableways are located on private property.

Regardless of the ownership of the land, written permission to locate a cableway must be obtained before construction is begun. USGS form 9-1482 is available for this purpose. Permission should include a right-of-way for construction, maintenance, and operation, especially if the access route crosses cultivated fields. It may take months to track down, verify, and obtain landowner permission.

\section{U.S. Army Corps of Engineers Requirements}

If the cableway is located on a river that is classed as "navigable," the U.S. Army Corps of Engineers (COE) may establish certain clearance requirements. Information about these requirements, as well as the necessary permits, may be obtained from the officer in charge of the local COE district. The permit from the COE usually specifies compliance with requirements issued by other departments of the Federal Government. These requirements must be ascertained as far in advance as possible and adhered to in the design and construction of the structure.

\section{Federal Aviation Administration Requirements}

Under the Federal Aviation Act of 1958, as amended, the Federal Aviation Administration (FAA) must receive notice of construction or alteration of structures more than $200 \mathrm{ft}$ in 
height, or of a height that exceeds other notice criteria found in Federal Aviation Regulations (FAR), Part 77. While it is unlikely that the USGS will build structures exceeding those criteria, this agency is encouraged to submit notice when cableways will be constructed in areas where low-flying small aircraft may be present. The notice should be on FAA Form 7460-1, "Notice of Proposed Construction or Alteration," and sent to the appropriate FAA regional office. Notice information, including addresses of FAA regional offices, is found on the cover sheet of the notice form. (See appendix A.)

Notice affords the FAA opportunity to study the potential effects of proposed objects on safe use of navigable airspace. One result of the FAA's notification is the inclusion on aeronautical charts of objects determined to be obstructions. Another result of the notification is the possible recommendation to mark and (or) light an obstruction to preserve air safety.

Other State and Local Laws and Regulations

State or local jurisdictions may require building permits, inspections, or other approvals. Some jurisdictions may require approval prior to excavation adjacent to streambanks. Local Survey offices are responsible for obtaining applicable permits or approvals.

\section{DESIGN CRITERIA}

The major factors that influence the design of a cableway installation are the elevations of the 100-year or design flood, the elevation of the bank at each of the support and anchorage locations, the stream width, the expected loading on the cable, and the soil characteristics at the cable support and anchorage locations. As the several parts of the design are interrelated to a considerable extent, some preliminary computations may be required before the final decision is made as to the cable size and the necessary sag. Appropriate sag diagrams (included in this report) are used in the preliminary computations. The physiography of the river banks and the approaches to the cableway may determine the positions of the supporting structures and anchorages and, therefore, the length of the span and the size and shape of the footings and anchorages. If possible, these should be on ground not subject to submergence because reduced soil-bearing strength will occur.

\section{Determination of the 100-Year Flood Stage}

Discharge measurements during high flow conditions are the most important and difficult to obtain. Cableways should be designed to allow 10 to $15 \mathrm{ft}$ clearance between the water 
surface and the loaded cable. An estimate of the 100-year stage should be made using appropriate Survey techniques.

Measurement of the Span

Preliminary studies, such as the analysis of the relative economies of practicable span length-support height combinations, may be based on approximate measurements of the span. However, before making the final design computations, an exact determination of the distance between the supports and the horizontal and vertical distances from the top of each support to the corresponding anchorage connection must be made. For short spans, the distance between the supports may be measured with steel tapes or a tag line, but, for spans exceeding several hundred feet, the distance should be determined by triangulation from a carefully measured base line or by highly accurate electronic distance-measuring equipment. The base line should be approximately as long as the span and all three angles of the triangle should be measured. If factory-installed socket connections are to be used, the measurements of the base line and the angles should be sufficiently exact to make it possible to compute the length of cable within an accuracy of $0.5 \mathrm{ft}$. To convert span distance to actual (catenary) cable length, a multiplier factor of 100.11 for 2 percent sag and 100.24 for 3 percent sag is used.

An error in determining the length of the span results in an error in the length of the wire rope purchased.

Consequently, compensating take-up adjustments must be made to achieve the required sag: the greater the uncertainty in the measurement of the span, the greater the provision required for take-up.

\section{Loads}

In structural design, the anticipated loads are the primary consideration. The structure is designed to carry those loads with an appropriate design factor. The maximum dead and live loads on a cableway in use for hydrologic data measurements can be determined.

The loads to be considered in the design of USGS cableway structures are (1) the dead-load weight of the cable, which may be the decisive or limiting load for long spans; (2) the concentrated load carried by the cable car, which includes the weight of the cable car and 2 people, the tension on the meter suspension cable attached to the car, and increased loads caused by debris snagged on the sounding line; and (3) loads caused by wind and ice.

The concentrated load that is carried by the cable car is critical to the safe design of the entire structure. As any experienced hydrographer knows, the greatest load is caused by 
snagging floating trees or similar debris during high-flow measurements. The breaking strength of the sounding cable, therefore, becomes an important component in the design load. The breaking strength of 0.125 -inch sounding cable used on some B-56 and all E-53 reels is 1,600 lb. The breaking strength of $0.100-i n c h$ sounding cable used on A-55 and some B56 reels is 1000 lb. Because no control is practical on the type of reel used at a particular site, use of the strongest (0.125-inch) cable must be assumed, except in a limited number of canals or other special light-duty cases. Other weight assumptions used in this report include the standard USGS cable car, $170 \mathrm{lb}$; sounding reel, $50 \mathrm{lb}$; and two field persons, 200 lb each. Therefore, a "standard design" should be about 2,250 1b. Where a power cable car may be used, a design load of 2,500 $\mathrm{lb}$ is appropriate. The concentrated design load is applied at the "worst case" location, the point of maximum sag.

The amount of allowable sag in the cable is also a critical design consideration. An unloaded sag of 2 percent of the span length is generally accepted and is used in the calculations that follow. A sag in excess of 3 percent of the span length could pose unrealistic difficulty to personnel operating the cable car and is not recommended.

The snagging of floating debris on the sounding line may cause a substantial downstream "tugging" on the cable, which would be transmitted to the cable supports (usually A-frames) as a rotational moment on the top of the support. This results in a large downward force on the downstream leg of the A-frame and may cause a negative (lifting) force on the upstream leg. Calculations used to compute loads on A-frames and their footings are based on (1) the maximum cable-car load at a distance of 25 percent of span, (2) all (150 ft) of the sounding line having been played out, and (3) a water surface to cable distance of $20 \mathrm{ft}$.

Wind and ice loadings were considered and were found to be negligible in comparison to the load previously discussed for cableways covered in this report. These loadings may be significant in the design of long spans or tall structures and should be carefully evaluated in site-specific designs where considered to be a factor.

\section{Soil Characteristics}

The design of anchorages and footings described in this report are based on soils, which are classified as one of the two soil types described below. Consultation with District personnel possessing a geology background is recommended. 


\section{Soil Type A}

Type A soils are described as coarse sand, gravel and coarse sand, fine sand, silty sands, loam, and granular soils with some clay. Calculations are based on an assumed sliding friction coefficient of 0.45 and a bearing strength of 3,000 $1 \mathrm{~b} / \mathrm{ft}^{2}$.

\section{Soil Type B}

Type B soils are described as soft clay and wet confined silt. Calculations are based on an assumed sliding friction coefficient of 0.35 and a bearing strength of $2,000 \mathrm{lb} / \mathrm{ft}^{2}$.

\section{DESIGN PROCEDURES}

This section provides standard designs for cableway system components. In the design of a cableway system, different factors of safety are used for its several parts. This is due to uncertainties with the nature of the material and the methods of its fabrication, the conditions of loading, and, in some instances, with the physical conditions at the site. The parts of the structure for which individual designs are necessary are (1) the wire rope or strand, commonly called the cable; (2) the supports, which are usually A-frames; the anchorages, usually imbedded in the ground; (4) the footings for the supports; (5) the anchorage connections; and (6) the backstays and guys. Local conditions and uses may require special consideration in the design such that standard plans can be used only to a limited degree. A Cableway Design Summary provides documentation of these selections and must be retained in District files (appendix B).

\section{Cables}

In the design process, it is necessary to consider the characteristics of each cable type in relation to the intended application. There are many cable configurations, each designed for specific purposes. The design process must include the selection of adequate design load, acceptable loaded and unloaded sag, and cable and hardware size and an economic analysis of alternatives.

\section{Characteristics and Application}

The material commonly referred to as "cable" within the Survey is technically known in the industry either as wire rope or as structural or tramway strand. These two types of cable differ significantly. 
Wire rope

Wire rope consists of three basic components; while few in number, these vary in both complexity and configuration so as to produce ropes for specific purposes or characteristics. The three basic components of a standard wire rope design are (1) the wires that form the strand, (2) the multi-wire strands laid helically around the core, and (3) the core.

Wire, for wire rope, is made of several materials, including steel, iron, stainless steel, monel, and bronze. By far the most widely used material is high-carbon steel, which is available in a variety of grades.

Steel wire strengths are appropriate to the particular grade of wire rope in which they are used. Grades of wire rope are referred to as traction steel (TS), mild plow steel (MPS), plow steel (PS), improved plow steel (IPS), and extra improved plow steel (EIP). Some manufacturers offer an even higher strength--extra, extra improved plow steel (EEIP).

The most common finish for steel wire is "bright" or uncoated. Steel wires may also be galvanized; that is, zinc coated. "Drawn galvanized" wire has the same strength as bright wire, but wire "galvanized at finished size" is usually 10 percent less in strength. In certain applications, "tinned" wire is used, but it should be noted that tin provides no sacrificial (cathodic) protection for the steel as does zinc and should not be used for USGS cableways.

Strands are made up of two or more steel wires, or a combination of steel and other materials such as natural or synthetic fibers, laid in any one of many specific geometric arrangements.

The core is the foundation of a wire rope; it is made of materials that will provide proper support for the strands under normal bending and loading conditions. Core materials include fibers (hard vegetable or synthetic) or steel. A steel core consists either of a strand or an independent wire rope. The two most commonly used core designations are: fiber core (FC) and independent wire rope core (IWRC). Catalog descriptions of the various available ropes usually include these abbreviations to identify the core type.

Lay is the term that defines the direction in which the strands pass around the core. Lang lay and regular lay are commonly used in wire rope. They can be fabricated in left or right lay; however, 90 percent of wire rope is right lay. If not fixed, the ends of lang-lay wire rope will untwist, which makes this type of wire rope unsuitable for most survey applications. Either right- or left-regular-lay wire rope better fits Survey needs, although right regular lay is more 
commonly available. Standard cable clips are designed for right lay ropes.

Fiber core ropes are important for retaining lubricating oils for moving ropes. However, for the Survey's applications, this type of rope is not recommended; the fiber may collect and hold moisture, which may cause internal corrosion and early failure.

The preferred wire rope for most Survey cableways of $1,000 \mathrm{ft}$ or less is $6 \times 19$, IWRC, EIP (or EEIP, if available) right-regular-lay galvanized wire rope.

This type of wire rope offers the best balance of durability, availability, strength, and cost for USGS applications. Other types may be used, but all features should be given careful consideration in the design process.

Tramway or structural strand

This type of cable consists of a single strand of wires. Typical construction features 19, 37, or 61 individual wires. Because the wire diameters are slightly larger than those used in typical wire rope, this type of cable is approximately 10 percent stronger than wire rope for comparable cable diameters. (A comparison of the strengths of various cable materials is presented in table 1.) However, it is less flexible than wire rope and its supporting structures require large-radius saddleblocks. End termination must be poured spelter or resin sockets or swaged sockets. Factory installations are strongly recommended for spelter or resin sockets and mandatory for swaged sockets. Its cost is substantially more than the cost of $6 \times 19$ IWRC wire rope. Survey usage of this type of cable is generally restricted to larger structures. Wire rope and structural strand construction are shown in figure 2 .

\section{Design Load Selection}

The selection of adequate design load is critical to reduce risks to field personnel. In addition to the obvious factors, the possibility of subsequent cableway enhancements and that of major flooding must also be taken into account in the selection process. Many cableways are built for streamflow measurement only; additional heavier or power equipment for sediment or water-quality work may be added later and should be considered in the design. Major flooding necessitates the use of heavier sounding weights and significantly increases the risk of snagging debris. If there is any doubt as to the optimal design, consideration should be given to selection of the larger cableway system. 
Table 1.--Strength comparison for various cable materials

[Design load (D.L.) = Catalog breaking strength of various galvanized materials (B.S.) $\div$ Design Factor of 5]

\begin{tabular}{|c|c|c|c|c|c|c|c|c|}
\hline \multirow[b]{2}{*}{$\begin{array}{l}\text { Diameter } \\
\text { (inches) }\end{array}$} & \multicolumn{2}{|c|}{$\begin{array}{c}\text { Structural } \\
\text { strand }\end{array}$} & \multicolumn{2}{|c|}{$\begin{array}{c}6 \times 19 \text { IWRC } \\
\text { EEIP }\end{array}$} & \multicolumn{2}{|c|}{$\begin{array}{c}6 \times 19 \text { IWRC } \\
\text { EIP } \\
\end{array}$} & \multicolumn{2}{|c|}{$\begin{aligned} 6 \times 19 \text { IWRC } \\
\text { IPS }\end{aligned}$} \\
\hline & $\begin{array}{l}\text { B.S. } 1 \\
\text { (pounds) } 5 \text { ) }\end{array}$ & $\begin{array}{c}\text { D.I. } \\
\text { (pounds) }\end{array}$ & $\begin{array}{l}\text { B.S. }{ }^{1} \\
\text { (pounds) }\end{array}$ & $\begin{array}{c}\text { D.I } \\
\text { (pounds) }\end{array}$ & $\begin{array}{l}\text { B.S. }{ }^{1} \\
\text { (pounds) }\end{array}$ & $\begin{array}{c}\text { D.L. } \\
\text { (pounds) }\end{array}$ & $\begin{array}{l}\text { B.S. } 1 \\
\text { (pounds) }\end{array}$ & $\begin{array}{c}\text { D.L. } \\
\text { (pounds) }\end{array}$ \\
\hline $3 / 4$ & 68,000 & 13,600 & 64,800 & 13,000 & 53,000 & 10,600 & 46,000 & 9,200 \\
\hline $\begin{array}{r}13 / 16 \\
7 / 8\end{array}$ & $\begin{array}{l}80,000 \\
92,000\end{array}$ & $\begin{array}{l}16,000 \\
18,400\end{array}$ & 78,800 & 15,800 & 71,600 & 14,300 & 62,200 & 12,400 \\
\hline $\begin{array}{r}15 / 16 \\
1\end{array}$ & $\begin{array}{l}108,000 \\
122,000\end{array}$ & $\begin{array}{l}21,600 \\
24,400\end{array}$ & 102,400 & 20,500 & 93,000 & 18,600 & 80,800 & 16,200 \\
\hline $\begin{array}{r}1 \quad 1 / 16 \\
11 / 8\end{array}$ & $\begin{array}{l}138,000 \\
156,000\end{array}$ & $\begin{array}{l}27,600 \\
31,200\end{array}$ & 128,700 & 25,700 & 117,000 & 23,400 & 108,800 & 21,800 \\
\hline $\begin{array}{r}13 / 16 \\
1 \quad 1 / 4\end{array}$ & $\begin{array}{l}172,000 \\
192,000\end{array}$ & $\begin{array}{l}34,400 \\
38,400\end{array}$ & 158,200 & 31,600 & 143,800 & 28,800 & 125,000 & 25,000 \\
\hline $13 / 8$ & 232,000 & 46,400 & 190,800 & 38,200 & 172,800 & 34,600 & 150,400 & 30,100 \\
\hline
\end{tabular}

${ }^{1}$ From Wire Rope Users Manual and catalogs of Briden American Corp. and Wire Rope Corporation of America, Inc. Similar values are available from other manufacturers' catalogs. 

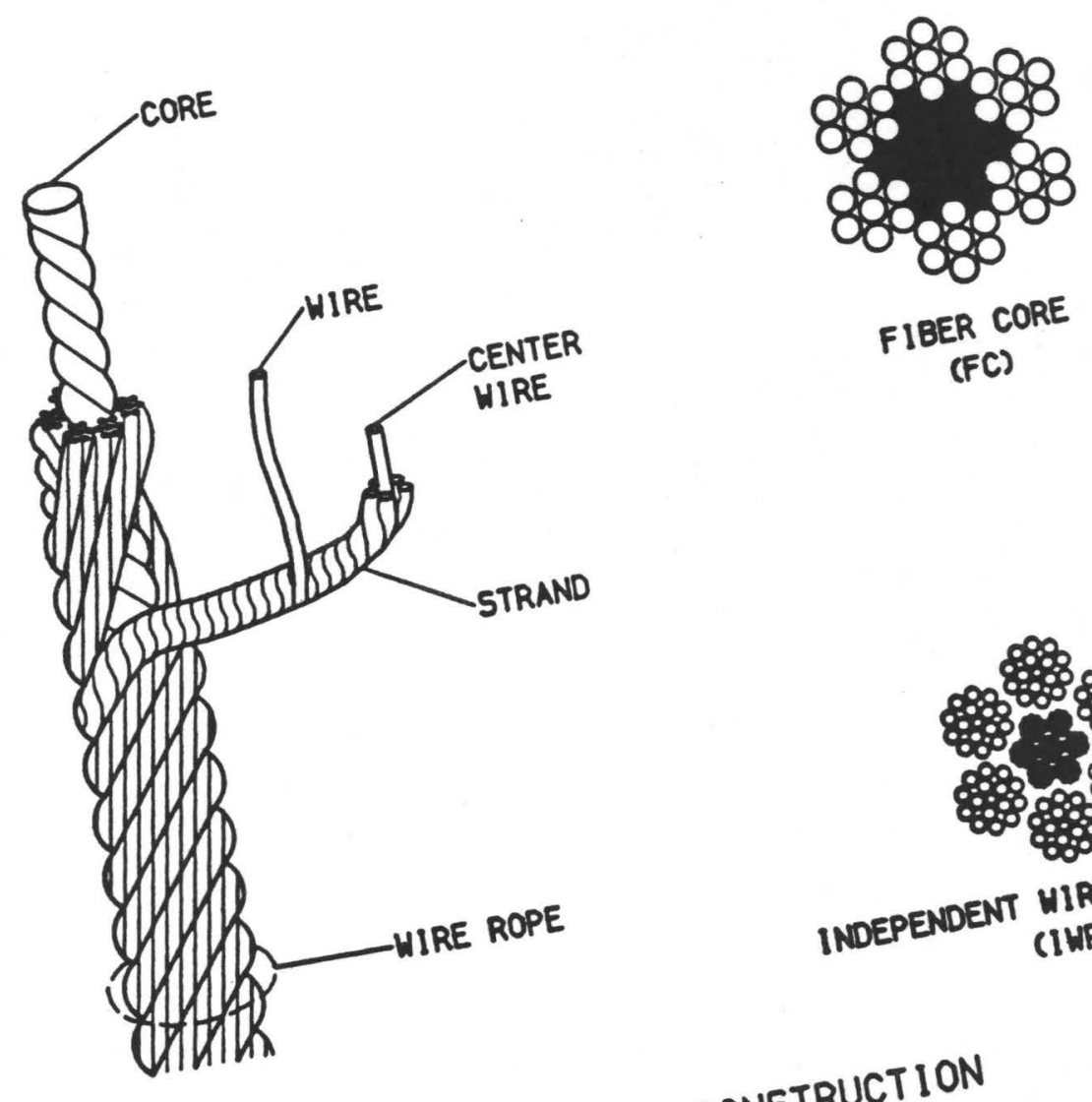

$$
\begin{aligned}
& \text { FIBER CORE } \\
& \text { (FC) }
\end{aligned}
$$

A. WIRE ROPE CONSTRUCTION INDEPENDENT UIRE ROPE CENTER
(IHRC)
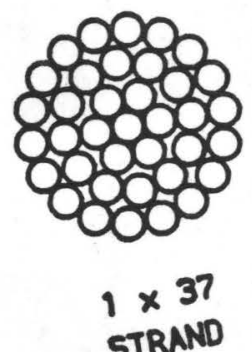

STRNND

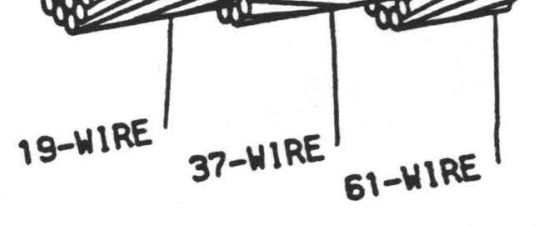

B. STRUCTURAL STRAND CONSTRUCTION Eigure 2.--Construction of (A) witral strand. 
Cableway design load criteria are as follows:

$1,500 \mathrm{lb} \quad$ Suitable only for cableways spanning slow-moving streams or canals with light suspension systems (A-pack or A-reels) and negligible possibility of floating drift.

$2,0001 b$

Suitable for small-to-medium streams with low velocity and little chance of floating debris during peak runoff periods.

$2,2501 \mathrm{~b}$

Suitable for most streamflow conditions. This system is designed for safe operations with two men in the cable car, with forces to failure in suspension systems on B-56 and E-53 reels.

$2,5001 b$

Suitable for heavy-duty sediment and water-quality sampling or streamflow measurements with powered cable cars.

Cableways will be designed for 2,250-pound loads except in unusual conditions. Station documentation must include justification to support installation of lighter load systems.

\section{Design Sag}

Sag is defined as the vertical distance between the low point in a cable measured from a straight line between two points of support. Unloaded, or erection, sag is this distance taking into consideration only the weight of the cable, and loaded sag is this distance with the design load applied at the point of maximum sag. In the application of a cable stretched horizontally between two anchors, the amount of allowable sag becomes a major design consideration. Decreasing the sag greatly increases the cable tension, resulting in the need for stronger cables and support and anchorage structures. Increasing the sag requires taller supports and imposes difficult operating conditions for personnel operating the system.

Sag calculations used in this report are based on unloaded sag of 2 percent of the span. The 2 percent sag is consistent with International Organization for Standardization (ISO) recommendations and has also been adopted by water Survey Canada. Sag expressed as a percentage of span also makes sag inspection easier as no tables or curves are necessary. 


\section{Design Factor}

Design load (tension) is defined as the cable's breaking strength divided by the design factor, previously known as safety factor.

Appropriate design factors for static cable have been suggested as 3 to 4 in Machinery's Handbook, 21st edition, page 84, and 3 to 5 in Marks' Handbook for Mechanical

Engineering, 8th edition, pages 10 to 35. A design factor of five is used in this application because of the potentially long service life--50 years or more. In the case of thimbleand-clip terminations, the strength of the termination is given as 80 percent of that of the cable. This reduction is deemed acceptable because integrity of the terminations is easily inspected.

\section{Calculation of Sag}

Loaded sag was calculated with the formula used by C.H. Pierce (1947). The formula is

$$
\begin{aligned}
& \text { Loaded } \text { sag }=\frac{S(W S+2 \mathrm{P})}{8 \mathrm{H}}, \\
& \text { where } \quad \begin{aligned}
\mathrm{S} & =\text { Span, in feet; } \\
\mathrm{W} & =\text { Cable weight per foot (from } \\
& \text { manufacturers' catalogs); } \\
\mathrm{P} & =\text { Concentrated load at center span; and } \\
\mathrm{H} & =\text { Horizontal component of tension. }
\end{aligned}
\end{aligned}
$$

This is the parabolic approximation of the basic physics relationship between the cable and the load it supports.

The calculation of unloaded sag was performed by a public domain computer program developed by the U.S. Navy (Knutson, 1987). This program has the advantage of solving the true catenary solution rather than the parabolic solution used in previous reports.

Calculations of unloaded and loaded sag were made for loads of $1,500,2,000,2,250$ and $2,500 \mathrm{lb}$ and 3/4-, 7/8-, 1-, 1 1/8-, 1 1/4-, and 1 3/8-inch diameters. The results of these calculations are presented as sag diagrams and selection guides in figures 3 through 14.

\section{System Hardware Design}

Sheaves, saddle blocks, and attachment hardware such as sockets, thimbles, and cable clips must be matched properly to the size of wire rope being used. The measurement of the size of a cable may be done with a caliper, a wire rope gage, or by measuring the circumference and dividing by 3.1416. New wire rope may be 0-to-5 percent oversize. As cable is stretched, 


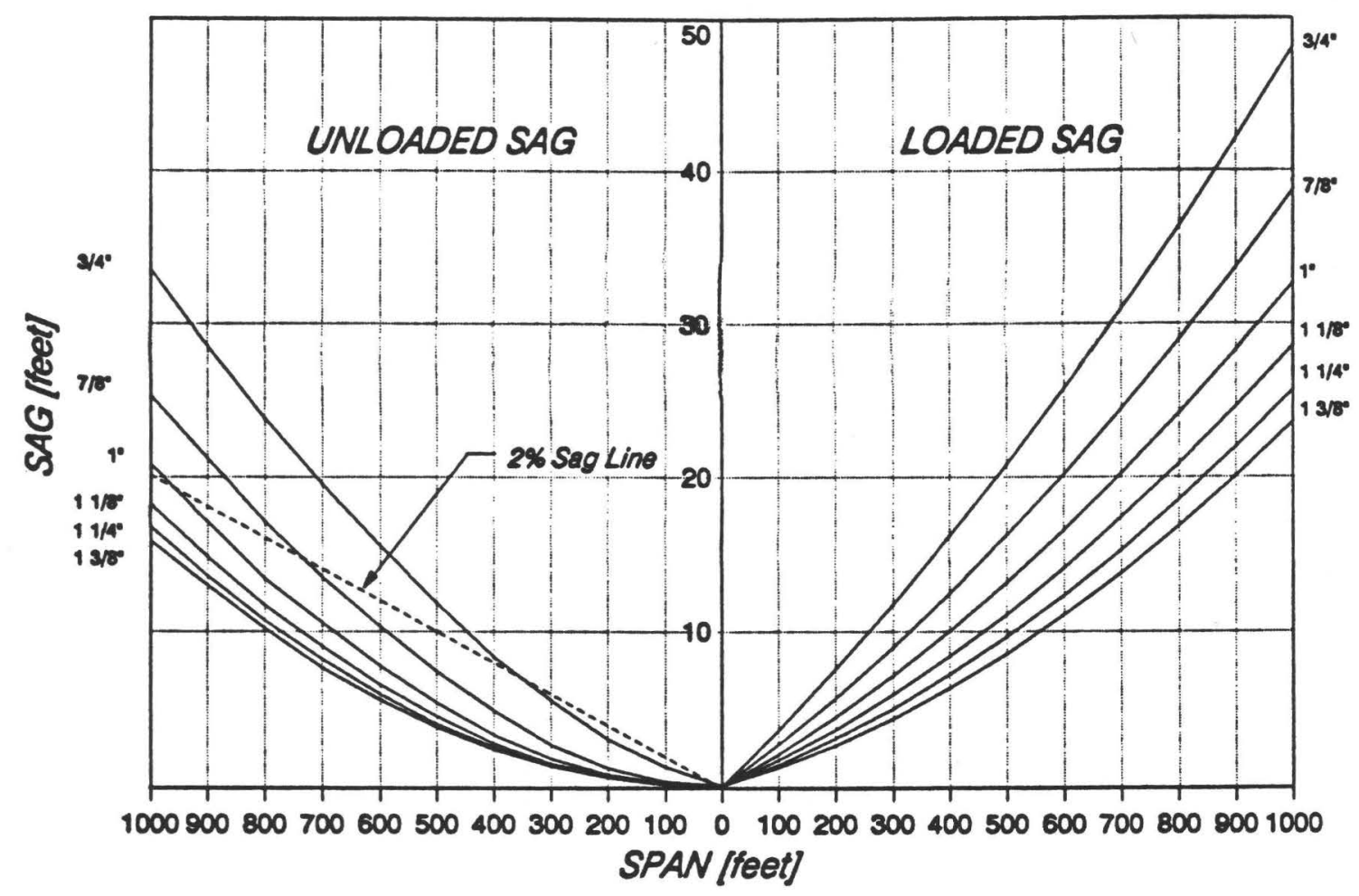

DIRECTIONS:

1. Select the desired span.

2. For unlisted spans, use the next largest span.

3. For the chosen span, use any cable diameter marked "OK".

\begin{tabular}{|c|c|c|c|c|c|c|}
\hline $\begin{array}{c}\text { CABLE DIAMETER } \\
\text { SPAN (feot) }\end{array}$ & $3 / 4^{\prime \prime}$ & $7 / 8^{\prime \prime}$ & $1^{\prime \prime}$ & $11 / 8^{\prime \prime}$ & $11 / 4^{\prime \prime}$ & $13 / 8^{\prime \prime}$ \\
\hline 100 & $O K$ & $O K$ & $O K$ & $O K$ & $O K$ & $O K$ \\
\hline 200 & $O K$ & $O K$ & $O K$ & $O K$ & $O K$ & $O K$ \\
\hline 300 & $O K$ & $O K$ & $O K$ & $O K$ & $O K$ & $O K$ \\
\hline 400 & $O K$ & $O K$ & $O K$ & $O K$ & $O K$ & $O K$ \\
\hline 500 & $x$ & $O K$ & $O K$ & $O K$ & $O K$ & $O K$ \\
\hline 600 & $X$ & $O K$ & $O K$ & $O K$ & $O K$ & $O K$ \\
\hline 700 & $x$ & $O K$ & $O K$ & $O K$ & $O K$ & $O K$ \\
\hline 800 & $x$ & $O K$ & $O K$ & $O K$ & $O K$ & $O K$ \\
\hline 900 & $x$ & $x$ & $O K$ & $O K$ & $O K$ & $O K$ \\
\hline 1000 & $X$ & $x$ & $O K$ & $O K$ & $O K$ & $O K$ \\
\hline
\end{tabular}

Figure 3.--Sag diagram and selection guide for $6 \times 19$ IWRC extra improved plow steel wire rope and cable-car load of $1,5001 \mathrm{~b}$. 


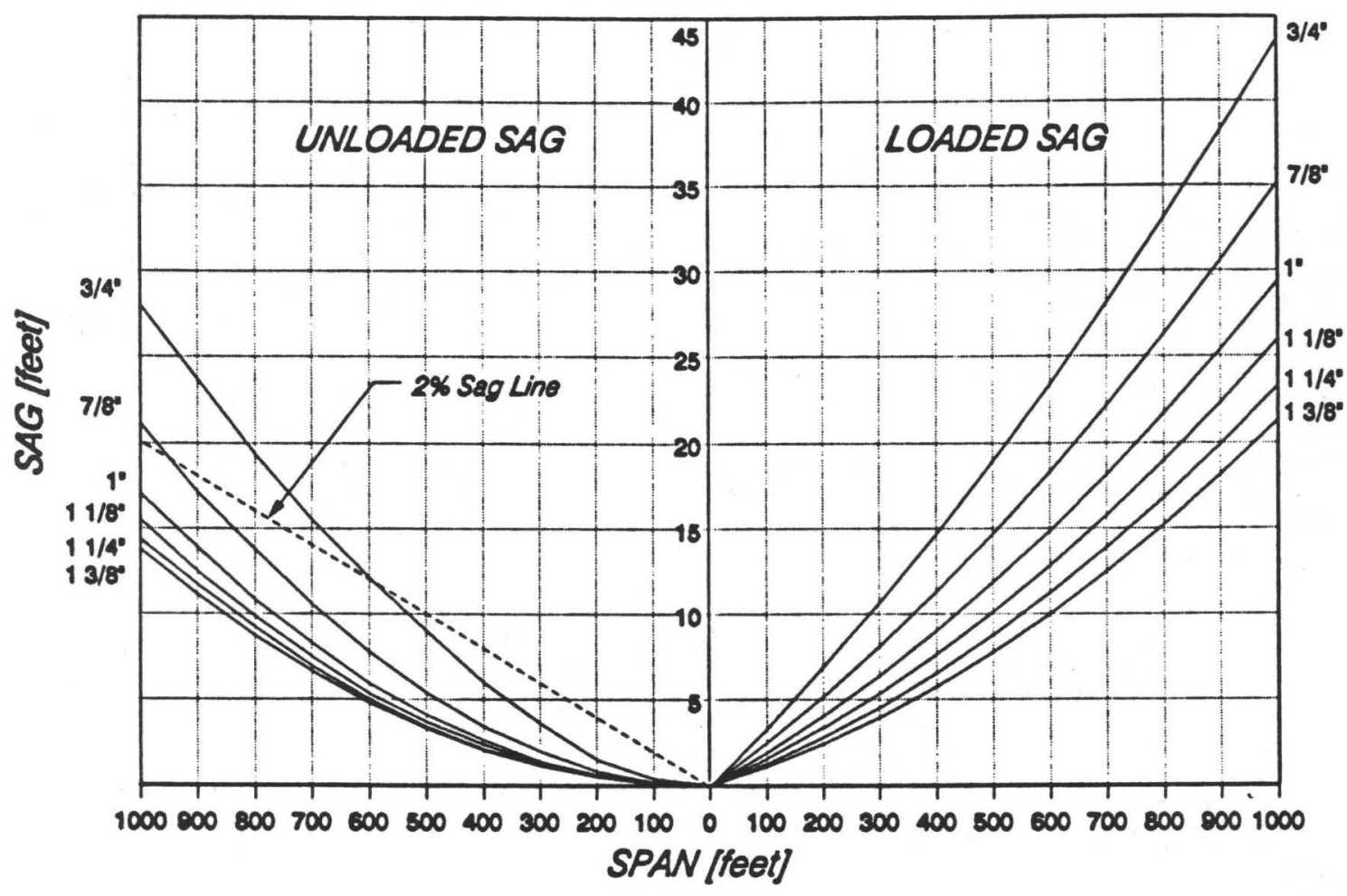

DIRECTIONS:

1. Select the desired span.

2. For unlisted spans, use the next largest span.

3. For the chosen span, use any cable diameter marked "OK".

\begin{tabular}{|c|c|c|c|c|c|c|}
\hline $\begin{array}{c}\text { CABLE DIAMETER } \\
\text { SPAN (feet) }\end{array}$ & $3 / 4^{\prime \prime}$ & $7 / 8^{\prime \prime}$ & $1^{\prime \prime}$ & $11 / 8^{\prime \prime}$ & $11 / 4^{\prime \prime}$ & $13 / 8^{\prime \prime}$ \\
\hline 100 & $O K$ & $O K$ & $O K$ & $O K$ & $O K$ & $O K$ \\
\hline 200 & $O K$ & $O K$ & $O K$ & $O K$ & $O K$ & $O K$ \\
\hline 300 & $O K$ & $O K$ & $O K$ & $O K$ & $O K$ & $O K$ \\
\hline 400 & $O K$ & $O K$ & $O K$ & $O K$ & $O K$ & $O K$ \\
\hline 500 & $O K$ & $O K$ & $O K$ & $O K$ & $O K$ & $O K$ \\
\hline 600 & $O K$ & $O K$ & $O K$ & $O K$ & $O K$ & $O K$ \\
\hline 700 & $X$ & $O K$ & $O K$ & $O K$ & $O K$ & $O K$ \\
\hline 800 & $X$ & $O K$ & $O K$ & $O K$ & $O K$ & $O K$ \\
\hline 900 & $X$ & $O K$ & $O K$ & $O K$ & $O K$ & $O K$ \\
\hline 1000 & $X$ & $X$ & $O K$ & $O K$ & $O K$ & $O K$ \\
\hline
\end{tabular}

Figure 4.--Sag diagram and selection guide for $6 \times 19$ IWRC extra extra improved plow steel wire rope and cable-car load of $1,500 \mathrm{lb}$. 


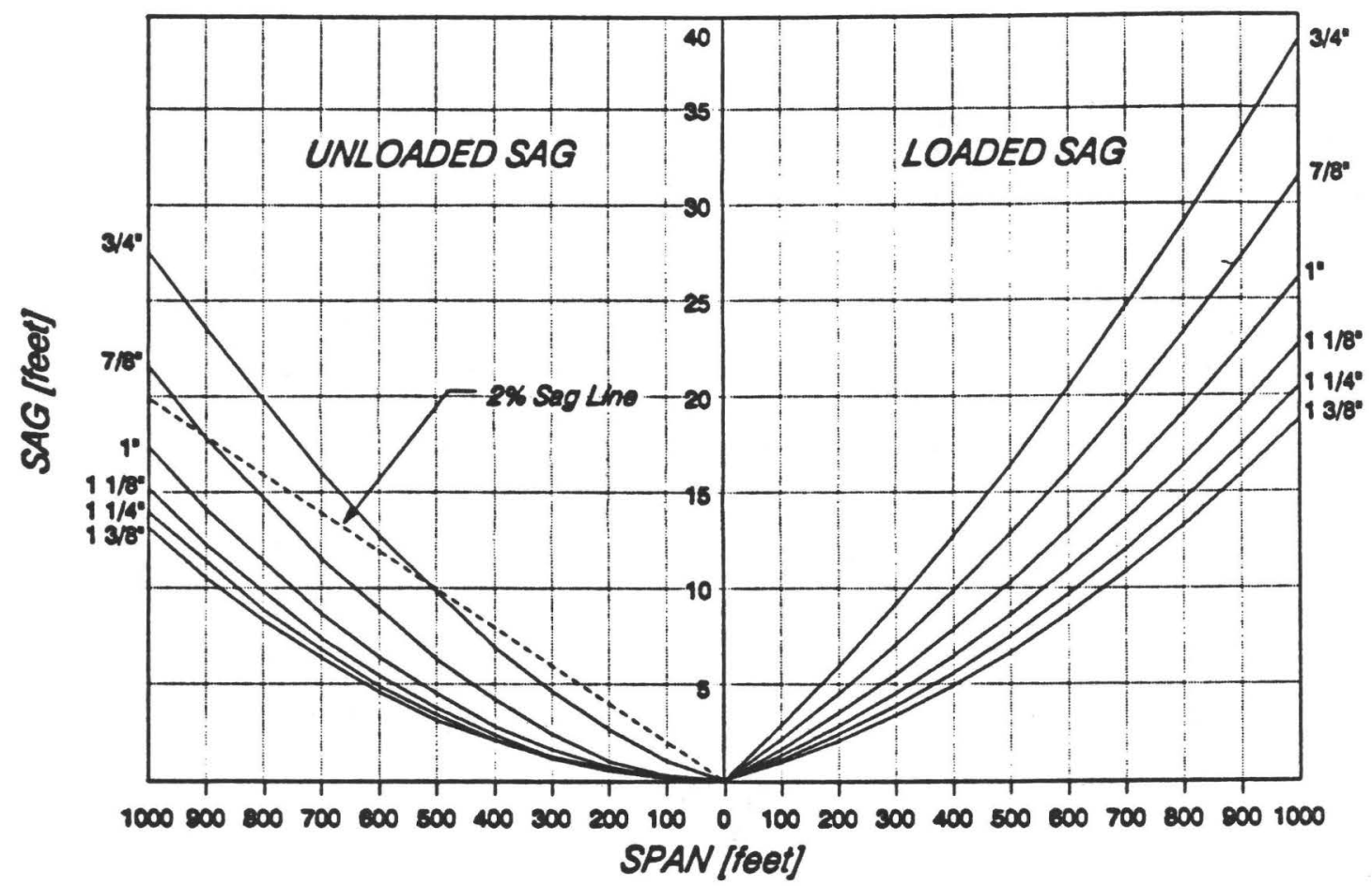

DIRECTIONS:

1. Select the desired span.

2. For unlisted spans, use the next largest span.

3. For the chosen span, use any cable diameter marked "OK".

\begin{tabular}{|c|c|c|c|c|c|c|}
\hline $\begin{array}{c}\text { CABLE DLAMETER } \\
\text { SPAN [foet] }\end{array}$ & $3 / 4^{\prime \prime}$ & $7 / 8^{\prime \prime}$ & $1^{\prime \prime}$ & $11 / 8^{\prime \prime}$ & $11 / 4^{\prime \prime}$ & $13 / 8^{\prime \prime}$ \\
\hline 100 & $O K$ & $O K$ & $O K$ & $O K$ & $O K$ & $O K$ \\
\hline 200 & $O K$ & $O K$ & $O K$ & $O K$ & $O K$ & $O K$ \\
\hline 300 & $O K$ & $O K$ & $O K$ & $O K$ & $O K$ & $O K$ \\
\hline 400 & $O K$ & $O K$ & $O K$ & $O K$ & $O K$ & $O K$ \\
\hline 500 & $O K$ & $O K$ & $O K$ & $O K$ & $O K$ & $O K$ \\
\hline 600 & $X$ & $O K$ & $O K$ & $O K$ & $O K$ & $O K$ \\
\hline 700 & $X$ & $O K$ & $O K$ & $O K$ & $O K$ & $O K$ \\
\hline 800 & $X$ & $O K$ & $O K$ & $O K$ & $O K$ & $O K$ \\
\hline 200 & $X$ & $O K$ & $O K$ & $O K$ & $O K$ & $O K$ \\
\hline 1000 & $X$ & $X$ & $O K$ & $O K$ & $O K$ & $O K$ \\
\hline
\end{tabular}

Figure 5.--Sag diagram and selection guide for class A structural strand and cable-car load of 1,500 lb. 


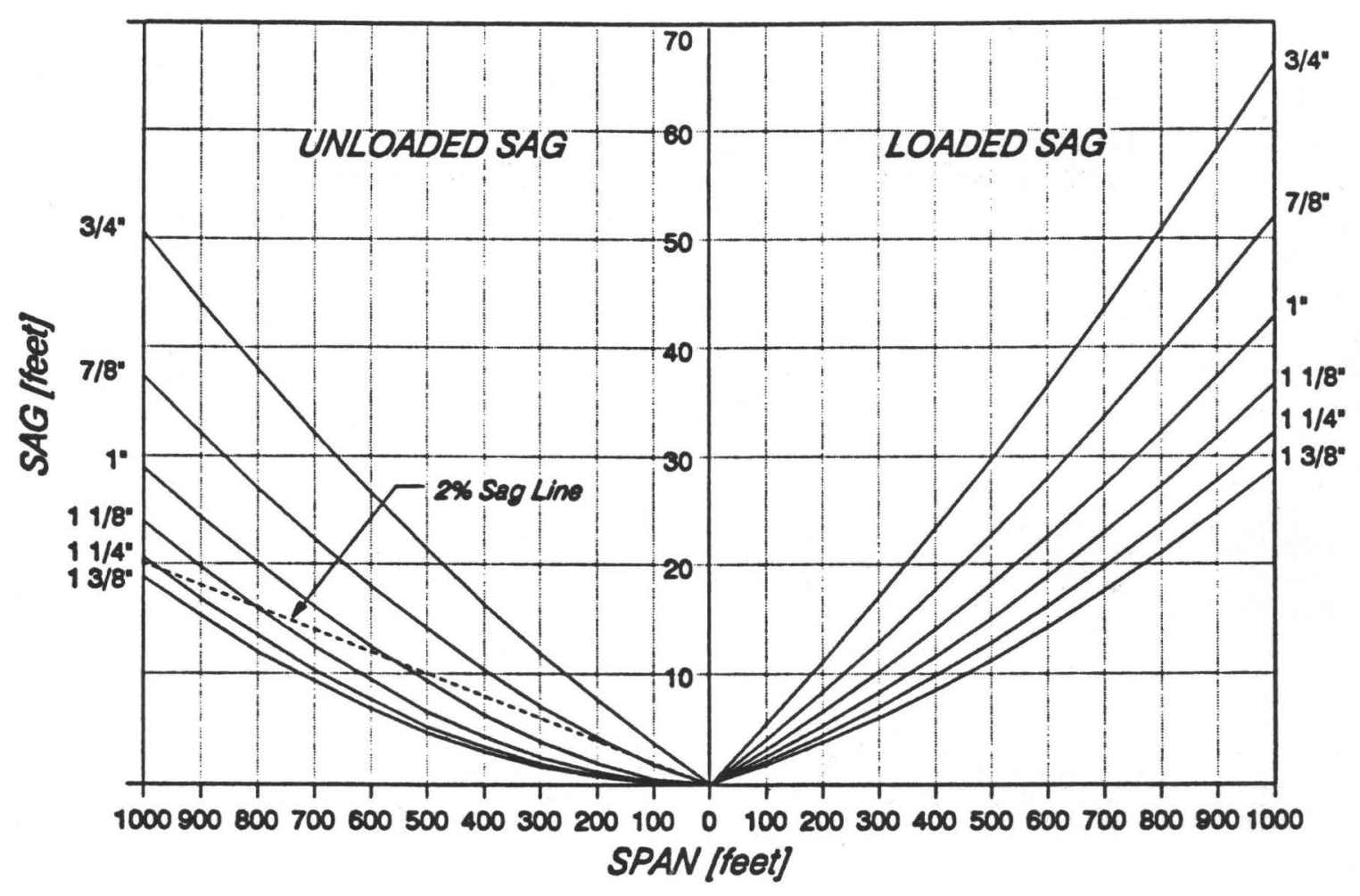

DIRECTIONS:

1. Select the desired span.

2. For unlisted spans, use the next largest span.

3. For the chosen span, use any cable diameter marked "OK".

\begin{tabular}{|c|c|c|c|c|c|c|}
\hline $\begin{array}{c}\text { CABLE DIAMETER } \\
\text { SPAN (FOEt] }\end{array}$ & $3 / 4^{\prime \prime}$ & $7 / 8^{\prime \prime}$ & $1^{\prime \prime}$ & $11 / 8^{\prime \prime}$ & $11 / 4^{\prime \prime}$ & $13 / 8^{\prime \prime}$ \\
\hline 100 & $x$ & $O K$ & $O K$ & $O K$ & $O K$ & $O K$ \\
\hline 200 & $x$ & $O K$ & $O K$ & $O K$ & $O K$ & $O K$ \\
\hline 300 & $x$ & $O K$ & $O K$ & $O K$ & $O K$ & $O K$ \\
\hline 400 & $x$ & $x$ & $O K$ & $O K$ & $O K$ & $O K$ \\
\hline 500 & $x$ & $x$ & $O K$ & $O K$ & $O K$ & $O K$ \\
\hline 600 & $x$ & $x$ & $O K$ & $O K$ & $O K$ & $O K$ \\
\hline 700 & $x$ & $x$ & $x$ & $O K$ & $O K$ & $O K$ \\
\hline 800 & $x$ & $x$ & $x$ & $O K$ & $O K$ & $O K$ \\
\hline 900 & $x$ & $x$ & $x$ & $x$ & $O K$ & $O K$ \\
\hline 1000 & $x$ & $x$ & $x$ & $x$ & $O K$ & $O K$ \\
\hline
\end{tabular}

Figure 6.--Sag diagram and selection guide for $6 \times 19$ IWRC extra improved plow steel wire rope and cable-car load of $2,000 \mathrm{lb}$. 


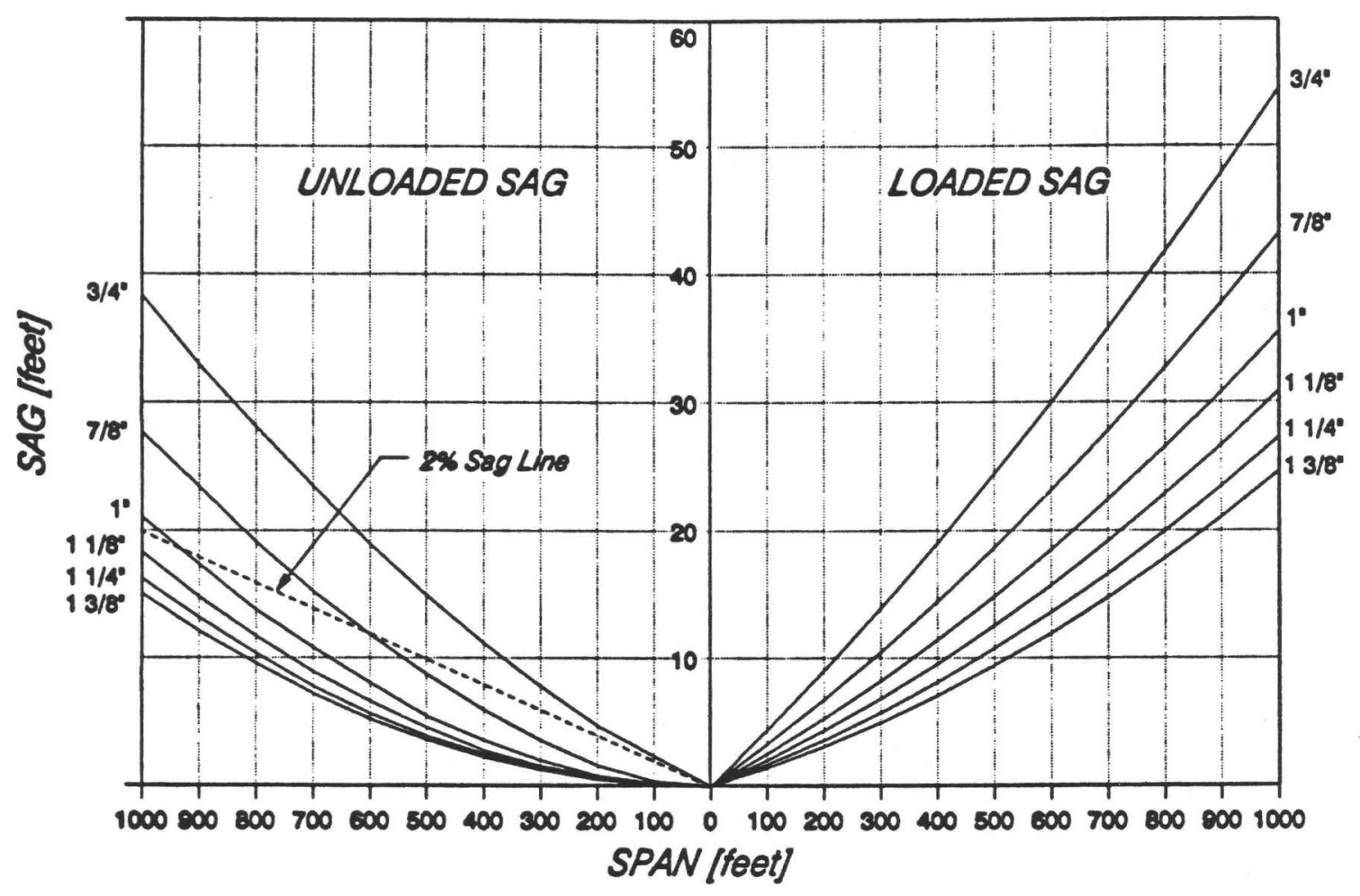

\section{DIRECTIONS:}

1. Select the desired span.

2. For unlisted spans, use the next largest span.

3. For the chosen span, use any cable diameter marked "OK".

\begin{tabular}{|c|c|c|c|c|c|c|}
\hline $\begin{array}{c}\text { CABLE DIAMETER } \\
\text { SPAN (feet) }\end{array}$ & $3 / 4^{\prime \prime}$ & $7 / 8^{\prime \prime}$ & $1^{\prime \prime}$ & $11 / 8^{\prime \prime}$ & $11 / 4^{\prime \prime}$ & $13 / 8^{\prime \prime}$ \\
\hline 100 & $x$ & $O K$ & $O K$ & $O K$ & $O K$ & $O K$ \\
\hline 200 & $x$ & $O K$ & $O K$ & $O K$ & $O K$ & $O K$ \\
\hline 300 & $x$ & $O K$ & $O K$ & $O K$ & $O K$ & $O K$ \\
\hline 400 & $x$ & $O K$ & $O K$ & $O K$ & $O K$ & $O K$ \\
\hline 500 & $x$ & $O K$ & $O K$ & $O K$ & $O K$ & $O K$ \\
\hline 600 & $x$ & $O K$ & $O K$ & $O K$ & $O K$ & $O K$ \\
\hline 700 & $x$ & $x$ & $O K$ & $O K$ & $O K$ & $O K$ \\
\hline 800 & $x$ & $x$ & $O K$ & $O K$ & $O K$ & $O K$ \\
\hline 900 & $x$ & $x$ & $O K$ & $O K$ & $O K$ & $O K$ \\
\hline 1000 & $x$ & $x$ & $x$ & $O K$ & $O K$ & $O K$ \\
\hline
\end{tabular}

Figure 7.--Sag diagram and selection guide for $6 \times 19$ IWRC extra extra improved plow steel wire rope and cable-car load of $2,000 \mathrm{lb}$. 


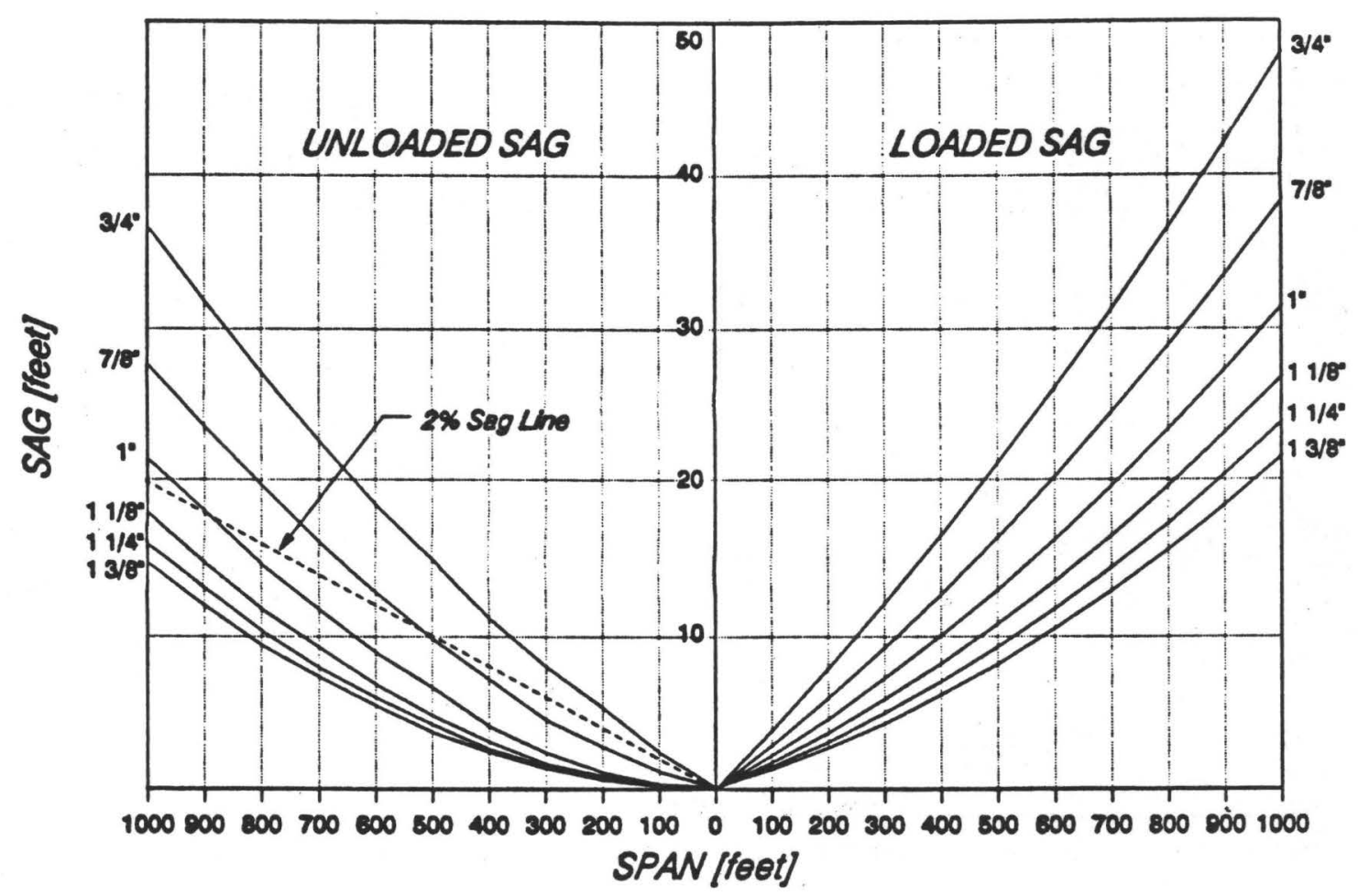

DIRECTIONS:

1. Select the desired span.

2. For unlisted spans, use the next largest span.

3. For the chosen span, use any cable diameter marked "OK".

\begin{tabular}{|c|c|c|c|c|c|c|}
\hline $\begin{array}{c}\text { CABLE DIAMETER } \\
\text { SPAN (loet] }\end{array}$ & $3 / 4^{\prime \prime}$ & $7 / 8^{\prime \prime}$ & $1^{\prime \prime}$ & $11 / 8^{\prime \prime}$ & $11 / 4^{\prime \prime}$ & $13 / 8^{\prime \prime}$ \\
\hline 100 & $x$ & $O K$ & $O K$ & $O K$ & $O K$ & $O K$ \\
\hline 200 & $x$ & $O K$ & $O K$ & $O K$ & $O K$ & $O K$ \\
\hline 300 & $x$ & $O K$ & $O K$ & $O K$ & $O K$ & $O K$ \\
\hline 400 & $x$ & $O K$ & $O K$ & $O K$ & $O K$ & $O K$ \\
\hline 500 & $x$ & $O K$ & $O K$ & $O K$ & $O K$ & $O K$ \\
\hline 600 & $x$ & $x$ & $O K$ & $O K$ & $O K$ & $O K$ \\
\hline 700 & $x$ & $x$ & $O K$ & $O K$ & $O K$ & $O K$ \\
\hline 800 & $x$ & $x$ & $O K$ & $O K$ & $O K$ & $O K$ \\
\hline 900 & $x$ & $x$ & $O K$ & $O K$ & $O K$ & $O K$ \\
\hline 1000 & $x$ & $x$ & $x$ & $O K$ & $O K$ & $O K$ \\
\hline
\end{tabular}

Figure 8.--Sag diagram and selection guide for class A structural strand and cable-car load of 2,000 lb. 


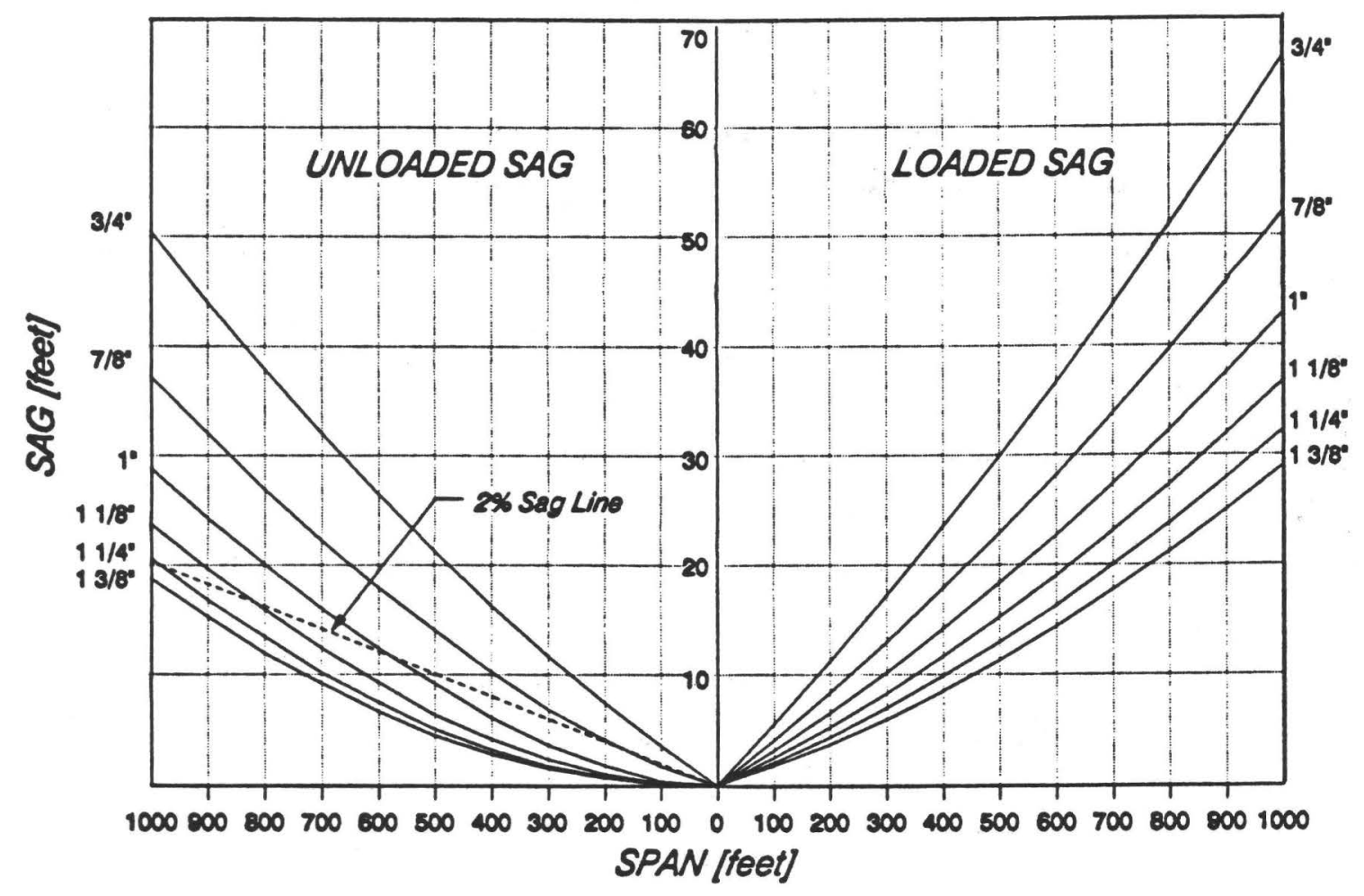

\section{DIRECTIONS:}

1. Select the desired span.

2. For unlisted spans, use the next largest span.

3. For the chosen span, use any cable diameter marked "OK".

\begin{tabular}{|c|c|c|c|c|c|c|}
\hline $\begin{array}{c}\text { CABLE DIAMETER } \\
\text { SPAN [feet] }\end{array}$ & $3 / 4^{\prime \prime}$ & $7 / 8^{\prime \prime}$ & $1^{\prime \prime}$ & $11 / 8^{\prime \prime}$ & $114^{\prime \prime}$ & $13 / 8^{\prime \prime}$ \\
\hline 100 & $x$ & $O K$ & $O K$ & $O K$ & $O K$ & $O K$ \\
\hline 200 & $x$ & $O K$ & $O K$ & $O K$ & $O K$ & $O K$ \\
\hline 300 & $x$ & $x$ & $O K$ & $O K$ & $O K$ & $O K$ \\
\hline 400 & $x$ & $x$ & $O K$ & $O K$ & $O K$ & $O K$ \\
\hline 500 & $x$ & $x$ & $O K$ & $O K$ & $O K$ & $O K$ \\
\hline 600 & $x$ & $x$ & $O K$ & $O K$ & $O K$ & $O K$ \\
\hline 700 & $x$ & $x$ & $x$ & $O K$ & $O K$ & $O K$ \\
\hline 800 & $x$ & $x$ & $x$ & $O K$ & $O K$ & $O K$ \\
\hline 900 & $x$ & $x$ & $x$ & $x$ & $O K$ & $O K$ \\
\hline 1000 & $x$ & $x$ & $x$ & $x$ & $O K$ & $O K$ \\
\hline
\end{tabular}

Figure 9.--Sag diagram and selection guide for $6 \times 19$ IWRC extra improved plow steel wire rope and cable-car load of $2,250 \mathrm{lb}$. 


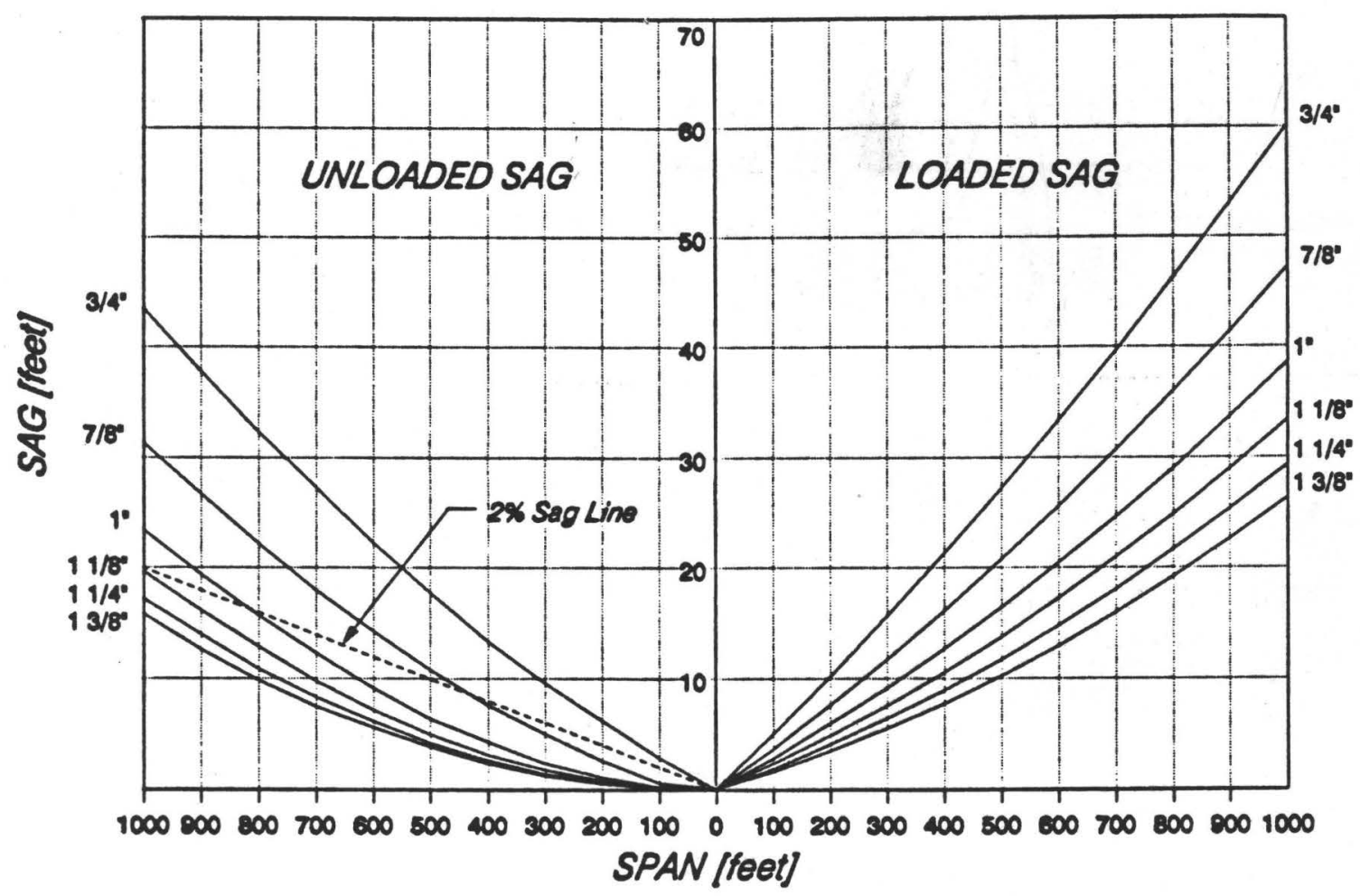

DIRECTIONS:

1. Select the desired span.

2. For unlisted spans, use the next largest span.

3. For the chosen span, use any cable diameter marked "OK".

\begin{tabular}{|c|c|c|c|c|c|c|}
\hline $\begin{array}{c}\text { CABLE DIAMETER } \\
\text { SPAN [fOet] }\end{array}$ & $3 / 4^{\prime \prime}$ & $7 / 8^{\prime \prime}$ & $1^{\prime \prime}$ & $11 / 8^{\prime \prime}$ & $11 / 4^{\prime \prime}$ & $13 / 8^{\prime \prime}$ \\
\hline 100 & $x$ & $O K$ & $O K$ & $O K$ & $O K$ & $O K$ \\
\hline 200 & $x$ & $O K$ & $O K$ & $O K$ & $O K$ & $O K$ \\
\hline 300 & $x$ & $O K$ & $O K$ & $O K$ & $O K$ & $O K$ \\
\hline 400 & $x$ & $O K$ & $O K$ & $O K$ & $O K$ & $O K$ \\
\hline 500 & $x$ & $O K$ & $O K$ & $O K$ & $O K$ & $O K$ \\
\hline 600 & $x$ & $x$ & $O K$ & $O K$ & $O K$ & $O K$ \\
\hline 700 & $x$ & $x$ & $O K$ & $O K$ & $O K$ & $O K$ \\
\hline 800 & $x$ & $x$ & $O K$ & $O K$ & $O K$ & $O K$ \\
\hline 900 & $x$ & $x$ & $x$ & $O K$ & $O K$ & $O K$ \\
\hline 1000 & $x$ & $x$ & $x$ & $O K$ & $O K$ & $O K$ \\
\hline
\end{tabular}

Figure 10.--Sag diagram and selection guide for $6 \times 19$ IWRC extra extra improved plow steel wire rope and cable-car load of $2,250 \mathrm{lb}$. 


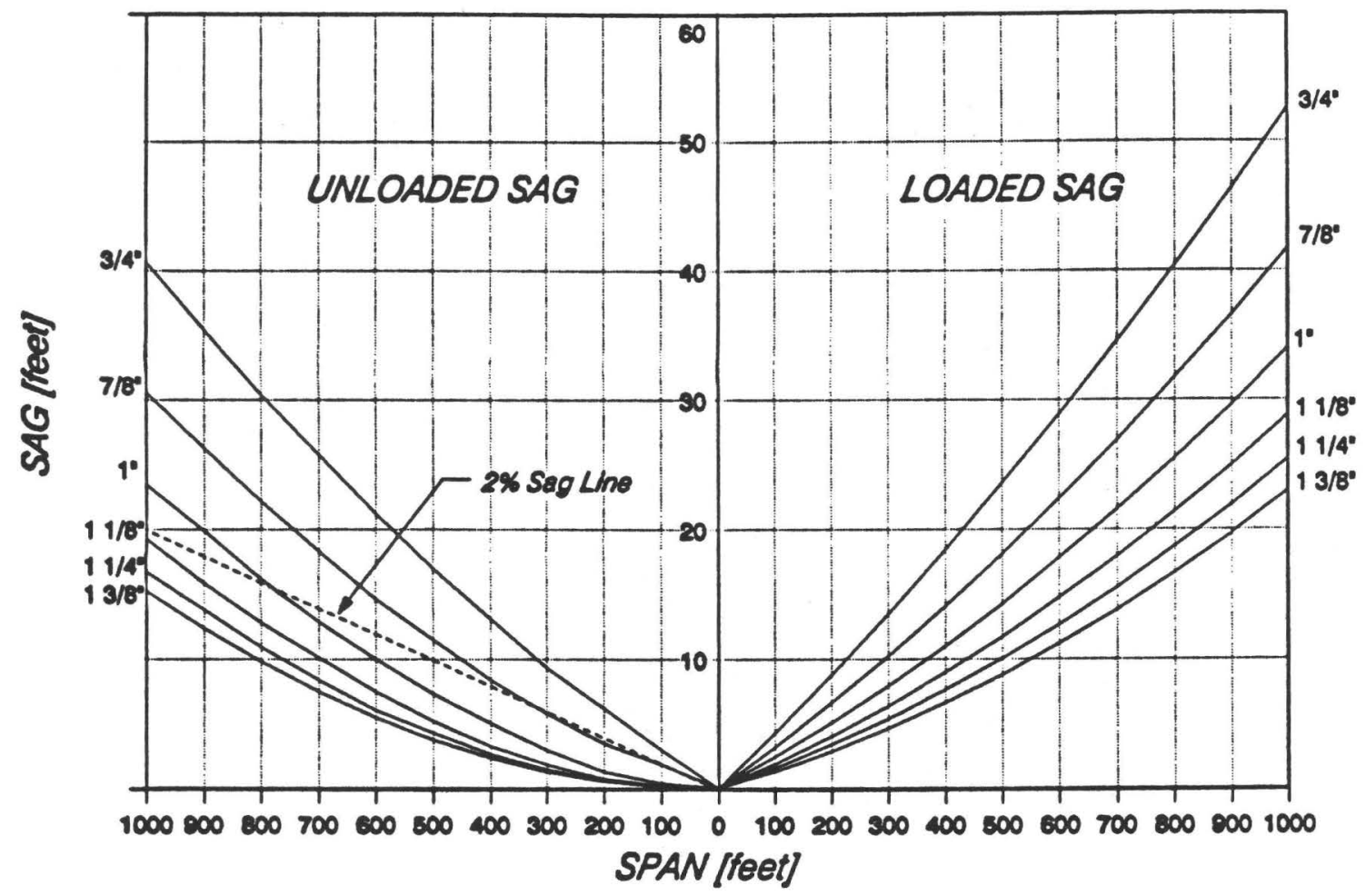

DIRECTIONS:

1. Select the desired span.

2. For unlisted spans, use the next largest span.

3. For the chosen span, use any cable diameter marked "OK".

\begin{tabular}{|c|c|c|c|c|c|c|}
\hline $\begin{array}{c}\text { CABLE DIAMETER } \\
\text { SPAN (fOet] }\end{array}$ & $3 / 4^{\prime \prime}$ & $7 / 8^{\prime \prime}$ & $1^{\prime \prime}$ & $11 / 8^{\prime \prime}$ & $11 / 4^{\prime \prime}$ & $13 / 8^{\prime \prime}$ \\
\hline 100 & $x$ & $O K$ & $O K$ & $O K$ & $O K$ & $O K$ \\
\hline 200 & $x$ & $O K$ & $O K$ & $O K$ & $O K$ & $O K$ \\
\hline 300 & $x$ & $O K$ & $O K$ & $O K$ & $O K$ & $O K$ \\
\hline 400 & $x$ & $O K$ & $O K$ & $O K$ & $O K$ & $O K$ \\
\hline 500 & $x$ & $x$ & $O K$ & $O K$ & $O K$ & $O K$ \\
\hline 600 & $x$ & $x$ & $O K$ & $O K$ & $O K$ & $O K$ \\
\hline 700 & $x$ & $x$ & $O K$ & $O K$ & $O K$ & $O K$ \\
\hline 800 & $x$ & $x$ & $O K$ & $O K$ & $O K$ & $O K$ \\
\hline 900 & $x$ & $x$ & $x$ & $O K$ & $O K$ & $O K$ \\
\hline 1000 & $x$ & $x$ & $x$ & $O K$ & $O K$ & $O K$ \\
\hline
\end{tabular}

Figure 11.--Sag diagram and selection guide for class A structural strand and cable-car load of 2,250 lb. 


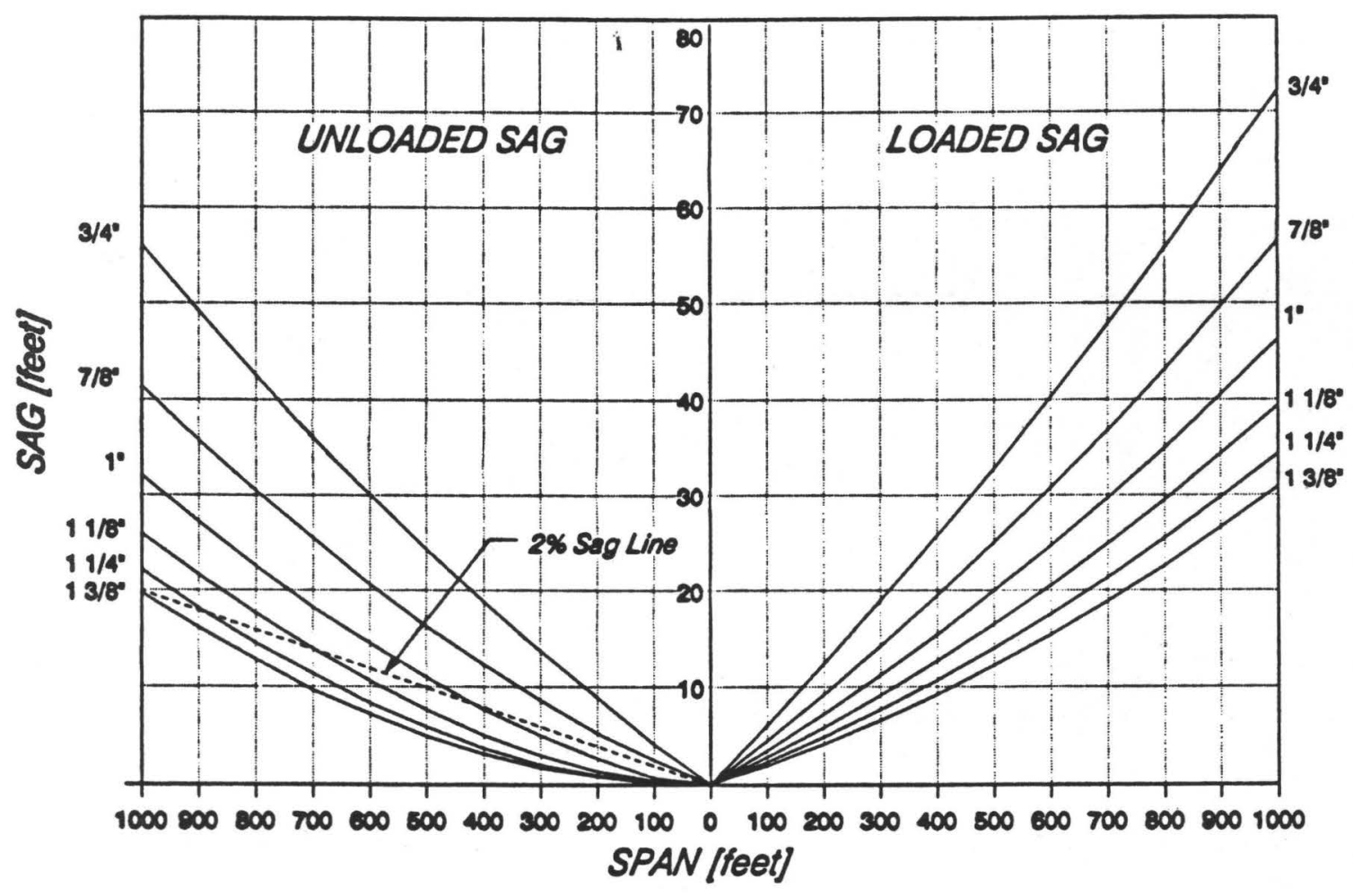

DIRECTIONS:

1. Select the desired span.

2. For unlisted spans, use the next largest span.

3. For the chosen span, use any cable diameter marked "OK".

\begin{tabular}{|c|c|c|c|c|c|c|}
\hline $\begin{array}{c}\text { CABLE DLAMETER } \\
\text { SPAN (feet) }\end{array}$ & $3 / 4^{\prime \prime}$ & $7 / 8^{\prime \prime}$ & $1^{\prime \prime}$ & $11 / 8^{\prime \prime}$ & $11 / 4^{\prime \prime}$ & $13 / 8^{\prime \prime}$ \\
\hline 100 & $x$ & $x$ & $O K$ & $O K$ & $O K$ & $O K$ \\
\hline 200 & $x$ & $x$ & $O K$ & $O K$ & $O K$ & $O K$ \\
\hline 300 & $x$ & $x$ & $O K$ & $O K$ & $O K$ & $O K$ \\
\hline 400 & $x$ & $x$ & $O K$ & $O K$ & $O K$ & $O K$ \\
\hline 500 & $x$ & $x$ & $O K$ & $O K$ & $O K$ & $O K$ \\
\hline 600 & $x$ & $x$ & $x$ & $O K$ & $O K$ & $O K$ \\
\hline 700 & $x$ & $x$ & $x$ & $O K$ & $O K$ & $O K$ \\
\hline 800 & $x$ & $x$ & $x$ & $x$ & $O K$ & $O K$ \\
\hline 900 & $x$ & $x$ & $x$ & $x$ & $O K$ & $O K$ \\
\hline 1000 & $x$ & $x$ & $x$ & $x$ & $x$ & $O K$ \\
\hline
\end{tabular}

Figure 12.--Sag diagram and selection guide for $6 \times 19$ IWRC extra improved plow steel wire rope and cable-car load of $2,500 \mathrm{lb}$. 


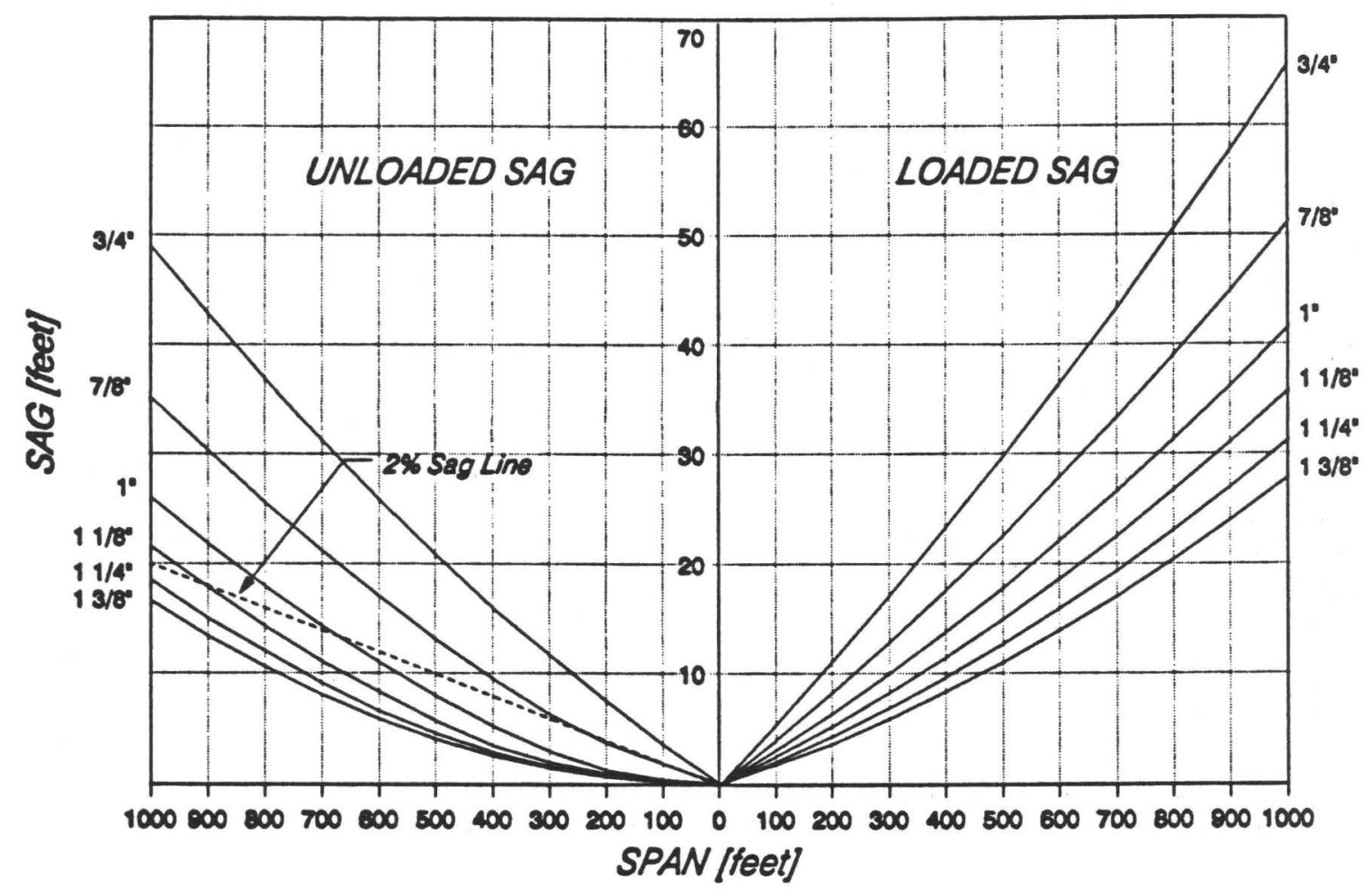

DIRECTIONS:

1. Select the desired span.

2. For unlisted spans, use the next largest span.

3. For the chosen span, use any cable diameter marked "OK".

\begin{tabular}{|c|c|c|c|c|c|c|}
\hline $\begin{array}{c}\text { CABLE DLAMETER } \\
\text { SPAN (feet) }\end{array}$ & $3 / 4^{\prime \prime}$ & $7 / 8^{\prime \prime}$ & $1^{\prime \prime}$ & $11 / 8^{\prime \prime}$ & $11 / 4^{\prime \prime}$ & $13 / 8^{\prime \prime}$ \\
\hline 100 & $x$ & $O K$ & $O K$ & $O K$ & $O K$ & $O K$ \\
\hline 200 & $x$ & $O K$ & $O K$ & $O K$ & $O K$ & $O K$ \\
\hline 300 & $x$ & $O K$ & $O K$ & $O K$ & $O K$ & $O K$ \\
\hline 400 & $x$ & $x$ & $O K$ & $O K$ & $O K$ & $O K$ \\
\hline 500 & $x$ & $x$ & $O K$ & $O K$ & $O K$ & $O K$ \\
\hline 600 & $x$ & $x$ & $O K$ & $O K$ & $O K$ & $O K$ \\
\hline 700 & $x$ & $x$ & $O K$ & $O K$ & $O K$ & $O K$ \\
\hline 800 & $x$ & $x$ & $x$ & $O K$ & $O K$ & $O K$ \\
\hline 900 & $x$ & $x$ & $x$ & $O K$ & $O K$ & $O K$ \\
\hline 1000 & $x$ & $x$ & $x$ & $x$ & $O K$ & $O K$ \\
\hline
\end{tabular}

Figure 13.--Sag diagram and selection guide for $6 \times 19$ IWRC extra extra improved plow steel wire rope and cable-car load of 2,500 lb. 


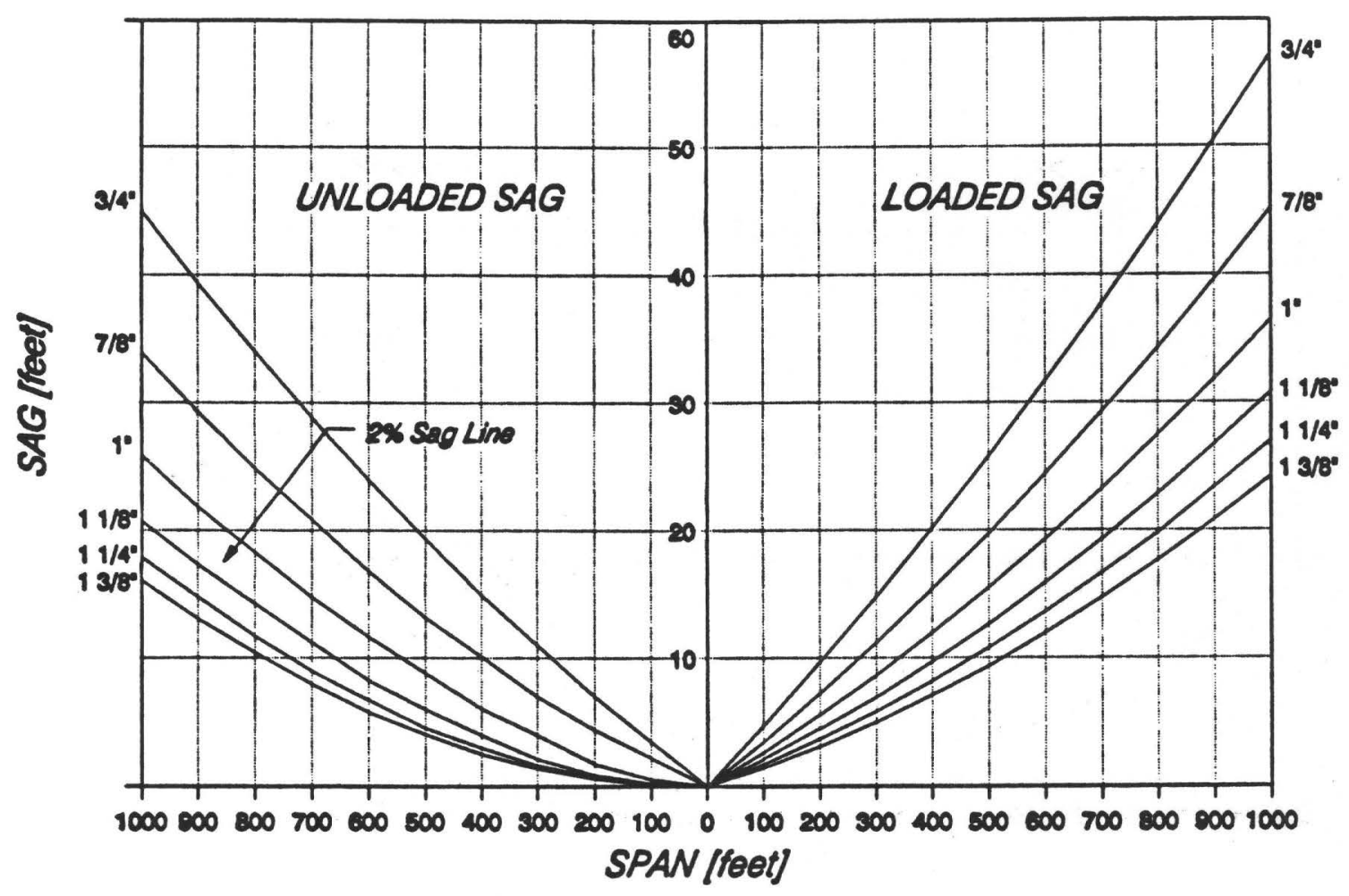

DIRECTIONS:

1. Select the desired span.

2. For unlisted spans, use the next largest span.

3. For the chosen span, use any cable dlameter marked "OK".

\begin{tabular}{|c|c|c|c|c|c|c|}
\hline $\begin{array}{c}\text { CABLE DIAMETER } \\
\text { SPAN [foet] }\end{array}$ & $3 / 4^{\prime \prime}$ & $7 / 8^{\prime \prime}$ & $7^{\prime \prime}$ & $11 / 8^{\prime \prime}$ & $11 / 4^{\prime \prime}$ & $13 / 8^{\prime \prime}$ \\
\hline 100 & $x$ & $x$ & $O K$ & $O K$ & $O K$ & $O K$ \\
\hline 200 & $x$ & $x$ & $O K$ & $O K$ & $O K$ & $O K$ \\
\hline 300 & $x$ & $x$ & $O K$ & $O K$ & $O K$ & $O K$ \\
\hline 400 & $x$ & $x$ & $O K$ & $O K$ & $O K$ & $O K$ \\
\hline 500 & $x$ & $x$ & $O K$ & $O K$ & $O K$ & $O K$ \\
\hline 600 & $x$ & $x$ & $O K$ & $O K$ & $O K$ & $O K$ \\
\hline 700 & $x$ & $x$ & $x$ & $O K$ & $O K$ & $O K$ \\
\hline 800 & $x$ & $x$ & $x$ & $O K$ & $O K$ & $O K$ \\
\hline 900 & $x$ & $x$ & $x$ & $O K$ & $O K$ & $O K$ \\
\hline 1000 & $x$ & $x$ & $x$ & $O K$ & $O K$ & $O K$ \\
\hline
\end{tabular}

Figure 14.--Sag diagram and selection guide for class A structural strand and cable-car load of 2,500 lb. 
it will decrease slightly in diameter. A recommended measurement procedure is shown in figure 15.

A sheave must be sized for the wire rope that will be used with it. The size of a sheave's groove can be measured with a groove gage. The various dimensions of a sheave are shown in figure 16. A sheave groove that is too large or too small will not properly support the wire rope, and crushing of some wires and loss of strength will result. A properly sized sheave will support the wire rope over about $150^{\circ}$ of its diameter. Correct, too tight, and too loose sheave-groove conditions are shown in figure 17.

Saddle blocks must be sized to match the cable. Measurements are made in a manner similar to those described above for sheaves. A typical saddle block is shown in figure 18.

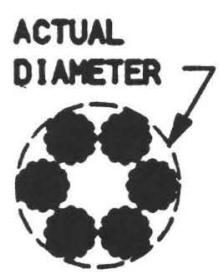

A

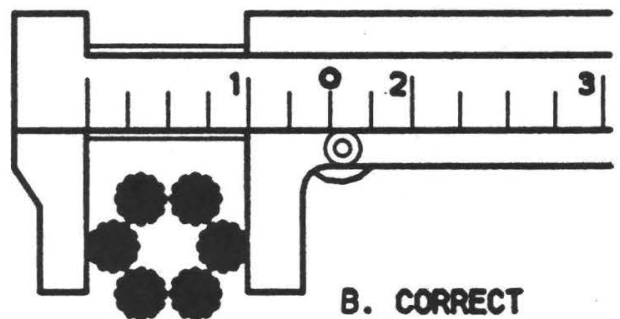

B. CORRECT

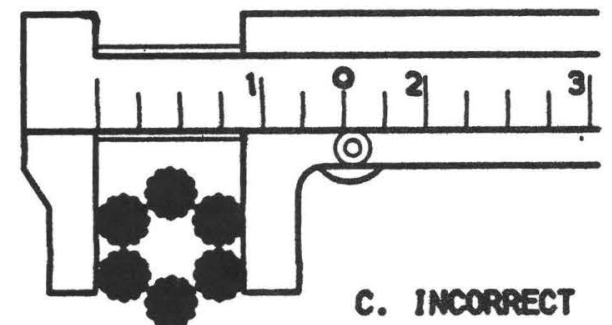

C. INCORRECT

Figure 15.--How to measure (or caliper) a wire rope.

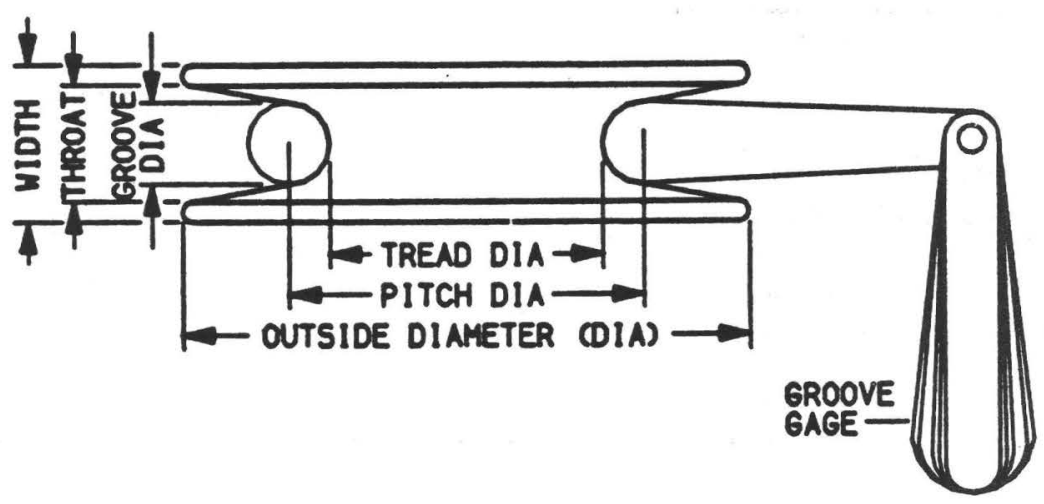

Figure 16.--Various dimensions of a sheave and the use of a groove gage. 

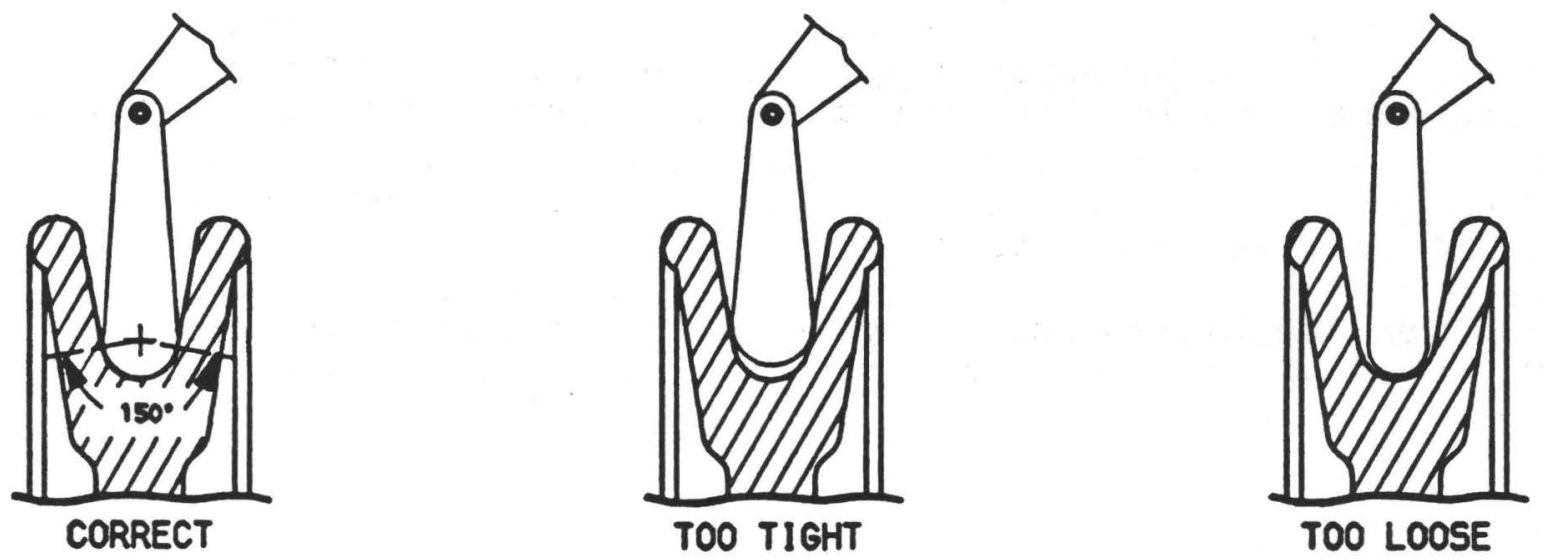

Figure 17.--Cross-section sketches illustrating three sheave-groove conditions.

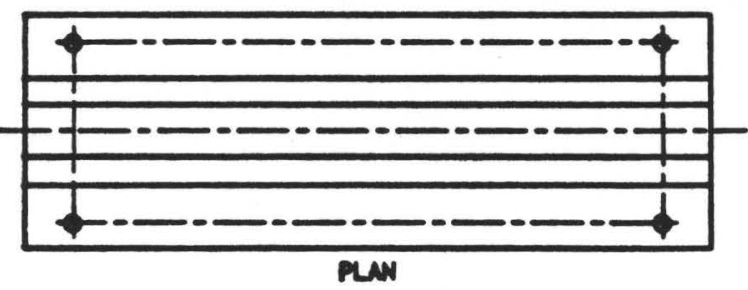

NOT TO SCALE

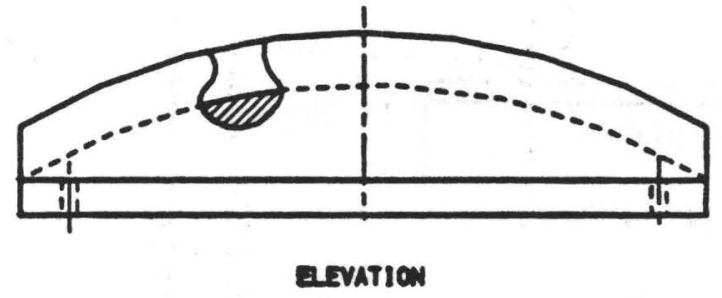

yaries yint.

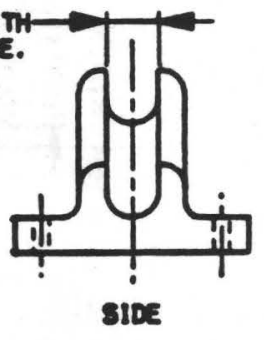

Figure 18.--Typical cast iron cable saddle block. 
Table 2.--Hardware component sizes

\begin{tabular}{|c|c|c|c|c|c|c|c|}
\hline \multirow{2}{*}{$\begin{array}{l}\text { Wire rope } \\
\text { diameter } \\
\text { (inches) }\end{array}$} & \multirow{2}{*}{$\begin{array}{c}\text { Turnbuckle } \\
\text { size } \\
\text { (inches) }\end{array}$} & \multicolumn{2}{|c|}{ U-Bar } & \multicolumn{2}{|c|}{ Aux. U-Bar } & \multirow{2}{*}{\multicolumn{2}{|c|}{$\begin{array}{l}\text { Backstay } \\
\text { cable } \\
\text { diameter } \\
\text { (inches) }\end{array}$}} \\
\hline & & $\begin{array}{l}\text { diameter } \\
\text { (inches) }\end{array}$ & $\begin{array}{l}\text { length } \\
\text { (feet) }\end{array}$ & $\begin{array}{l}\text { diameter } \\
\text { (inches) }\end{array}$ & $\begin{array}{l}\text { length } \\
\text { (feet) }\end{array}$ & & \\
\hline $3 / 4$ & $11 / 4$ & $11 / 8$ & 6 & 1 & 5 & $7 / 16$ & \\
\hline $7 / 8$ & $11 / 2$ & $11 / 4$ & 7 & 1 & 5 & $9 / 16$ & \\
\hline 1 & $11 / 2$ & $13 / 8$ & 8 & 1 & 6 & $7 / 16$ & (2 cables) \\
\hline $11 / 8$ & $13 / 4$ & $11 / 2$ & 8 & 1 & 6 & $1 / 2$ & (2 cables) \\
\hline $11 / 4$ & $13 / 4$ & $15 / 8$ & 9 & 1 & 7 & $9 / 16$ & (2 cables) \\
\hline $13 / 8$ & 2 & $13 / 4$ & 9 & 1 & 7 & $5 / 8$ & (2 cables) \\
\hline
\end{tabular}

Turnbuckles, U-bar anchors for insertion in concrete or rock anchors, bearing blocks, and backstay cables must be sized to the main cable. This information is summarized in table 2 and shown in figure 19.

There are several qualities of cable clips, thimbles, turnbuckles, eyebolts, shackles, and other attachment hardware. Field inspection indicates that poor quality hardware has frequently been used in past installations. Quality hardware usually will not be available at hardware stores but is easily available through industrial supply houses or directly from several manufacturers. The following specifications are based on accepted industry standards for high quality products.

Cable clips must be forged steel (not malleable iron), galvanized to ASTM standard A-153 (American Society for Testing and Materials), and must meet Federal specification FF-C-450D, Type 1, Class 1. Thimbles must be heavy duty, be galvanized to ASTM specification A-153, and meet Federal specification FF-T-276b, Type III.

Sockets for spelter or resin attachment must be forged, meet Federal specification RR-S-550D, Type A (open) or Type B (closed), and be galvanized to ASTM specification A-153.

Turnbuckles must be forged steel (not malleable iron), be galvanized to ASTM specification A-153, and meet Federal specification FF-T-791b, Type 1. U-bars must be formed and heat treated at proper heats to prevent deterioration of structural strength. Round stock must meet ASTM structural steel specification A-36. Post-forming galvanizing must meet ASTM specification A-153. 

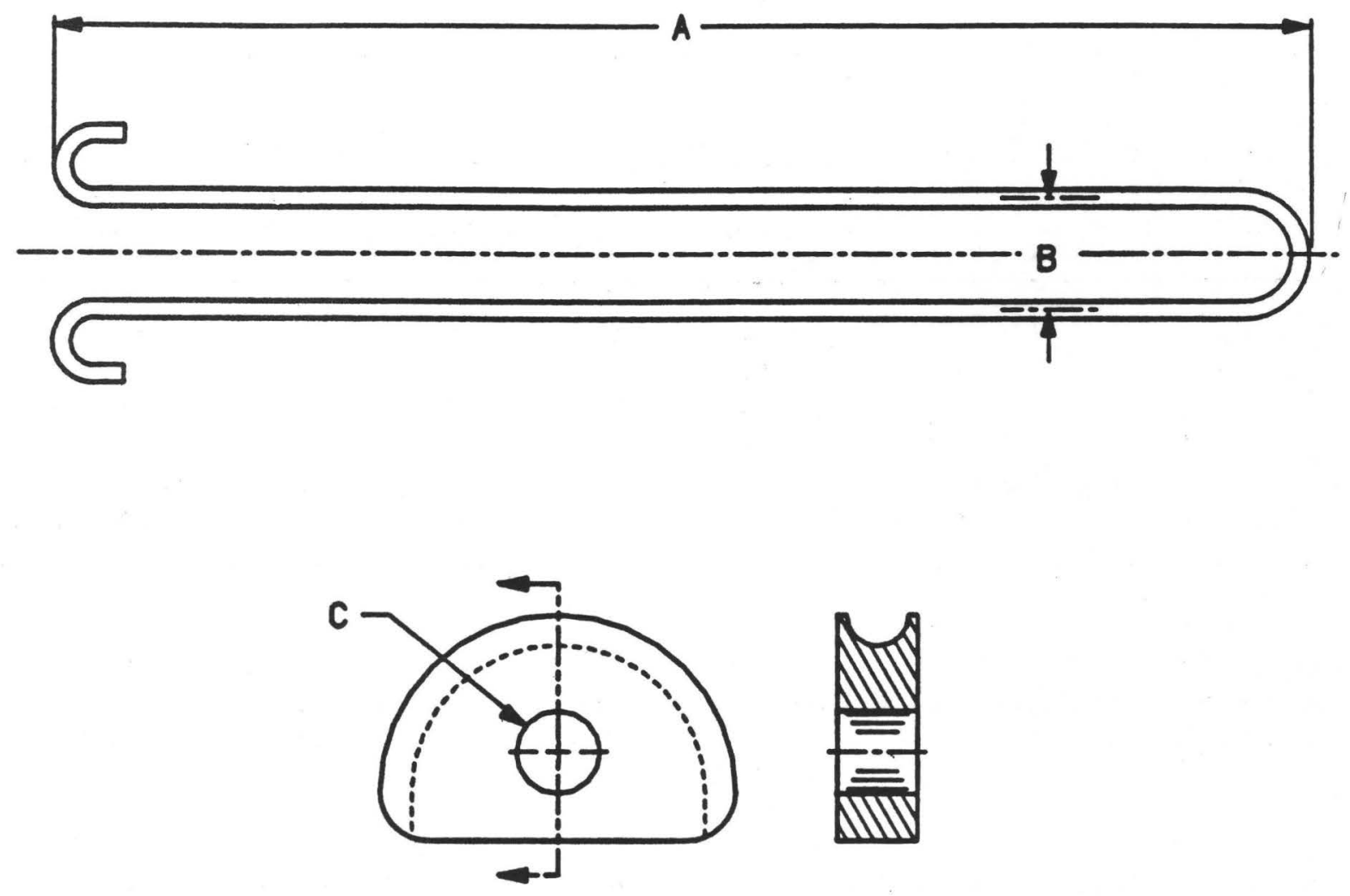

Main Cable U-Bar Bearing Block

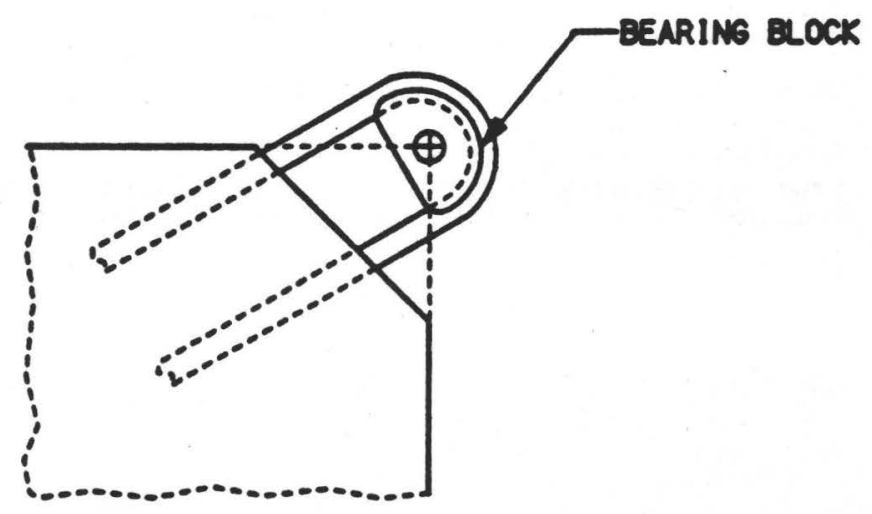

Anchorage Corner Assembly

EXPLANATIONS: 1 . Length (A) from table 2 .

2. Width (B) usually 5 to 8 inches; must match bearing block.

3. Drill hole (C) to match turnbuckle pin diameter.

Figure 19.--U-bar and bearing block. 
Attachment of backstay cables to A-frames or other support structures is important for the safety of the cableway structure. This can be accomplished in several ways. For steel support structures, a 5/8-inch or larger U-shaped steel bar approximately 3 in. in radius should, prior to galvanizing, be welded to a rear member at or near the center just below the sheave attachment. For any structure, a heavyduty, forged steel, shoulder-type eyebolt, galvanized to ASTM specification A-153, may be bolted to the support structure. The eyebolt should be $5 / 8$ in. to $3 / 4$ in. in diameter depending on structure size. The receiving hole should be drilled or punched prior to galvanizing. All fittings and connecting hardware should be industrial quality and galvanized to ASTM specification $\mathrm{A}-153$.

All wire rope should meet Federal specification RR-W-410. Orders for wire rope should always include a request for a Certification of Compliance. This document certifies that a sample from the same reel or production run has been tested to breaking and that it meets or exceeds the catalog breaking strength. The certificate should be maintained with other design information in station files.

\section{Support Structures}

Most cableway systems require supports at each end of a cable to maintain necessary clearance above high-flow river conditions. It is generally desirable to have the top of the supports at the same elevation. In some cases, the necessity for clearance over a railroad, highway, or other feature along one side of the river, or the desirability for greater ease of operation on the operating side, may be sufficient reason for a difference in elevation. The difference in height should not exceed 0.5 percent of the span between supports. If the support on the side where the car is stored is lower, return of the cable car will be easier. If the recommended height difference is exceeded, precautions must be taken by operators to prevent the cable car from slamming into the lower support.

A river stage for the 100-year flood should be estimated in determining the height of the structure. A structure that is too low to measure floodflow would not serve its intended purpose. The height of the cable supports should be such that when the system is under design load and the stream is at the estimated 100-year flood elevation, there will be about 10 to 15 feet of clearance between the low point of the cable and the water surface.

The type of structure most frequently used for USGS cableways is an A-frame mounted on a concrete footing. Wooden A-frames were commonly used until the 1960's when steel Aframes came into common usage. 
Galvanized steel A-frames offer high strength with longlasting and low-maintenance performance; the use of this type of A-frame is encouraged. Vertical I- or WF- (wide flange) beams are also used for vertical supports. Trees have frequently been used and their use is described later in this section on support structures.

\section{Footings}

Footings are required to transmit the load of the support structure, cable, and cable-car load to the ground. The size of footing required depends primarily on the total load of the structure and the bearing capacity of the particular soil type at the site. Bearing strength is diminished when the ground surface is saturated. Footings should generally extend from at least 6 in. above to $4 \mathrm{ft}$ below ground surface to provide lateral stability. In areas where ground freezing occurs, the footing should extend at least 1 ft below the normal frost line. In areas of permafrost, larger and shallower footings are required to spread loads over a larger area. Where bedrock exists near the ground surface, holes should be drilled into the bedrock and pins installed to tie the footing to the rock and prevent lateral movement. At sites where ice jams or debris may be transported high up a bank or overflow channel, concrete piers may protect A-frames if the piers are several feet above ground surface and prow-shaped. Anchor bolts for attaching the A-frame to footings should be set in place prior to pouring concrete. Anchor bolts should be L- or $\mathrm{J}$-shaped, should not be smaller than $3 / 4$ in. in diameter, should be galvanized to ASTM specification A-153, and should extend into the concrete a minimum distance of 30 times the bolt diameter. Concrete must meet ACI-318 (American Concrete Institute) and ASTM specification C-94. Concrete must have compressive strength of $3,0001 \mathrm{~b} / \mathrm{in}^{2}$.

\section{Footing Design}

The A-frame footings that are discussed in this section are designed to provide a minimum design factor of 1.5 in saturated soil conditions. Footings were sized for soil types $A$ and $B$. Footing design calculations were made for cable-car loads of $1,500,2,000,2,250$, and 2,500 lb. and for A-frame heights of 6 to $30 \mathrm{ft}$.

The footing loads for the 30-foot A-frame are not significantly greater than the footing loads for the 6-foot Aframe. Consequently, single-footing designs are given for the 30-foot A-frame for each cable size. In addition, the footings are designed for loads with the main cable at $45^{\circ}$ from the horizontal. Footings designed for the $45^{\circ} \mathrm{cable}$ angle are also sufficient for the $30^{\circ}$ cable angle. 
[One combined footing or two single footings are required for each A-frame. For combined footings, the length is determined by adding the distance between the centers of the A-frame legs and $2 \mathrm{X} S$ from the table below, where $S$ is the distance from the leg to the end of the footing. The footing width is indicated in column $W$ below. No footing shall have a side less than 2 feet 3 inches.]

\begin{tabular}{|c|c|c|c|}
\hline \multirow{2}{*}{$\begin{array}{l}\text { Cable } \\
\text { diameter } \\
\text { (inches) }\end{array}$} & \multirow{2}{*}{$\begin{array}{l}\frac{\text { Single }}{\text { Area }} \\
\text { (square feet) }\end{array}$} & \multicolumn{2}{|c|}{ Combined } \\
\hline & & $\begin{array}{c}W \\
\text { (feet) }\end{array}$ & $\begin{array}{c}S \\
\text { (feet) }\end{array}$ \\
\hline \multicolumn{4}{|c|}{ Soil type $A$} \\
\hline $3 / 4$ & 5 & 2.5 & 1.5 \\
\hline $7 / 8$ & 6 & 2.5 & 1.5 \\
\hline 1 & 7 & 3.0 & 1.5 \\
\hline $11 / 8$ & 8 & 3.0 & 1.5 \\
\hline $11 / 4$ & 9 & 3.0 & 2.0 \\
\hline $13 / 8$ & 10 & 3.0 & 2.0 \\
\hline \multicolumn{4}{|c|}{ Soil type $B$} \\
\hline $3 / 4$ & 9 & 3.0 & 2.0 \\
\hline $7 / 8$ & 10 & 3.0 & 2.5 \\
\hline 1 & 12 & 3.0 & 2.5 \\
\hline $11 / 8$ & 14 & 3.5 & 2.5 \\
\hline $11 / 4$ & 16 & 3.5 & 3.0 \\
\hline $13 / 8$ & 18 & 4.0 & 3.0 \\
\hline
\end{tabular}

The footing areas of the different load cases were compared. The greatest difference among the footing sizes for a given cable size is approximately $2 \mathrm{ft}^{2}$. This small variance does not warrant the use of different footings for each load case and cable size. It is recommended that the footing size be chosen based only on cable size and soil type as shown in table 3 . 
Due to the varying base widths of the A-frames, single footings of the required sizes may be too large to remain as single footings. For this reason, combined footings were designed primarily for short A-frames. The total length of these footings is determined by adding the distance that the footing extends past each hinge of the A-frame to the base width of the A-frame.

The use of steel reinforcement in A-frame footings for cableways is recommended. Reinforcing steel will reduce the cracking, which occurs due to temperature shrinkage of the concrete. Reinforcing steel placement in footings is shown in figure 20 .

The shape of the footing may be square, rectangular, or round. The bearing area, however, must meet the above requirements. The base of a rectangular footing shall not have a side less than $2 \mathrm{ft} 3 \mathrm{in.}$ in length. Good drainage should be provided around footings to prevent erosion.

Steel A-Frames

As previously mentioned, galvanized steel A-frames are the preferred cable support device. Steel A-frames of various sizes have been developed by various offices of USGS. These designs, with minor changes, have become the USGS standard and are recommended for future installations. Drawings and specifications of WRD approved A-frames are available on request from the Hydrologic Instrumentation Facility (HIF). A-frames fabricated from structural steel I- or WF-beams are preferred. A-frames fabricated from pipe or tubular sections are discouraged because inspection of the condition of the interior is impossible. A drawing of a typical WRD steel Aframe is shown in figure 21 .

Three means of supporting the cable at the top of the Aframe may be used. The first, and recommended, method has the main cable passing over a rolling sheave and attached to an anchor. The rolling sheave is desirable because it moves as the cable moves due to use and thermal expansion and contraction.

The second method has the main cable resting in a metallic or wooden saddle. The disadvantage of this type of attachment is that movement of the cable results in sliding (with subsequent wear) between the cable and saddle. Also, the wooden saddles deteriorate relatively quickly and must be replaced. Saddles generally are used with structural strand cables because this material is adversely affected by the smaller radii of rolling sheaves.

The third method uses a main cable that is attached to the A-frame and another cable that is attached to the back 

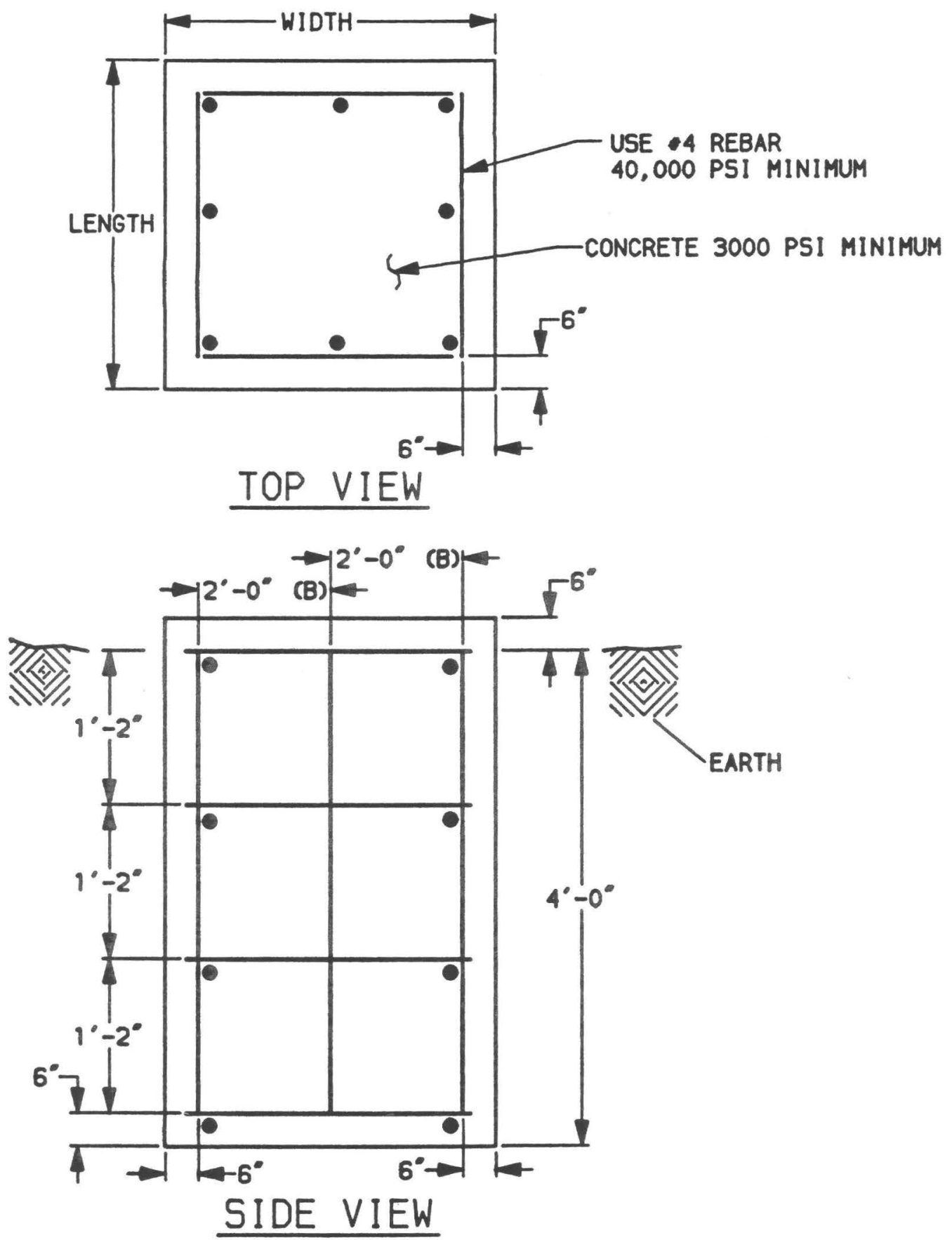

EXPLANATIONS: 1. Cross section dimensions will vary.

2. Distance (B) between vertical reinforcing bar shall not exceed 2 feet. Add vertical reinforcing bars according to footing dimensions.

Figure 20.--Single and combined footing reinforcing bar placement. 


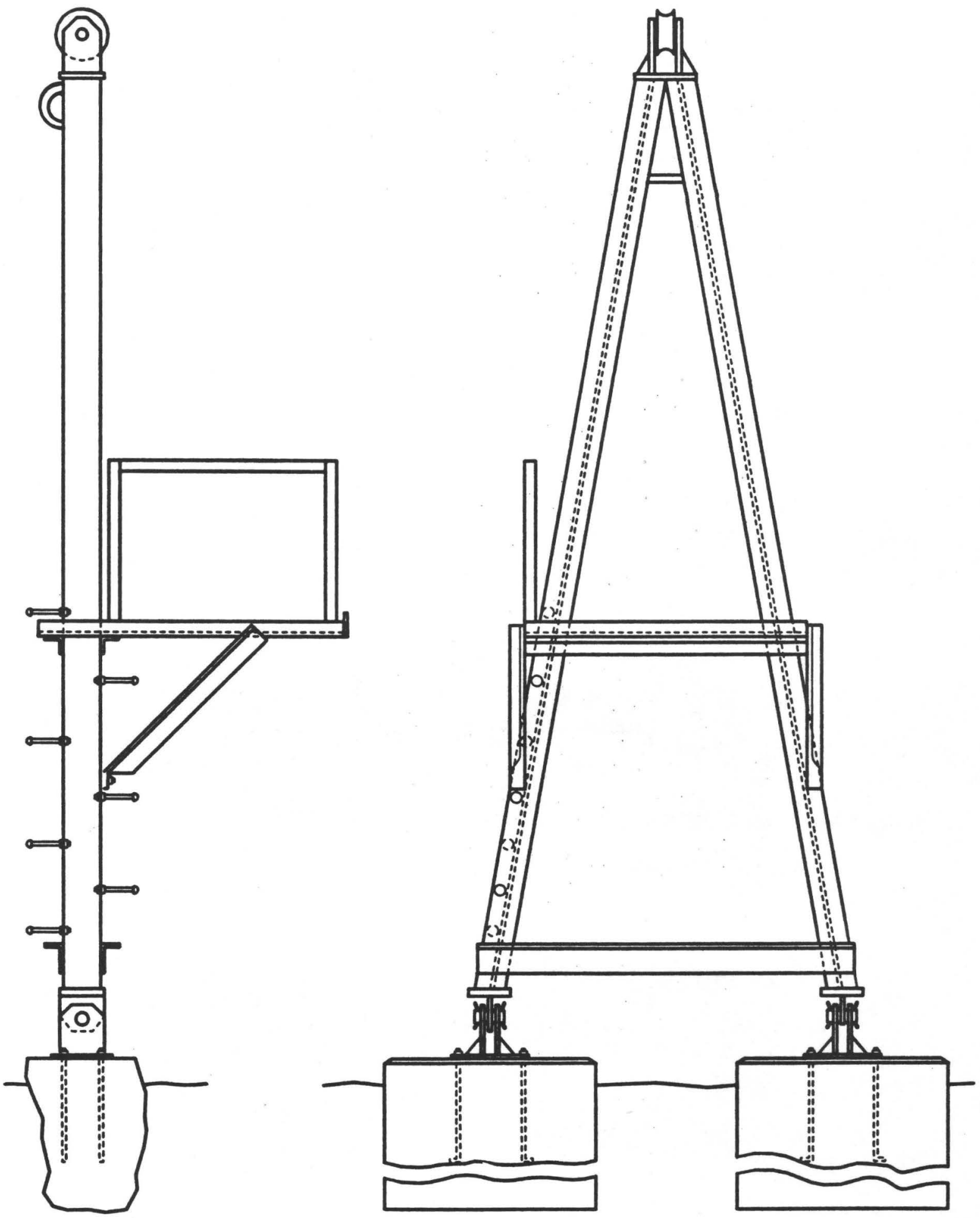

Figure 21.--Steel A-frame. 
side of the A-frame and also to the anchorage. The disadvantage of this third method is that the cable must be ordered with an exact length to maintain A-frames in a plumb position. This method has been used infrequently but is completely acceptable. The top of an A-frame may require modification to provide an adequate attachment for this type of connection. However, if an open socket is used for the main cable and a closed socket is used for the backstay segment, the A-frame sheave pin can provide an adequate attachment.

A-frames should have hinged attachments to their footings because of the considerable movement during erection and use. Fixed-leg A-frames may place extreme forces on bolts connecting the A-frame legs to the footings as the structure moves during use. A-frames up to about $15 \mathrm{ft}$ in height are generally welded together in one piece. Larger sizes may be fabricated in sections and assembled on the site. All welding, drilling, punching, or other processes must be done prior to galvanizing.

Fabricating and galvanizing should be performed only by a proven shop and must meet the following industry standards. Welding must be in compliance with American Welding Society Structural Welding Code, AWS D1.1. Work must be performed in a shop certified by the American Welding Society or by a fabricator certified Category I Conventional steel Structure by the American Institute of Steel Construction Quality Certification Program. Galvanizing must meet ASTM standard $\mathrm{A}-123$.

Wood A-Frames

The use of wooden A-frames is discouraged because they deteriorate rapidly and must be replaced frequently. In some areas, such as national parks, wooden structures may be required to blend into a natural environment. A drawing of a typical wooden A-frame is shown in figure 22.

Where wooden structures are used, the design loads are computed similarly as done with steel. Generally 8- by 8-inch wooden beams will meet strength requirements for USGS structures, but calculations should be made for strength characteristics of the species of timber selected. Pressuretreated wood, which will last much longer than non-treated wood, is highly recommended. Painting of wooden structures adds to moisture retention and subsequent rotting and is discouraged. Painting may also camouflage rotted wood. Cross bracing must be bolted in place with $5 / 8$-inch or larger bolts.

Steel Beams

Steel I or WF structural shapes fabricated to single leg supports have been used as cable supports. Because these 


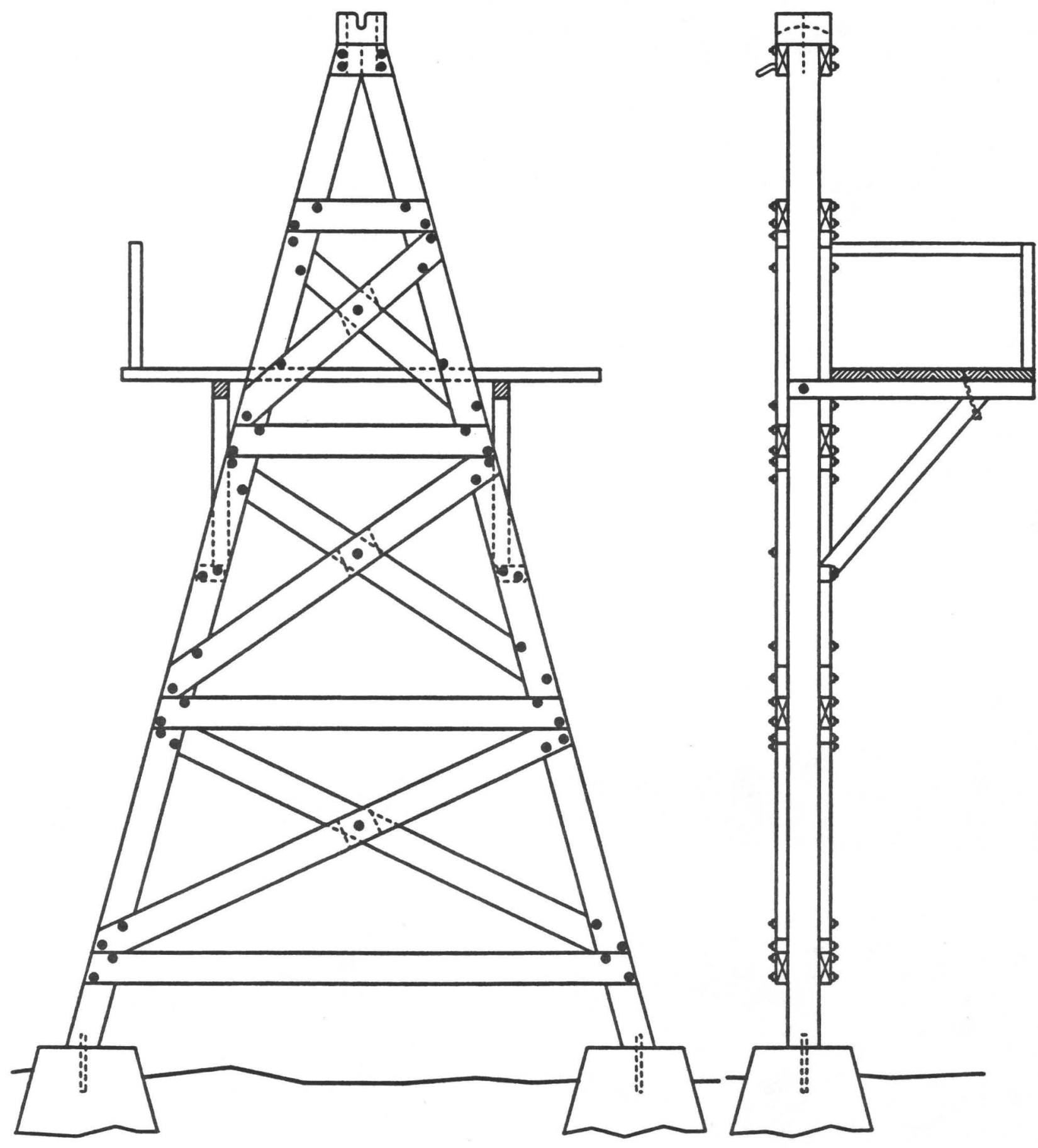

Figure 22.--Wooden A-frame. 
fabrications, unlike A-frames, offer no lateral stability, additional anchors must be installed on the upstream and downstream sides for guying the beam. These anchors should be approximately one-half of the length and width of appropriate main cable anchors and not less than $4 \mathrm{ft}$ in depth. The entire load is carried on a single footing, and, as such, requires a footing of twice the bearing area of the single footings shown in table 3 . I-beam supports should be galvanized after fabrication and should meet the requirements set forth in the section on steel A-frames.

In general, the cost of this type of cable support will exceed that of an A-frame because of the cost of additional sidestays and anchorages.

\section{Trees as Supports}

Trees have been used in many locations as cable supports. Their use is not recommended for new cableway locations. However, there may be locations where conventional structures are not practical and large sturdy trees may be used.

Trees as supports have been used in two ways. The first is an application in which the tree supports the cable vertically and the main cable is attached to a concrete mass anchor or to the base of another tree. In this case, the loading is vertical and little or no horizontal load is placed on the tree. A variety of sheave or other attachments have been used to attach the cable to the tree. In the second application, the cable is wrapped around the tree, and both vertical and horizontal forces are placed on the tree. The higher up the tree that the cable is attached, the greater the bending moment that acts on the tree's root system.

When a tree is to be used as a support, there are special design considerations, which require the exercise of practiced judgment. Design and construction should only be performed by personnel with experience in using trees as cable supports. Consultation with a qualified forester may be required to evaluate a tree's health and stability. Only large, healthy, and well-rooted trees should be considered. Care must be exercised in attachments to prevent present or future damage to the tree.

\section{Platforms, Walkways, and Ladders}

Many support structures require a ladder-type structure to reach the cable car. Platforms are required in most cases on the cable-car storage side. The Occupational Safety and Health Act (OSHA) requires a safety railing on all platforms over $4 \mathrm{ft}$ above ground level. Detailed OSHA guidelines are contained in 29 CFR (Code of Federal Regulations) Parts 1910.23 and 1910.27 . 
In some cases, walkways to gage shelters or down banks are required. Standard A-frame plans include properly designed platforms and railings. However, most walkways are site unique and are designed for each location. Strength and durability should be considered in the design. Galvanized steel provides long-term, low-maintenance performance. Walkways and steps should be of an open-grate, skid-resistant material. Preformed, skid-resistant, aluminum walkway material is commonly available, but caution is advised in attaching it to other metals because of galvanic action, which may rapidly deteriorate the aluminum. Wooden walkways, platforms, and ladders are discouraged, except as required for environmental or aesthetic reasons. All wood should be pressure treated with preservative meeting the American WoodPreservers' Association standard C1, designated as ACZA or $\mathrm{CCA}-\mathrm{C}$, and having retention (PCF value) of $0.40 \mathrm{lb} / \mathrm{ft}^{3}$ or greater. This information should be stamped on the wood or contained in a tag attached to the individual piece. Pressure-treated wood should not be painted. Fiber glass grating and support members that are light and long lasting are available.

\section{Grounding for Lightning Protection}

Very few USGS cableways have been grounded in the past, and lightning-induced structural damage has been negligible. Most USGS cableways use concrete anchors to provide cable tension. This mass of concrete with a long steel U-bar attached to the cable, in effect, serves as an effective ground, known as the "Ufer" ground. The Ufer technique uses foundation reinforcing bars and the moisture retaining properties of concrete as grounds. The diameter and length of the U-bars used in USGS cable anchorages are usually adequate for carrying the energy of average lightning strikes to ground. Increased protection can be obtained by attaching the standard U-bar to anchorage reinforcement bars.

The advent of solid-state electronic sensing and recording and transmission devices in gaging stations has increased the need to provide suitable grounding procedures for instrument shelters and the electronic instrumentation. The procedures involved in protecting this instrumentation are outside the scope of this manual. However, many cableways are located in proximity to instrument shelters, and a lightning strike on the cableway system could indirectly damage electronic equipment. In these locations, or in areas of abnormally heavy lightning strikes, additional grounding procedures may be desirable. Grounding rods and wire grounds are inexpensive and effective methods of providing protection. Numerous reference materials are available that provide detailed instructions on installation procedures for a variety of lightning-protection systems. The Standard of Practice LPI-175 (Lightning Protection Institute) provides detailed procedures. 


\section{Anchorages}

Anchorages are used to tension the cable. In the case of a steeply sloping topography, the anchorage may be attached directly to a cable. Most frequently, anchorages are located behind a cable support structure such as an A-frame. Anchorages must be designed to withstand safely all forces transmitted by the cableway with an appropriate design factor. Several types of cable anchors have been used and are described in this section.

\section{Concrete Mass Anchors}

Concrete mass anchors (gravity anchors) are most frequently used by the Survey. A properly designed and installed concrete anchor will last indefinitely with minimal maintenance. This type of anchor is strongly recommended. High-quality concrete can now be delivered and mixed on-site nearly everywhere. However, transporting the concrete from the truck to the cableway site may require innovation on the part of the local construction crew. Even if this process is relatively costly, long-term durability and low maintenance over many years make this type of anchor desirable.

Concrete must meet ACI-318 (American Concrete Institute) and ASTM C-94 (American Society for Testing and Materials) specifications. Concrete for anchors must have compressive strength of $3,000 \mathrm{lb} / \mathrm{in}^{2}$.

The size and shape of this type of anchor depends on the bearing and shear strength of the soil. Design considerations include the load (tension) acting on the end of the cable calculated vertically and horizontally, the coefficient of friction between concrete and various soils, the bearing strength of various soils, the weight of the concrete, and design factors against overturning and material yield stress.

In cases of submergence during high water, a buoyant effect occurs. This dictates the use of heavier anchors. The following designs provide for a factor of 2 for moist soil conditions and 1.5 for saturated soil conditions.

The angle of the cable from the horizontal affects the forces acting on the anchor and is therefore a significant factor in determining the size of the anchor. An angle of $45^{\circ}$ is preferred because the forces acting on the anchor block are divided equally between sliding and bearing support of the earth. A $30^{\circ}$ angle places a larger component of forces on sliding friction and a smaller component on the bearing capability of the soil. The greater the angle of the cable to the anchor, the greater the streamward component of forces acting on the top of the cable support and backstay. Angles greater than $45^{\circ}$ are not recommended. Should angles greater 
than $45^{\circ}$ be required, individual designs for footings, support structures, anchors, and backstays must be made.

The strength of various cable materials varies widely within a given cable diameter. Therefore, standard anchorages have been developed for cables of various design loads.

Standard designs for concrete mass anchors are given in figures 23 and 24 for attachment angles of $30^{\circ}$ and $45^{\circ}$. Anchorage dimensions for various cable design loads are given in table 4. Spacing of reinforcing bars should be prorated to the larger size; however, placing boundary reinforcement is critical and should never be placed less than 3 in. from outside surfaces.

U-bars in concrete anchors must always be placed in a vertical plane to minimize fatigue induced by cable vibration.

\section{Hillside Anchors}

A hillside anchor is a modification of a mass anchor and is designed to be built into a sloping streambank. The shape of the anchor and weight of soil on top of the concrete increase resistance to horizontal movement. The anchor must be completely buried, with the exception of the U-bar area, to work as designed. Standard designs are shown in figures 25 through 29 for design loads of 10,000 through 30,000 1b.

Excavation and backfilling must be performed carefully to maintain maximum soil-bearing strength.

\section{T-Anchors}

A T-anchor is a combination mass anchor and "deadman" anchor. T-anchors are not recommended for general usage. These anchors have been used in locations where concrete placement is difficult. Excavation must be carefully undertaken to minimize soil disturbance. The placement of the forms and reinforcement bars must be precise and is therefore costly. The U-bar and main stem of the anchor must be in exact alignment with the cable. Misalignment would cause a rotational moment on the transverse load-bearing component that could in turn cause cracking and a resultant strength loss. T-anchor design has been considered only for $30^{\circ}$ applications. Installations at $45^{\circ}$ would require a deeper and larger design, which would not be practical. Standard designs are shown in figure 30. Anchorage dimensions are given in table 5 for design loads of 10,000 to $30,000 \mathrm{lb}$.

Rocks as Anchors

Rock anchors are used in locations where solid rock formations are available. A rock anchor can be a steel U-bar or single-bolt-type device that is either grouted into rock 


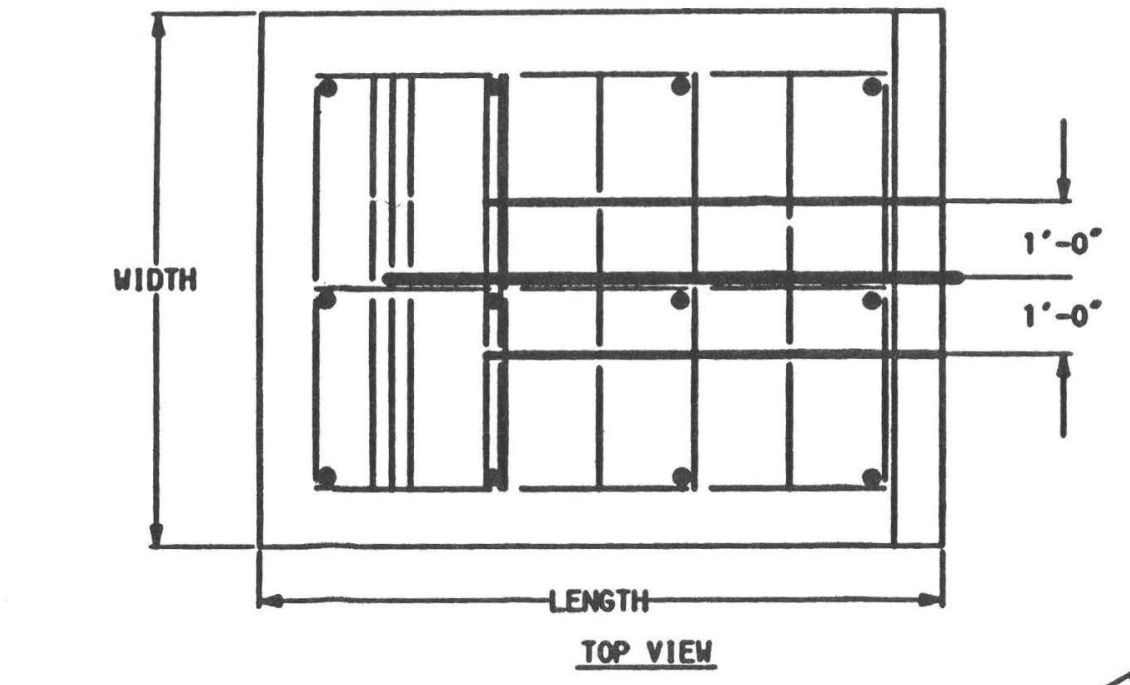

EXPLANATIONS:

1. KoL.M INDICATE TYPICAL of REBAR PLACEMENT.
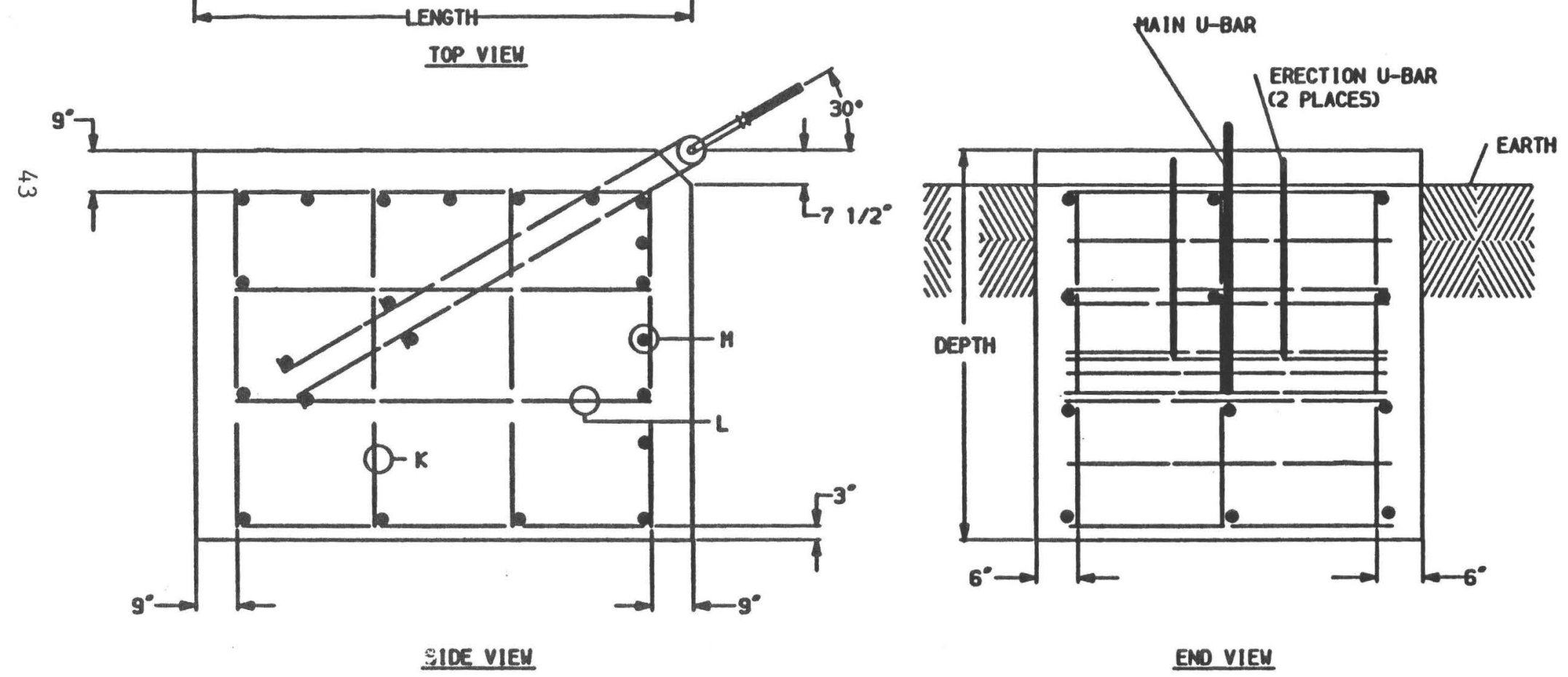

Figure 23.--Anchorage for cableway positioned at $30^{\circ}$. 


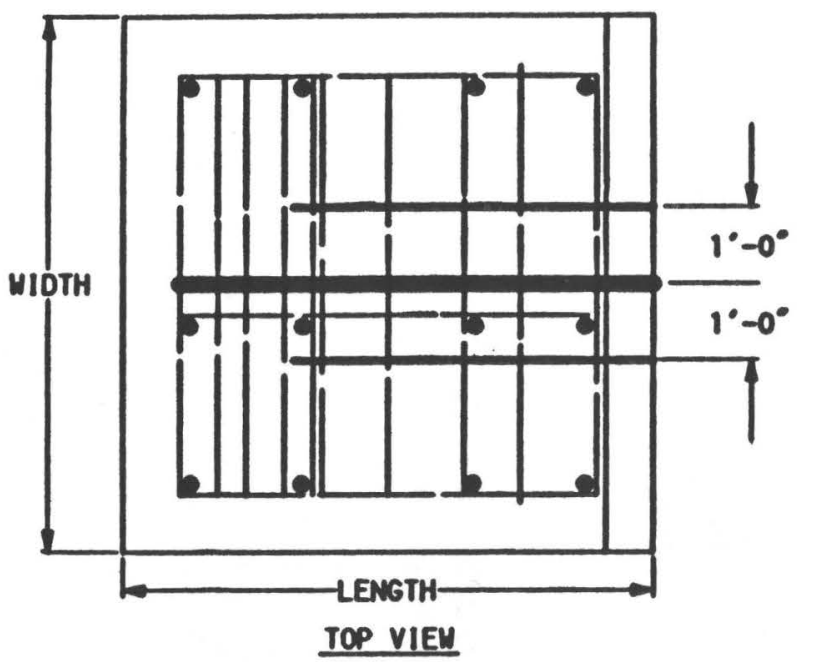

\section{EXPLANATIONS}

1. K,L,M INDICATE TYPICAL -4 REBAR PLACEMENT.
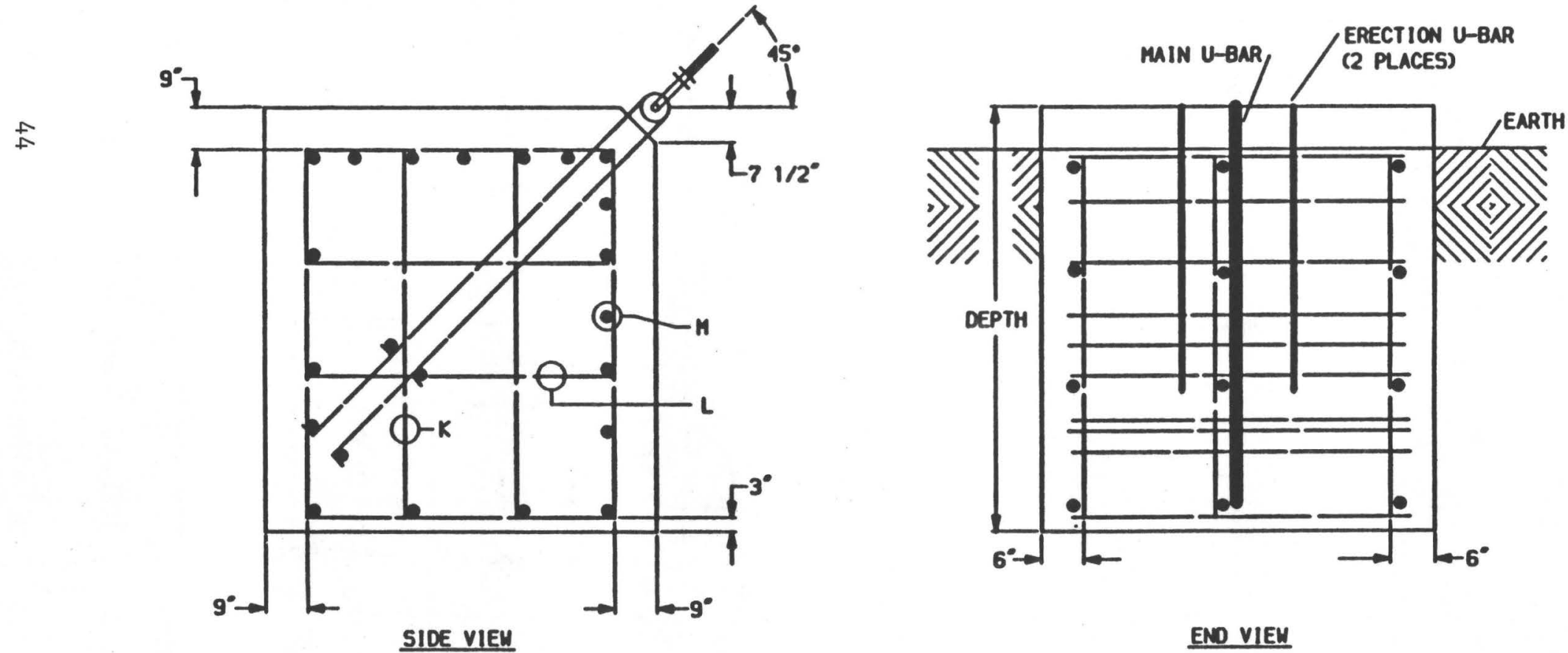

Figure 24.--Anchorage for cableway positioned at $45^{\circ}$. 
Table 4.-- Anchorages for $35^{\circ}$ and $45^{\circ}$ cables

\begin{tabular}{|c|c|c|c|c|c|}
\hline \multirow{2}{*}{$\begin{array}{l}\text { Soil } \\
\text { type }\end{array}$} & \multirow{2}{*}{$\begin{array}{c}\text { Cable } \\
\text { design } \\
\text { loadi } \\
\text { (pounds) }\end{array}$} & \multicolumn{3}{|c|}{ Anchorage dimensions } & \multirow{2}{*}{$\begin{array}{l}\text { Concrete } \\
\text { quantity } \\
\text { (cubic } \\
\text { yards) }\end{array}$} \\
\hline & & (feet) & (feet) & (feet) & \\
\hline \multicolumn{6}{|c|}{ Archorages for $30^{\circ}$ cables } \\
\hline A & $\begin{array}{l}10,000 \\
15,000 \\
20,000 \\
25,000 \\
30,000 \\
40,000\end{array}$ & $\begin{array}{r}7.00 \\
7.75 \\
8.50 \\
9.00 \\
9.50 \\
10.00\end{array}$ & $\begin{array}{l}5.50 \\
6.25 \\
7.00 \\
7.50 \\
8.00 \\
8.50\end{array}$ & $\begin{array}{l}5.00 \\
5.75 \\
6.00 \\
6.50 \\
7.00 \\
725\end{array}$ & $\begin{array}{r}8.2 \\
10.3 \\
13.2 \\
16.3 \\
19.7 \\
22.8\end{array}$ \\
\hline \multirow[t]{2}{*}{$\mathrm{B}$} & $\begin{array}{l}10,000 \\
15,000 \\
20,000 \\
25,000 \\
30,000 \\
40,000\end{array}$ & $\begin{array}{r}7.75 \\
8.75 \\
9.75 \\
10.50 \\
11.00 \\
12.00\end{array}$ & $\begin{array}{r}6.25 \\
7.25 \\
8.00 \\
8.50 \\
3.00 \\
10.00\end{array}$ & $\begin{array}{l}5.75 \\
6.50 \\
7.00 \\
7.50 \\
0.00 \\
8.50\end{array}$ & $\begin{array}{l}10.3 \\
15.3 \\
20.2 \\
24.8 \\
29.3 \\
37.8\end{array}$ \\
\hline & \multicolumn{4}{|c|}{ Anchorages for $45^{\circ}$ cables } & \\
\hline A & $\begin{array}{l}10,000 \\
15,000 \\
20,000 \\
25,000 \\
30,000 \\
40,000\end{array}$ & $\begin{array}{l}6.00 \\
6.75 \\
7.50 \\
8.25 \\
8.75 \\
9.50\end{array}$ & $\begin{array}{l}5.50 \\
6.25 \\
7.00 \\
7.75 \\
8.25 \\
9.00\end{array}$ & $\begin{array}{l}5.00 \\
5.75 \\
6.25 \\
6.75 \\
7.25 \\
7.75\end{array}$ & $\begin{array}{r}6.1 \\
9.0 \\
12.2 \\
16.0 \\
19.4 \\
24.5\end{array}$ \\
\hline $\mathrm{B}$ & $\begin{array}{l}10,000 \\
15,000 \\
20,000 \\
25,000 \\
30,000 \\
40,000\end{array}$ & $\begin{array}{r}6.50 \\
7.25 \\
8.00 \\
8.75 \\
9.25 \\
10.25\end{array}$ & $\begin{array}{l}6.00 \\
6.75 \\
7.50 \\
8.00 \\
8.50 \\
9.50\end{array}$ & $\begin{array}{l}5.50 \\
6.00 \\
6.50 \\
7.00 \\
7.50 \\
8.25\end{array}$ & $\begin{array}{r}7.9 \\
10.9 \\
14.4 \\
18.8 \\
21.8 \\
29.8\end{array}$ \\
\hline
\end{tabular}

lCable design load from table 1 or manufacturers' specifications. 


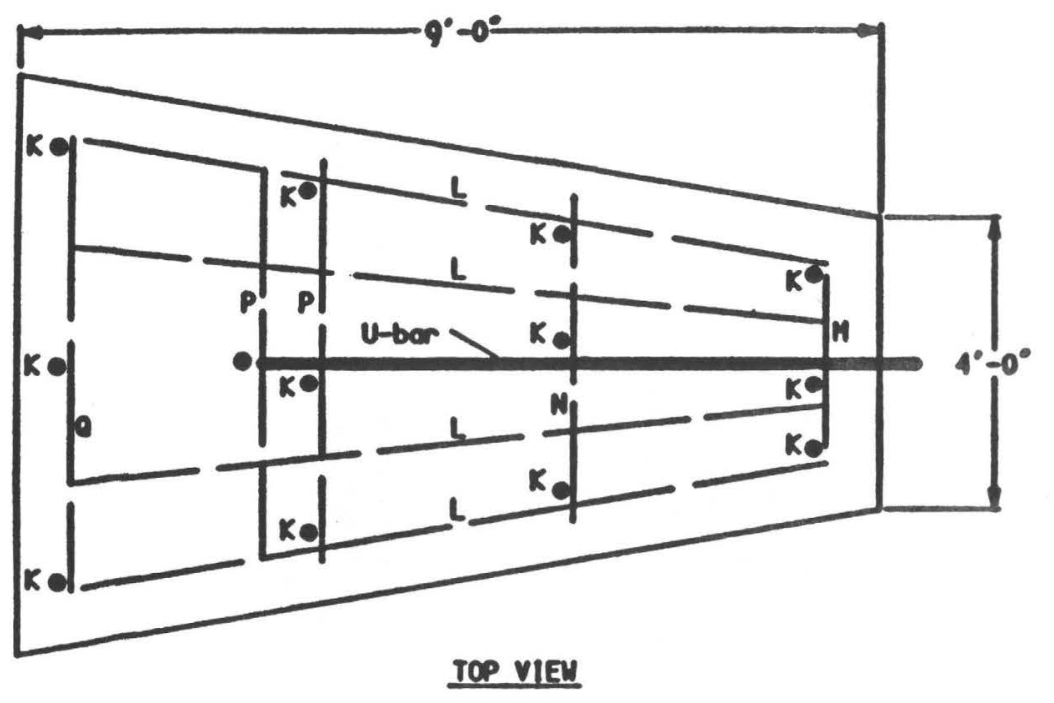

\section{Explamations:}

1. SOIL TYPE $A_{1}$

VOLUHE OF CONCRETE, 9.25 CUBIC YAROS.

LENGTHS OF 4 REBAR RECUIRED.

(C) 12 AT 4 FEET $=48$ FEET

(C) 2 AT 7 FET 2 FEET $=90$ FEET

(W) 3 AT $31 / 2$ FEET $=101 / 2$ FEET

(P) 5 AT 5 HeET Fet $=13$ FeET

(C) 3 AT 5 2/3 FEET = 17 FEET

2. SOIL TYPE 8 ,

IMCREASE MUCHORAGE DEPTH MN LENGTH I FOOT.

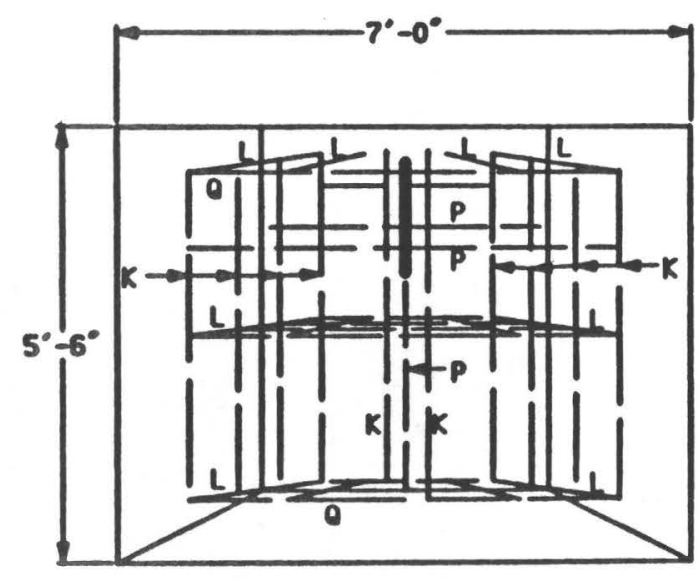

ERD VIEU

Figure 25.--Sidehill anchorage for 10,000-pound working load. 


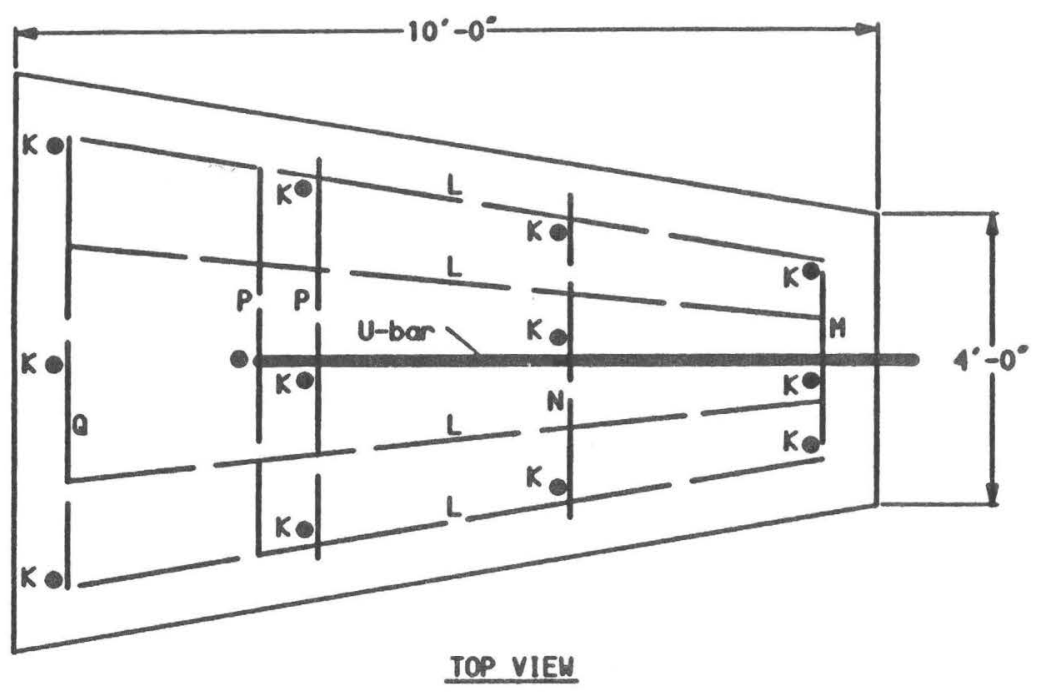

\section{EXPLANATIONS:}

1. SOIL TYPE A,

VOLUME OF CONCRETE: 11.23 CUBIC YARDS.

LENGTHS OF 4 REBAR REQUIRED.

(K) 12 AT 4 FEET $=48$ FEET

(L) 12 AT 8 1/2 FEET $=102$ FEET

(M) 3 AT $31 / 2$ FEET $=10 \quad 1 / 2$ FEET

(N) 3 AT $41 / 2$ FEET $=131 / 2$ FEET

(Q) 3 AT $61 / 2$ FEET $=191 / 2$ FEET

2. SOIL TYPE $B$,

INCREASE ANCHORAGE DEPTH AND LENGTH I FOOT.

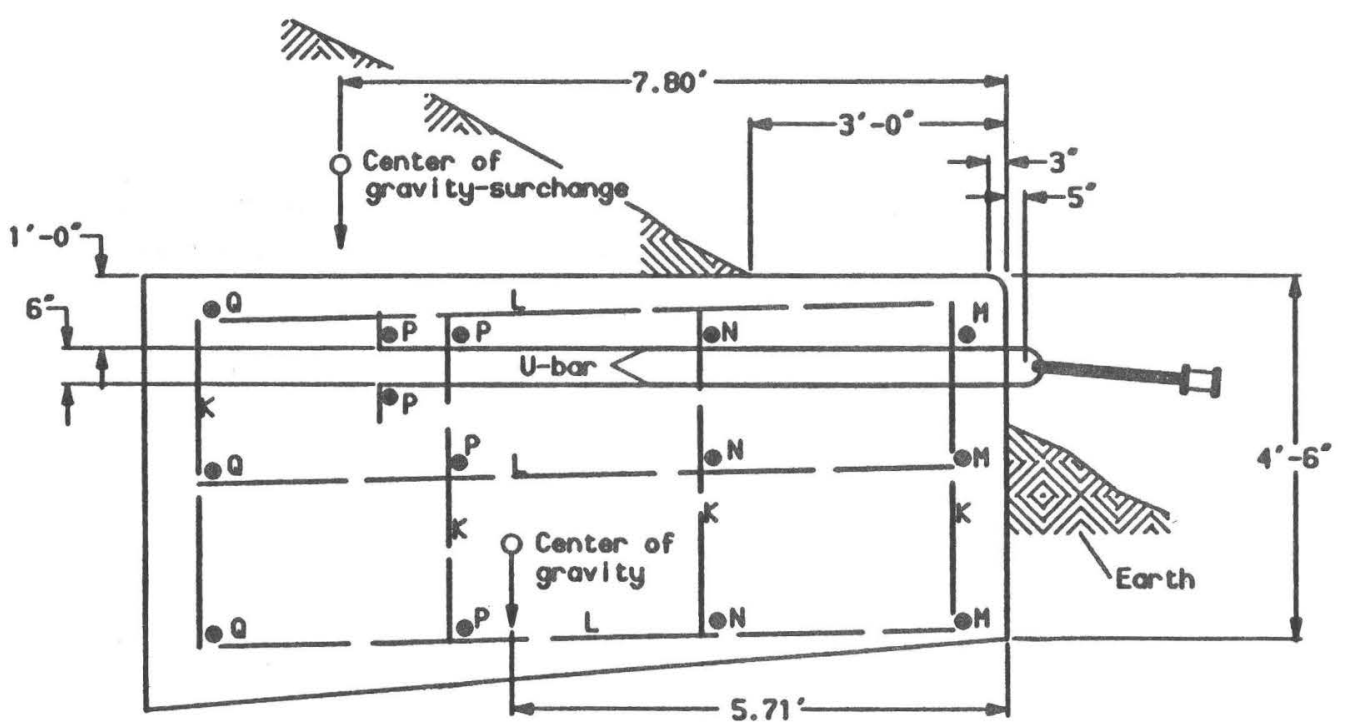

SIDE VIEW

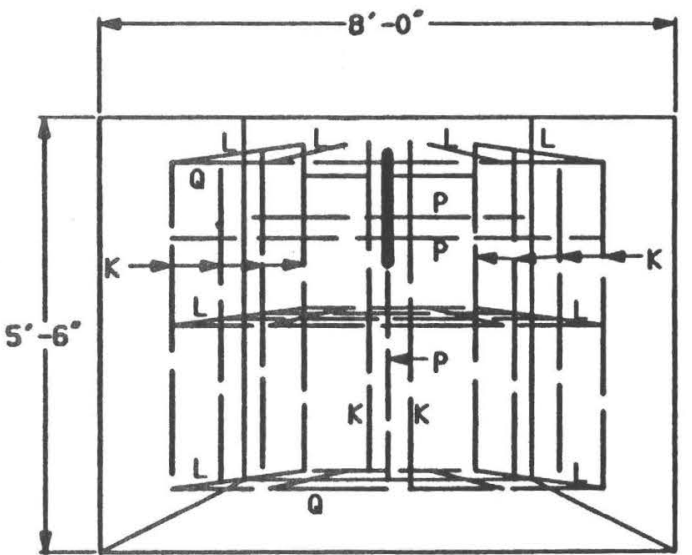

END VIEM

Figure 26.--Sidehill anchorage for 15,000-pound working load. 


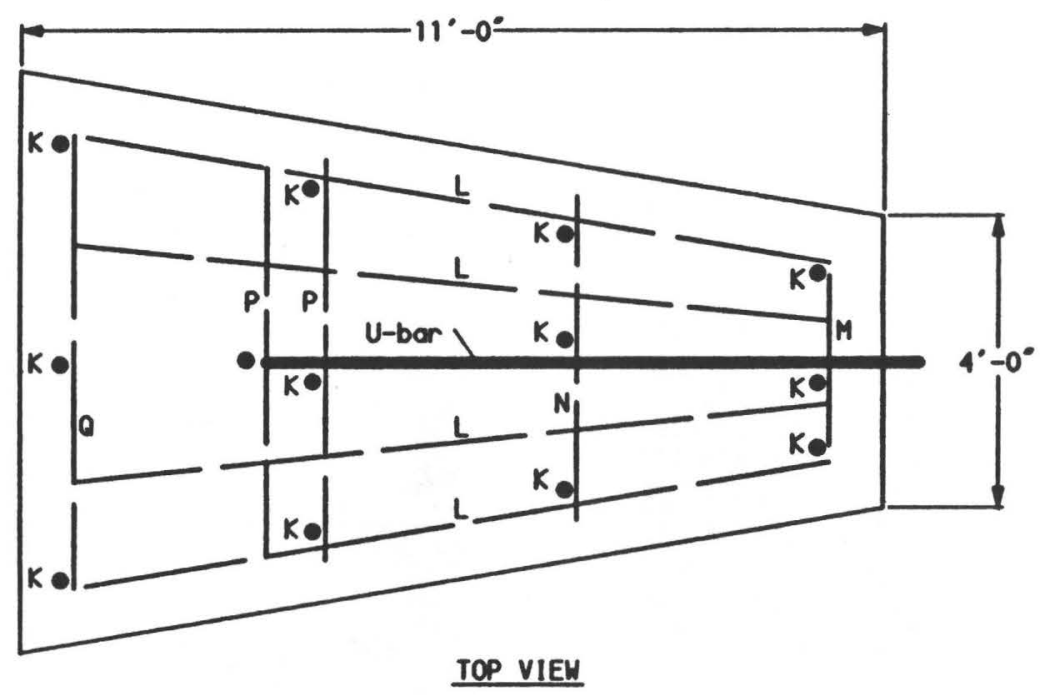

\section{EXPLANATIONS,}

1. SOIL TYPE $A_{1}$

VOLUME OF CONCRETE, 13.58 CUBIC YAROS.

LENGTHS OF 4 REBAR RECUIRED,

(K) 12 AT $41 / 2$ FEET $=54$ FEET

(L) 12 AT $91 / 2$ FEET $=114$ FEET

(M) 3 AT $31 / 2$ FEET $=101 / 2$ FEET

(N) 3 AT $1 / 2$ FEET $=131 / 2$ FEET

(P) 5 AT $51 / 2$ FEET $=271 / 2$ FEET

(Q) 3 AT 6 1/2 FEET $=191 / 2$ FEET

2. SOIL TYPE $B_{\text {, }}$

INCREASE ANCHORAGE DEPTH 1 1/2 FEET AND LENGTH I FOOT.

TOP VIEH
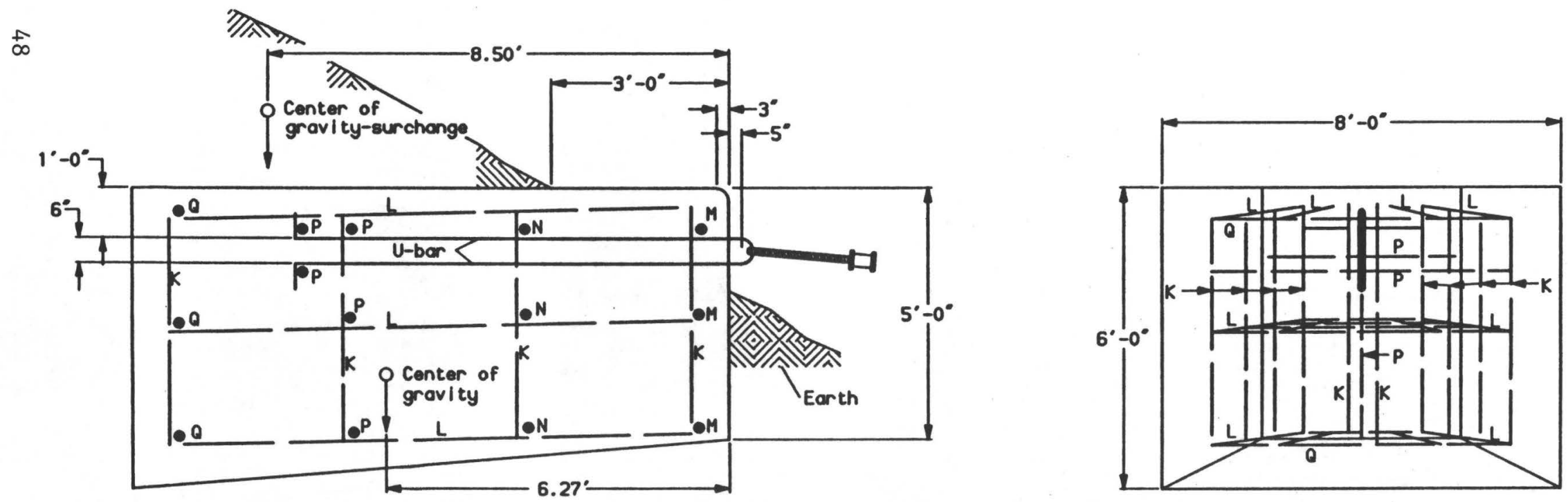

SIDE VIEW

END VIEH

Figure 27.--Sidehill anchorage for 20,000-pound working load. 


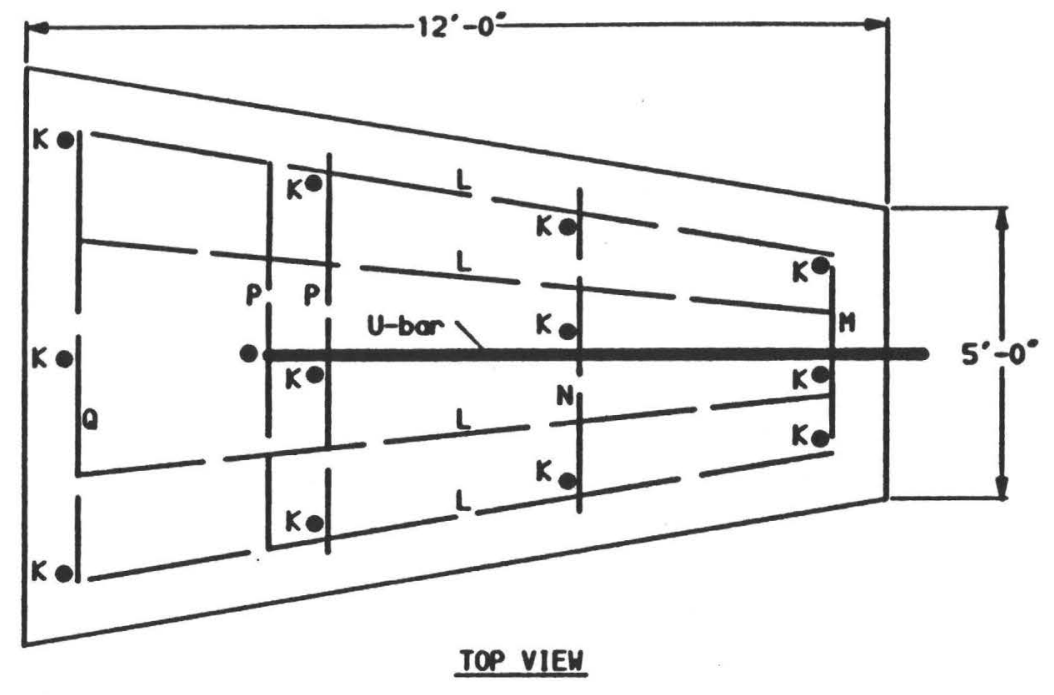

\section{EXPLANATIONS,}

1. SOIL TYPE $A$

VOLUME OF CONCRETE, 17.26 CUBIC YARDS.

LENGTH OF 44 REBAR REOUIRED

(K) 12 AT $41 / 2$ FEET $=54$ FEET

(L) 12 AT $101 / 2$ FEET $=126$ FEET

(A) 3 AT $41 / 2$ FEET $=131 / 2$ FEET

(N) 3 AT 5 1/2 FEET $=161 / 2$ FEET

(P) 5 AT 6 1/2 FEET = 32 1/2 FEET

2. SOIL TYPE B,

INCREASE ANCHORAGE DEPTH I 1/2 FEET AND LENGTH I FOOT.
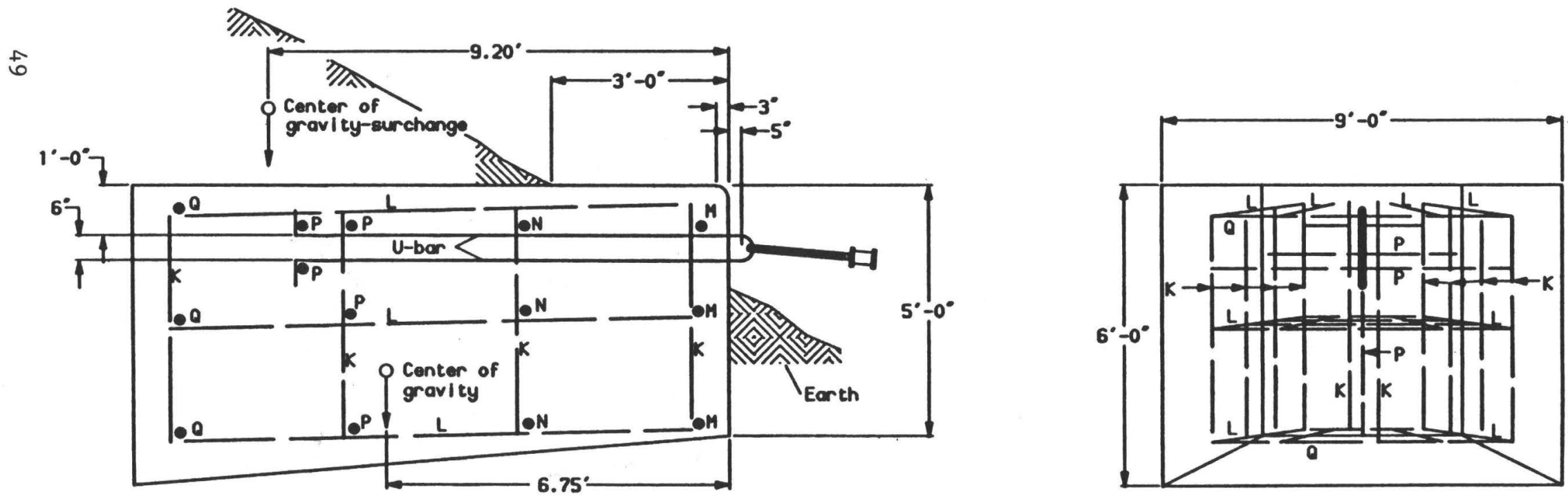

SIDE VIEW

END VIEW

Figure 28.--Sidehill anchorage for 25,000-pound working load. 


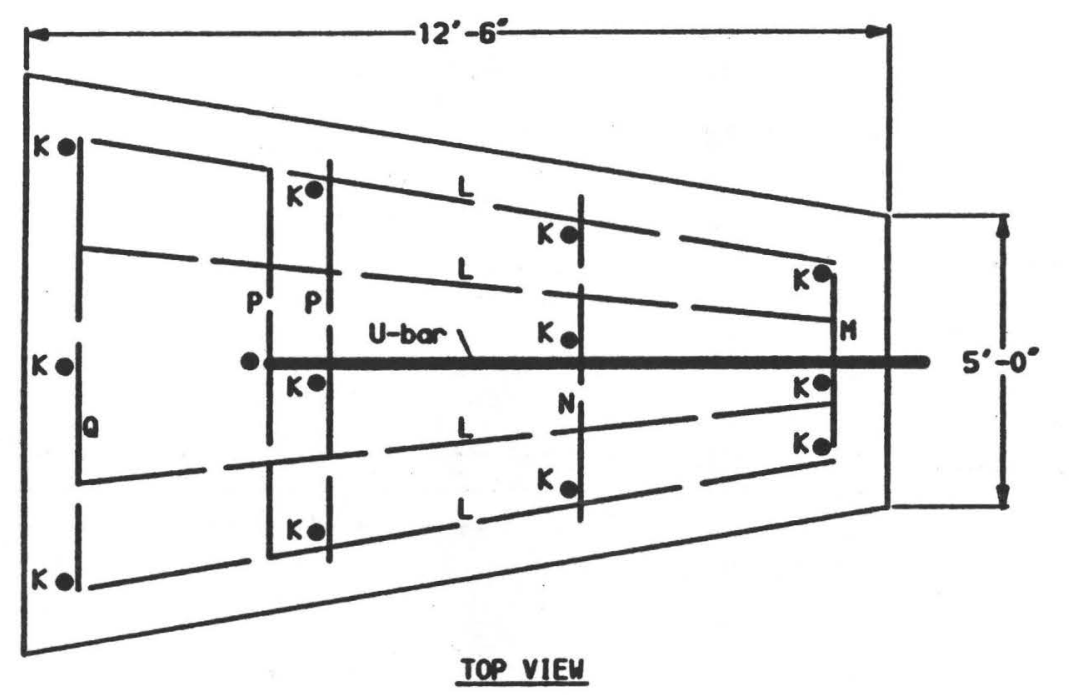

\author{
EXPLANATIONS. \\ 1. SOIL TYPE $A_{1}$ \\ VOLUAE OF CONCRETE, 21.02 CUBIC YARDS \\ LENGTHS OF 4 REBAR RECUIRED. \\ (K) 12 AT 5 FEET $=60$ FEET \\ (C) 12 AT II FEET = 132 FEET \\ (M) 3 AT 4 I/2 FEET $=131 / 2$ FEET \\ (N) 3 AT 5 I/2 FEET $=16$ 1/2 FEET \\ (Q) 3 AT 8 1/2 FEET $=251 / 2$ FEET
}

2. SOIL TYPE B, INCREASE ANCHORAGE DEPTH I 1/2 FEET AND LENGTH 1 FOOT.
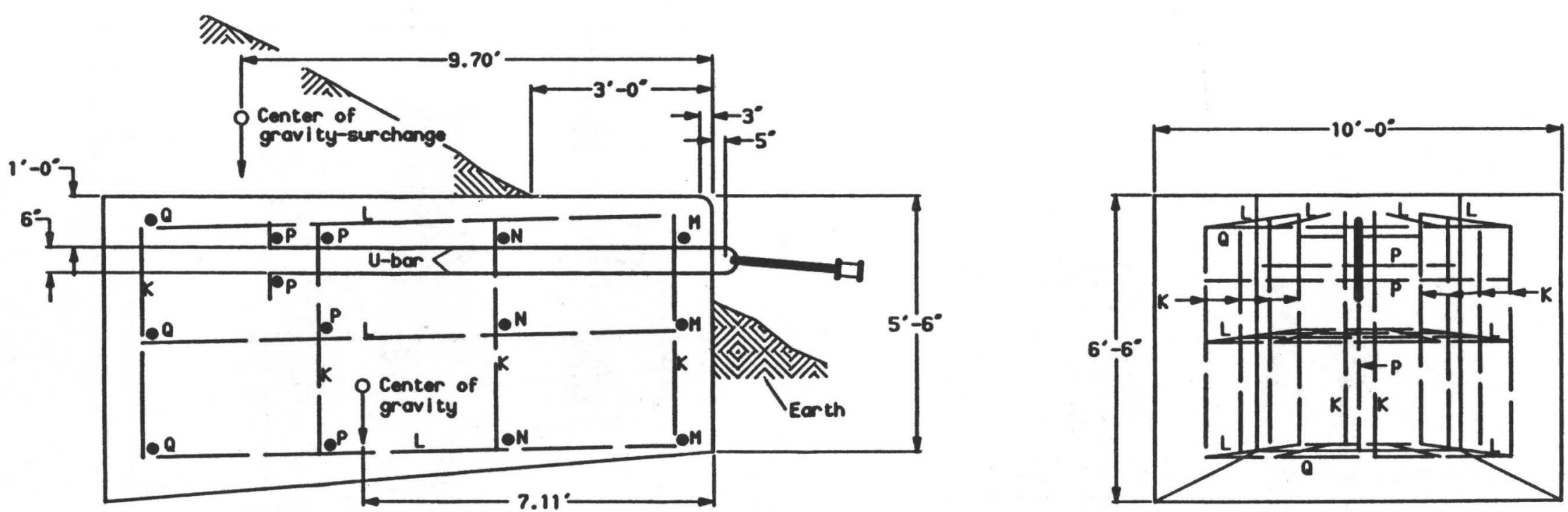

SIDE VIEW

END VIEY

Figure 29.--Sidehill anchorage for 30,000-pound working load. 

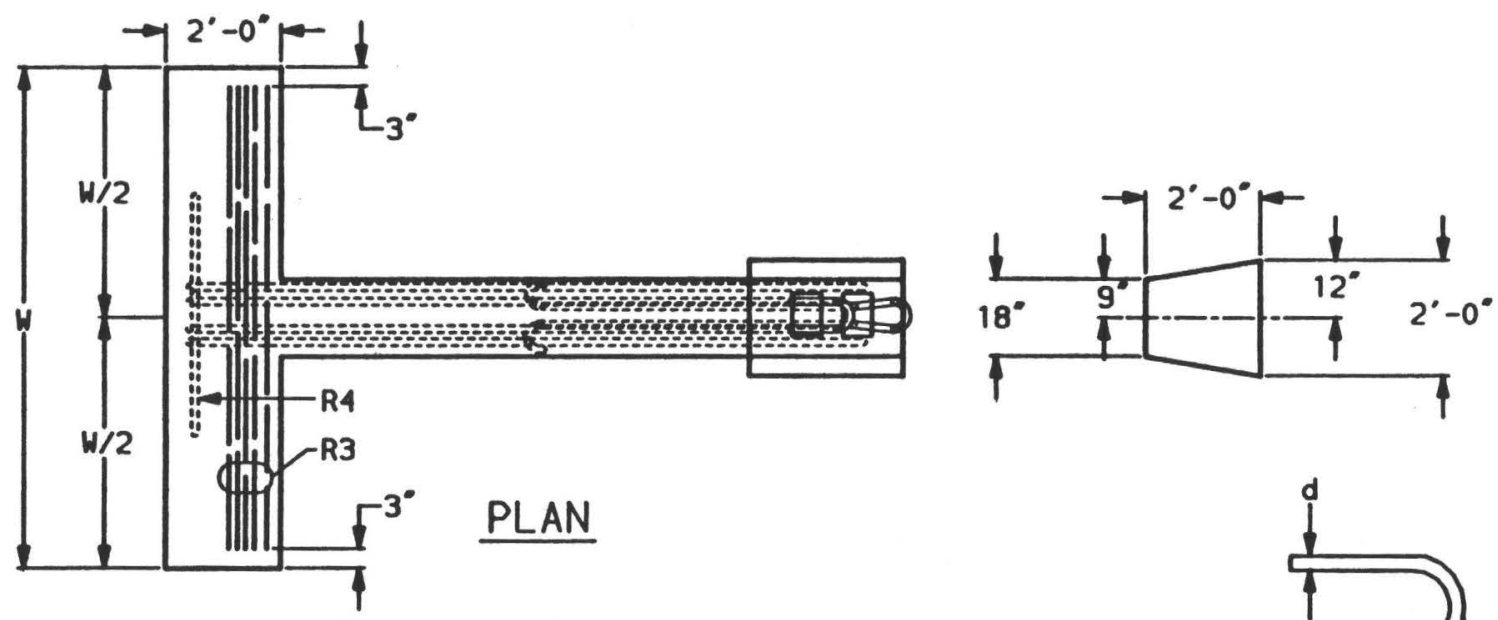

EXPLANATIONS: Steel ReInforcement Specifications

. Diameter--30,000-pound design load is are reinforcement if. 2. Length--calculated as follows using length
(L) and width (iV) derlved from table 5 .

V1 $=1.155 \mathrm{~L}+3.7$ feet

$\mathrm{U} 2=0.577 \mathrm{~L}+3.7$ feet

$R_{2}=1.155 \mathrm{~L}+6.0 \mathrm{seet}$

$R^{3}=W-0.5$ teet

$R 4=.5 W$

$S 1=5$ feet
$S 2=4.75$ feet

8* EXTENDED$12^{\circ}$ EXTENDED

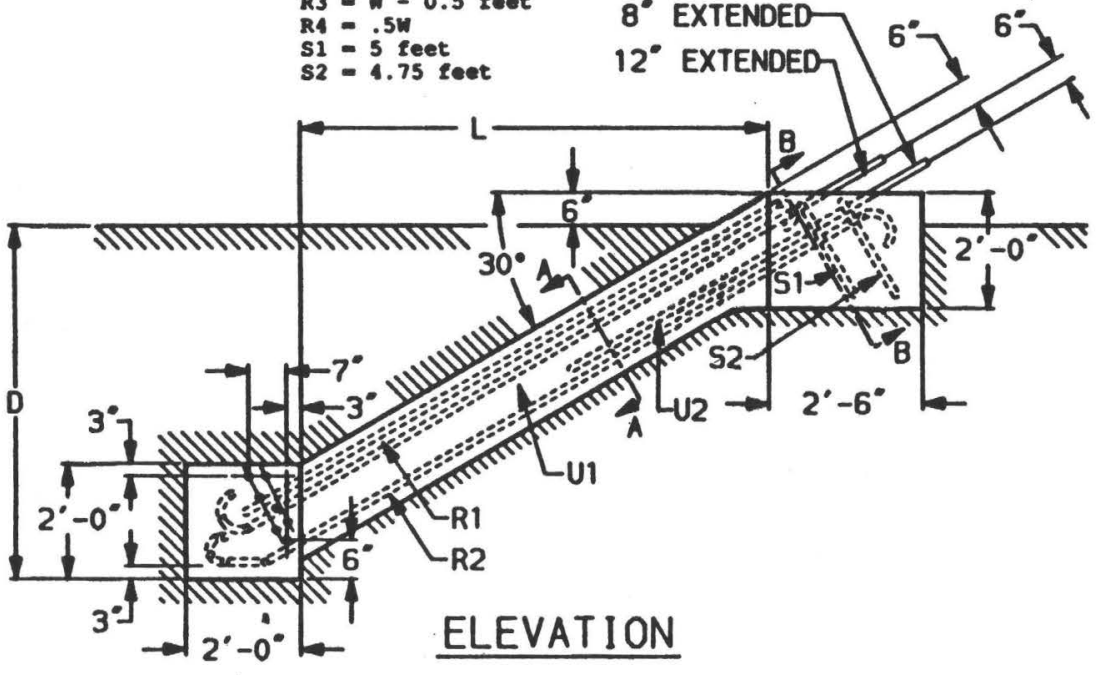

Figure 30.--T-anchor.
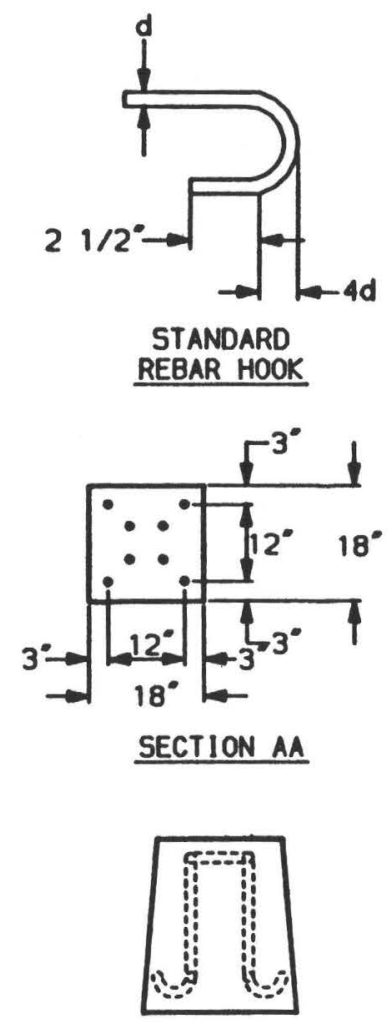

SECTION BB 
Table 5.--T-anchor dimensions

\begin{tabular}{|c|c|c|c|}
\hline \multirow{2}{*}{$\begin{array}{l}\text { Cable design } \\
\text { load1 } \\
\text { (pounds) }\end{array}$} & \multicolumn{3}{|c|}{$\begin{array}{c}\text { Dimensions } \\
\text { (feet) }\end{array}$} \\
\hline & Depth (D) & Width (W) & Length $(\mathrm{L})$ \\
\hline \multicolumn{4}{|c|}{ Soil type A } \\
\hline 10,000 & 6 & 6 & 7.8 \\
\hline 15,000 & 6 & 8 & 7.8 \\
\hline 20,000 & 7 & 8 & 9.5 \\
\hline 25,000 & 7 & 10 & 9.5 \\
\hline 30,000 & 8 & 10 & 11.25 \\
\hline \multicolumn{4}{|c|}{ Soil type $B$} \\
\hline 10,000 & 6 & 10 & 7.8 \\
\hline 15,000 & 7 & 10 & 9.5 \\
\hline 20,000 & 8 & 11 & 11.25 \\
\hline 25,000 & 9 & 12 & 13 \\
\hline 30,000 & 9 & 16 & 13 \\
\hline
\end{tabular}


with expanding cement grout, poured sulfur, or other material that expands on setting or incorporates a wedge-shaped expansion device that tightens as force is applied. Should the rock crack, such as might be caused by freezing, by a change in the bond between the rock and the steel bar due to alternate loading, or by a sudden change in loading direction as a result of wind loading or a streamgager's sounding line snagging a floating object, the connection may lose some of its strength.

Rock anchors generally are installed in a vertical position so that the cable tension pulls at or near $90^{\circ}$ to the axis of the anchor. In some cases, two or more anchors are installed several feet apart, and the cable is attached to them with a metal bar or cable bridle. The design of a multianchor system requires a careful engineering analysis of all forces and selection of adequate auxiliary hardware.

Anchors should extend into solid rock for at least $3 \mathrm{ft}$, preferably 4 to $5 \mathrm{ft}$. The hole in the rock should be drilled to at least $2 \mathrm{in}$. in diameter and at least $1 / 2 \mathrm{in.}$ larger than the U-bar or bolt diameter to allow for drilling misalignment and to allow penetration of the bonding material.

Vertically installed rock anchors transmit cable tension to the rock by shear forces. Therefore, larger diameter Ubars are required than for concrete anchors. A design factor of 2 is used.

The anchor should be fabricated so as not to reduce its strength. The leg parts of the anchor should be deformed to increase holding strength in bonding media. Galvanizing of the exposed part is recommended. Grouting or sulphur installation must be done by experienced personnel, following the manufacturer's instructions completely. A typical vertically installed rock anchor is shown in figure 31.

Horizontal rock anchors have been used where the cable tension pulls in a straight line. Because this type of rock anchor is in tension, it is more difficult to install and is more susceptible to failure. It is recommended that the site evaluation, design, and installation of this type of anchor be contracted to a qualified specialist such as a mining engineering consultant. A horizontal rock anchor is shown in figure 32 .

\section{Trees as Anchors}

Trees have been used as anchors for cableways in the past. Use of trees as anchorages will be covered here only for limited applications where large healthy trees are available and installation of concrete anchors would be difficult. When a tree is used as an anchorage, it may be subjected to only a horizontal force or, if the cable first 


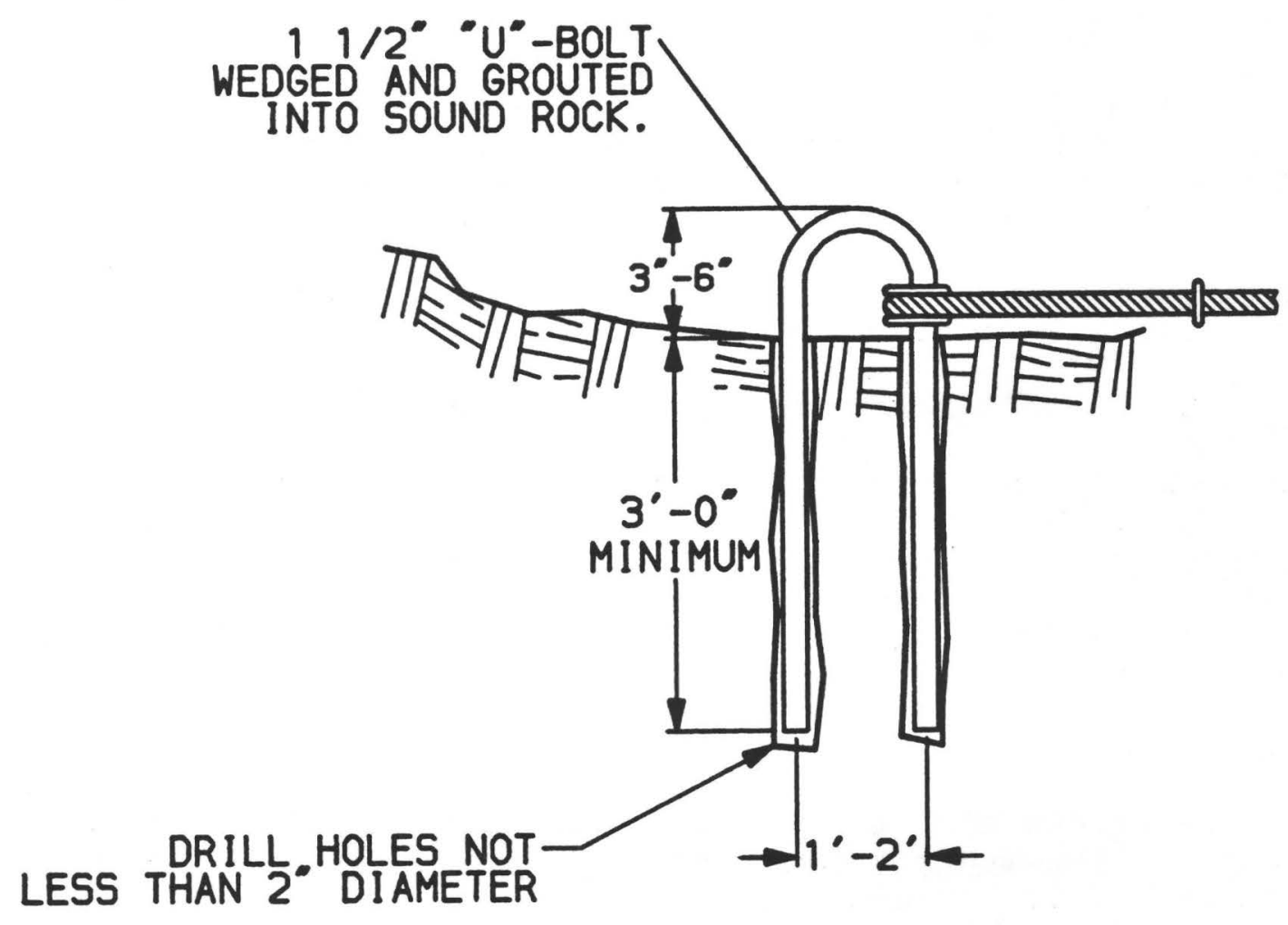

EXPLANATIONS: 1. Drill holes in rock at least 2 in. diameter or $1 / 2$ in. larger than anchor diameter.

2. Width normally between 6 and 12 in.

3. Anchor diameter (in.) for cable working load (lb): 1 1/2 in., 10,000 lb; $15 / 8$ in., 15,000, 1b; $17 / 8$ in., 20,000 1b; 2 in., 25,000 lb; 2 1/8 in., $30,000 \mathrm{lb} ; 21 / 4$ in., $40,0001 \mathrm{~b}$.

Figure 31.--Vertical rock anchor. 
passes over a structural support such as an A-frame or another tree, to both vertical and horizontal forces. Because the physics of tree root to soil has not been quantified mathematically, calculation of permissive loads on a particular tree become impossible. Differing species have root systems with substantially differing holding strength. Soil types, moisture content, and distance above ground (bending moment) that a cable is attached also affect a tree's stability.

If a tree is used, it must be a large, live, mature tree with a solid root system located in stable soil. Core borings should be obtained if disease or decay is suspected. Since considerable judgment is required to ensure a safe installation, the design and construction should only be performed by personnel with experience in using trees as cable anchors. Consultation with an experienced forester to evaluate a tree's health and stability may be required.

Buried Deadmen

The use of buried timber or steel "deadmen" was once commonplace, but it is now AGAINST USGS POLICY to use deadman anchors because deterioration of cable and anchor material may be rapid and unobservable. Existing deadmen should be replaced with concrete anchors.

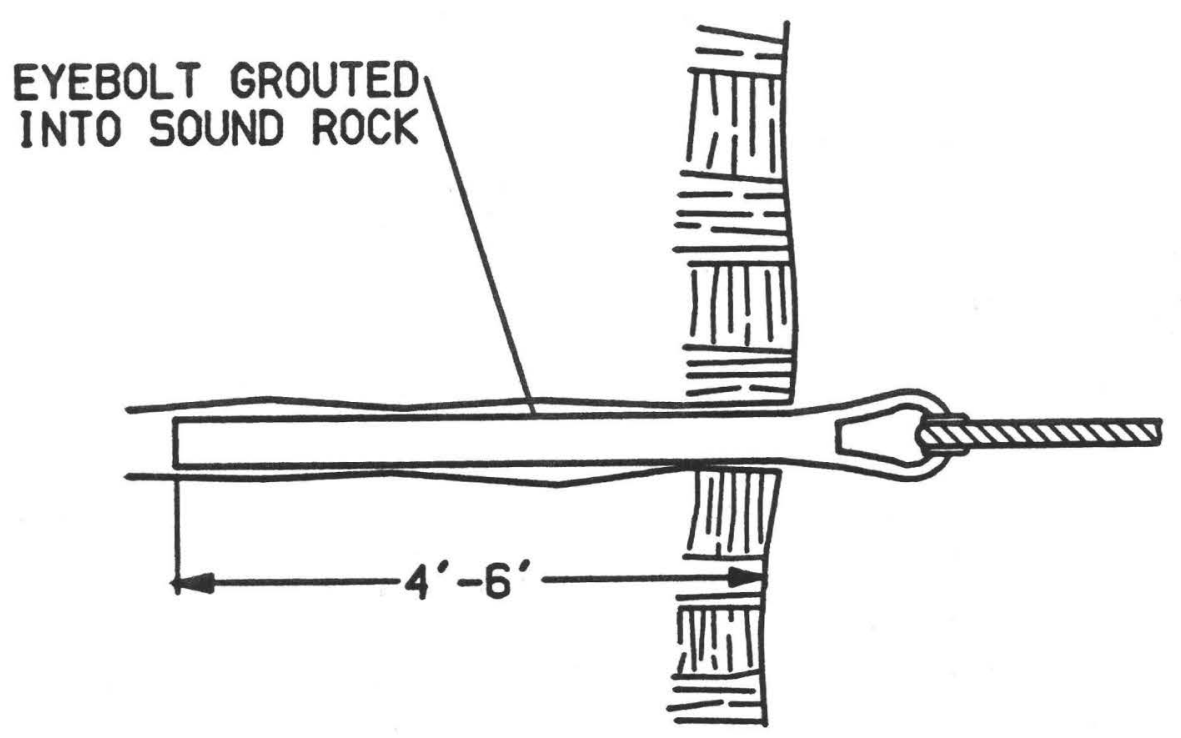

Figure 32.--Horizontal rock anchor. 


\section{Aircraft Warning Devices}

Aircraft warning markers usually will not be required, as described in an earlier section. However, some cableway locations are in remote areas where aircraft density is high and installation of markings may be desirable. Current regulations on appropriate and approved marking devices should be obtained from FAA.

Orange spherical markers are usually suitable for USGS cableway marking. A 3/8-inch, 6 × 19 IWRC or similar wire rope is adequate support for spans to about $500 \mathrm{ft}$. For greater spans, use a 1/2-inch wire rope. The support cable, sometimes referred to as a messenger cable should be mounted about $3 \mathrm{ft}$ above the main cable. This cable should have about the same sag as the main cable. An aircraft warning system places additional dead and live loads on the cable support components and anchorages and must be included as part of the design. Additional backstays and U-bars may be required. Markers should be spaced about $200 \mathrm{ft}$ apart or as otherwise directed by current FAA regulations. There are no standard plans for modifications to support structures such as. A-frames for aircraft warning markings.

Painting of cable supports for aircraft warning is not required except in unusual circumstances. Contact the FAA for guidance as required.

\section{Cable Cars}

Two styles of manually propelled fabricated aluminum cable cars are commonly used by the Survey. One is a sitdowntype car with space for two field persons. The sitdown style is 60 in. long, 21 in. wide, and approximately 55 in. from footrest to cable. The other is a standup-style car, 52 in. long, 27 in. wide, and 73 in. from floor to cable. Two persons can work in the standup cable cars. Both cable car types are provided with an integral reel mount, which will accept all standard sounding reels. Both models are equipped with a follower brake to hold the car in place during observations or sampling procedures. Several styles of car pullers are available. Exterior mounting brackets for watersample bottles are available for both styles of cable cars.

All cable cars and accessories mentioned above are available to the Survey and other Federal agencies through the HIF. Battery- and gasoline-powered cable cars are sometimes used at sites located on large rivers that are frequently and extensively monitored. The HIF has designed a gasolinepowered cable car with a hydraulic pump that drives two hydraulic motors, one that moves the cable car along the cable and another that operates a type $E$ sounding reel. This cable car is available from the HIF on special order. 


\section{CONSTRUCTION}

Construction of cableway systems must be carried out using sound construction and safety practices. Survey personnel have been injured building or maintaining cableways. Most incidents involved poor training, inadequate or makeshift equipment, or carelessness. Although it is not the intent of this publication to teach a course in engineering design or construction practices, the following information is provided only for informational purposes for those with limited experience in constructing this type of structure.

\section{Excavating for Anchors and Support Structures}

Most excavation for typical A-frame footings and anchors is done by power equipment. Small backhoes of the type frequently mounted on industrial or farm tractors are best suited for this work because of their mobility. In general, the bearing strength of soil decreases when disturbed; therefore, it is essential to dig as close to the desired dimensions as possible. In the case of concrete anchor blocks, a carefully dug rectangle may require a concrete form only for the top foot or so to provide for the above-ground portion. However, it is sometimes desirable in such cases to line the sides of the hole and adjacent ground with plastic sheeting before placing the forms and pouring the concrete to prevent dirt from falling into and contaminating the concrete. A careful and attentive backhoe operator and a little hand shoveling can result in a considerable savings of time and materials.

The use of cylindrical forms for A-frame footings is cost efficient and minimizes excavation and the resultant soilbearing loss. Cylindrical cardboard form materials are commercially available in a variety of sizes and can be easily cut as needed in the field. Steel culvert pipe makes an excellent form, and A-frame anchor bolts can be welded in exact positions before being taken to the site. (Neither type of form material is removed after pouring.) Careful attention to vertical and horizontal control in construction layout surveys is necessary to ensure that all components are exactly located.

The size and placement of steel reinforcement is critical to the strength of concrete structures. Concrete has excellent strength in compression but little if any strength in tension. Therefore, the integrity of concrete anchors depends primarily on the tensile strength of the reinforcement steel and proper bonding to the concrete.

Any space that has been excavated around formed concrete must be carefully replaced by "puddling" before erection of Aframes and cable. "Puddling" involves pouring water into the void between the cured concrete and the excavation and 
carefully hand backfilling and tamping to ensure a condition as close as possible to original soil conditions.

\section{Preparing Concrete for Anchors and Support Structures}

Concrete is best procured from a local "ready-mix" vendor. On-site hand mixing often results in a low-strength product and, in most cases, is not cost effective. In inaccessible locations, innovation may be necessary to transport concrete from the mixer-truck to the forms. If a long delay is expected, request a slow-setting mix. A temporary cableway or a cableway that is to be replaced may be used to transport concrete to a location on the far side of a stream. A washed-clean front-end bucket on a tractor may be used or, in some cases, a helicopter may be required.

Concrete for footings and anchorages must have compressive strength of $3,000 \mathrm{lb} / \mathrm{in}^{2}$ ( 5 sacks/yd). All concrete should meet ACI-318 (American Concrete Institute) and ASTM C-94 (American Society for Testing and Materials) specifications. All concrete should be placed within 60 minutes after water has been added. When pouring concrete in forms, not more than 12 to 18 in. shall be poured before concrete is consolidated into all corners and around all reinforcing bars. Care must be taken to avoid disturbing the position of the reinforcing or U-bars. The process of consolidation or compaction of concrete must be done during and immediately after pouring. Mechanical vibrators are recommended; however, on small pours, hand spading (rodding) is acceptable as long as it is done thoroughly and carefully. The entire operation of depositing and consolidating the concrete must be conducted such that the finished concrete is smooth, dense, and free from honeycombs and pockets of segregated aggregate. Once started, no pour should be interrupted for more than $30 \mathrm{~min}$. Water should never be added to the concrete mix to make it flow better because this seriously reduces the strength of the final product. Concrete should not be poured if below-freezing temperatures are expected within $48 \mathrm{~h}$, unless heated concrete is used or other means are available on-site to protect the curing concrete. All freshly poured concrete should be kept moist and should be protected from rapid drying by waterproof paper, plastic sheeting, wet burlap, or straw. Concrete poured during extremely hot or below-freezing conditions requires appropriate protection.

Concrete achieves approximately 75 percent strength in 7 days and approximately 100 percent strength in 28 days. Therefore, erection of A-frames and cables should never be started in less than 7 days. A longer curing time is preferable. A variety of readily available admixtures will retard or increase the setting and curing time of concrete. High, early-strength concretes achieve nearly full strength in 3 days; however, special curing procedures are required due to 
the large amounts of heat generated. All admixtures must meet applicable ASTM specifications (C-260 or C-494). Special mixtures should be agreed upon with the concrete supplier prior to formulation and delivery.

All placement of reinforcing bars and U-bars must be completed prior to starting a pour. The placement of anchor bars and A-frame attachment bolts in concrete must be done carefully to ensure proper connection with the steel components of the system. Misalignment of U-bars in concrete anchors would result in added stresses to the U-bars if the Ubars were not set at the proper angle. Even a slight misalignment of A-frame anchor bolts would result in a poor or impossible attachment to the steel A-frame. A convenient way of maintaining the proper spacing of anchor bolts is to weld the bolts for one leg of an A-frame together with reinforcing bars at the exact spacing. The bolt "cluster" is then inserted into the wet concrete as a unit. Alignment for bolt "clusters" for the legs of both A-frames can be maintained by drilling appropriate bolt holes in a 1- by 12-inch board, long enough to extend between the two pedestals. U-bars must always be placed vertically and in alignment with the cable. Proper placement is necessary to transmit tension forces to the entire concrete anchor. Personnel preparing form work, installing reinforcement, and positioning anchor bolts and Ubars should have experience in construction carpentry and must follow design instructions.

Concrete should have a smooth and level finish with a slight pitch to encourage water to drain away from metal connections such as A-frames and U-bars on anchors.

In locations where soil instability is suspected, inserting a gaging station reference mark or a bolt slightly above the concrete surface serves as a reference point (RP) and also allows measurements to be taken over time to determine if movement of any components has occurred.

\section{Installing Rock Anchors}

The installation of rock anchors must be done with great care to ensure adequate holding strength. Anchors should not be installed near fractures or near the edges of the rock formation. Installation of mechanical expansion anchors must follow the manufacturer's instructions. U-bar anchors require precision drilling of two parallel holes to accommodate the two legs of the bolt. Drill size must be selected to allow adequate clearance for grout or epoxy bonding materials. Vibrating the anchor will assist in working the bonding material along the entire anchor axis. Proper setting time is necessary prior to tensioning. 


\section{Installing Tree Supports or Anchors}

The construction of cableways using trees as anchors or support structures should only be performed by persons who have had experience with such designs. When a tree is incorporated into the design of a cableway, it must be a large, live, mature tree with a solid root system located in stable soil. If there is any reason to suspect that a tree is diseased or decaying, core borings should be obtained. Careful consideration of all factors must support the tree's suitability for use.

The main cable may be looped directly around the tree, or a separate cable may be looped around the tree and attached to the main cable with a turnbuckle or other appropriate fittings. Wooden bearing blocks, such as hardwood 2 by 4 's, should be placed between the tree and cable to protect both the cable and the tree. The cable should be loose enough to allow for the growth of the tree. If a sheave or other attachment hardware is used to attach the cable to a tree, it must be installed in a manner to adequately carry the load and not injure the tree.

\section{Erecting A-Frames and Cable}

The construction of a cableway must be done with experienced personnel emphasizing safe practices. Safety shoes, hard hats, and heavy work gloves should be worn. No member of the crew should work in any location that would be unsafe in the event of a slippage or failure of a cable or component.

Preparation of a cable is essential to prevent unraveling and subsequent loss of strength. Seizing is the procedure of making a secure binding at the end of a wire rope to prevent unraveling. If a wire rope unravels, it will lose strength several feet from the point of disturbance. Wire rope should be seized prior to being cut. Seizing with wire wrappings has been the traditional method; however, stainless steel crimptype hose clamps are non-corrosive and an effective means of seizing wire rope. If wire seizing is used, the wire should be soft annealed rustproof wire or strand, about $0.075 \mathrm{in}$. in diameter for most main cable applications. Correct placement techniques are shown in figure 33.

Once a wire rope is properly seized, it should be cut, preferably with a shearing-type cutter. A number of portable manual cutters that will meet most Survey needs are commercially available. A hammer-type cable cutter is shown in figure 34. Wire rope should not be cut with acetylene torches; this tends to weld together the individual wires and inhibit movement in the wire rope, reducing its strength. 

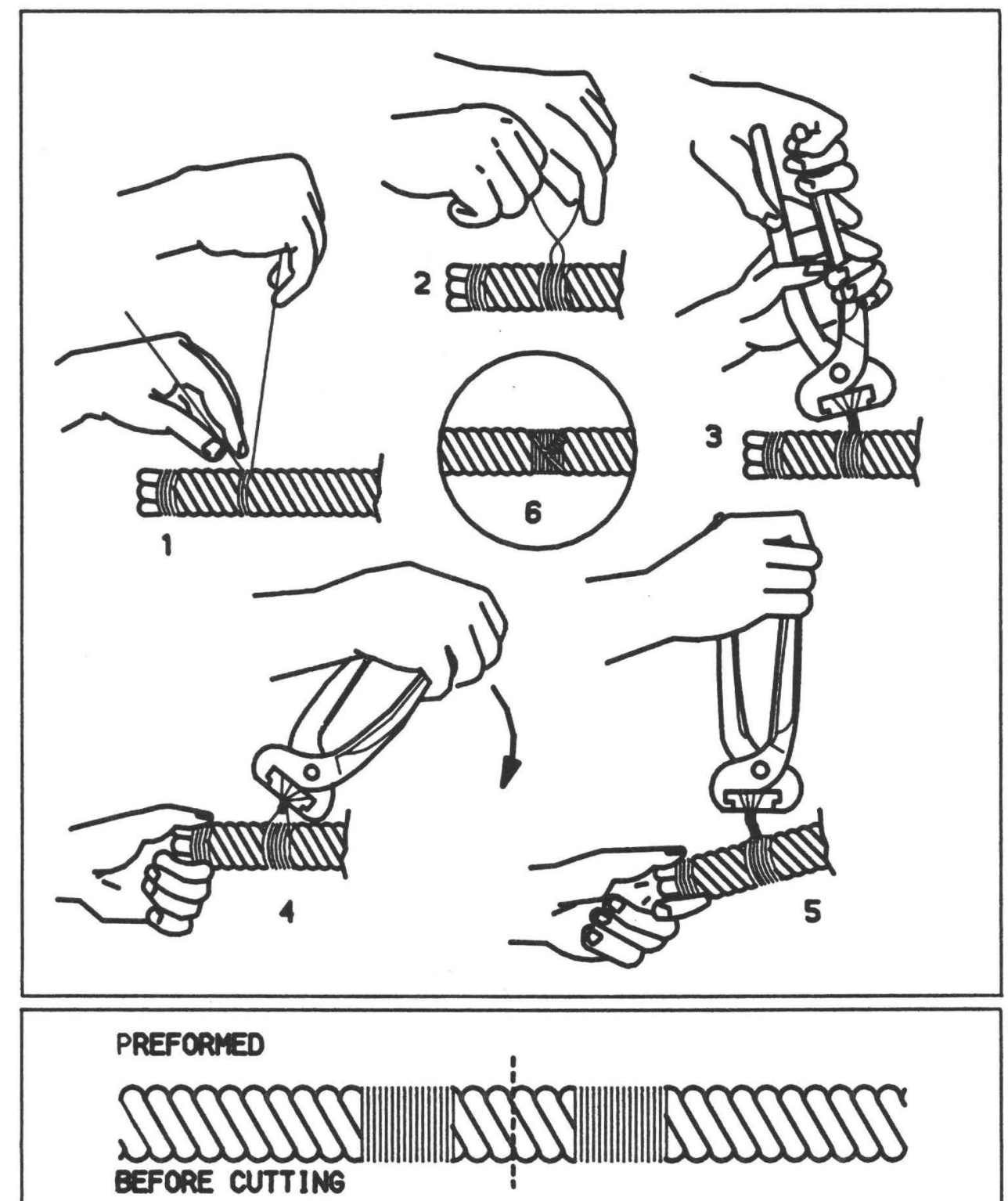

JammPIIIIIBP

sillinambers

AFTER CUTTING

Figure 33.--Wire-rope seizing technique and final product. 
The erection of A-frames of about $15 \mathrm{ft}$ and less and cable spans of 400 to 500 ft can usually be performed by a 3or 4-person team without power equipment. Larger

installations may require the use of power equipment.

Backhoes of the type previously mentioned for excavation usually are appropriate for lifting the A-frame into place and pulling the cable tight.:

Usually the A-frames are aligned and bolted into place first, with the A-frame pointing to the river. In the case of A-frames without pivoting legs or I-beam supports, it is necessary to erect the supports and guy them in position before the cable is installed. For pivoting structures, the cable can be pulled across the stream and raised as the Aframes are lifted into position.

Pulling a cable across a large or deep river is best accomplished by first pulling a fiber rope across the river using a boat and then pulling the steel cable with the rope. Usually, the cable is attached on the least accessible side first. The cable and turnbuckle are assembled and the cable is laid over the sheave or bearing block of the A-frame. The A-frame is then pulled to a nearly upright position and guyed. Usually the second side is handled by lifting the A-frame into position before end connections are made to the main cable; if exact measurements are made, the end connections can be done prior to lifting the A-frame into place.

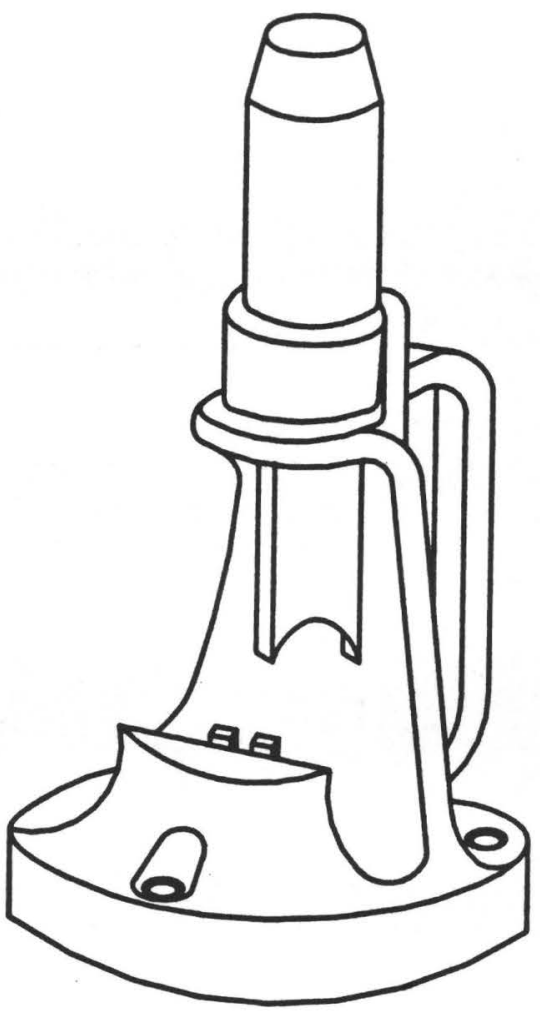

Figure 34.--Hammer-type cable cutter. 
The raising and tightening of a main cable presents the most dangerous part of the construction process because of the large amount of energy involved. It is strongly recommended that prior to this activity, the construction crew take a brief break and carefully review assignments, personnel positions, and safety procedures. Also, all connections and lifting equipment should be double-checked prior to final tensioning.

CAUTION--Various block and tackle, cable
hoists (come-a-longs), and chain hoists
are used to erect A-frames and tighten
cables. Make certain that the lifting
devices being used are rated for the loads
involved. Always use a cable grip of the
proper type and size to attach the lifting
device to the main cable to prevent damae
to the cable or avoid slippage or failure
during lifting. Common sense and caution
are critical. A l/4-inch cable hoist is
not capable of tightening a l-inch steel
cable. Double check connections to the
main cable when chains are used to assist
in the lifting. Make sure that all pulls
are straight. Make sure that all personnel
are clear, should something go wrong as
the cable is pulled up.

The following method is recommended for tightening a wire rope and fastening it to its anchorage. With one end of the hoisting device hooked to the anchor and the other to the main cable, take up the cable to slightly tighter than unloaded sag. Fasten the turnbuckle to the anchor and place a thimble in the cable end. The turnbuckle should be in its fully extended position. Pass the end of the main wire rope around the thimble and install clips to achieve maximum holding power. See figure 35 for proper clip placement. Follow the directions listed to attach the U-bolts to the cable.

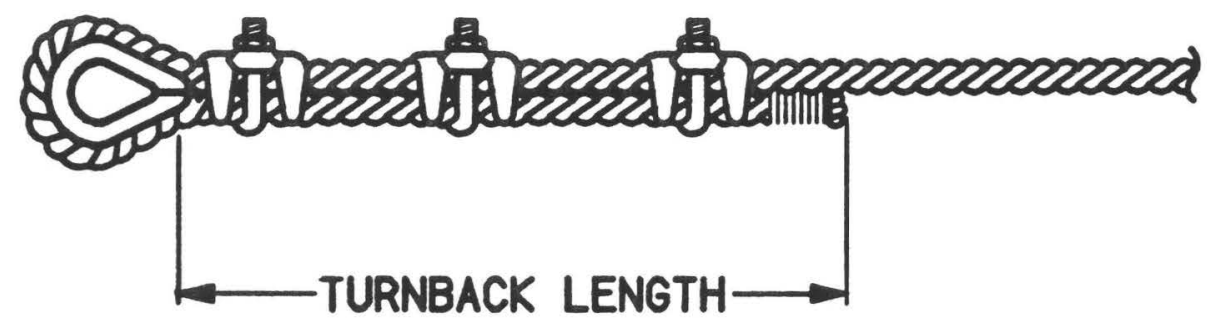

Figure 35.--Correct way to attach cable clips. 
Table 6.--Recommended number of clips, torque, and dead-end turnback for wire rope

\begin{tabular}{cccc}
\hline $\begin{array}{l}\text { Wire rope } \\
\text { diameter } \\
\text { (inches) }\end{array}$ & $\begin{array}{l}\text { Minimum } \\
\text { number clips }\end{array}$ & $\begin{array}{c}\text { Torque } \\
\text { (foot-pound) }\end{array}$ & $\begin{array}{c}\text { Minimum } \\
\text { turnback } \\
\text { (inches) }\end{array}$ \\
\hline $7 / 16$ & 2 & 65 & 7 \\
$1 / 2$ & 3 & 65 & 12 \\
$9 / 16$ & 3 & 95 & 12 \\
$5 / 8$ & 3 & 95 & 12 \\
$3 / 4$ & 4 & 130 & 18 \\
$7 / 8$ & 4 & 225 & 19 \\
1 & 5 & 225 & 26 \\
$1 / 8$ & 6 & 225 & 34 \\
$1 / 4$ & 7 & 360 & 44 \\
\hline
\end{tabular}

1. Turn back the specified amount of rope from the thimble. Apply the first clip approximately one base width (width of clip saddle) from the dead end of the wire rope (Ubolt over dead end, live end rests in clip saddle). Tighten nuts evenly to recommended torque.

2. Apply the next clip as near the loop as possible. Install nuts firmly but do not tighten.

3. Place additional clips, as required, equally spaced between the first two. (Spacing between clips should be 1 to 2 base widths.) Install nuts firmly but do not tighten; back off lifting device to place a slight tension on the wire rope, and tighten all nuts evenly on all clips to recommended torque.

4. Release lifting device, placing full tension on connection, and retorque all nuts. Rope will stretch and be reduced in diameter when loads are applied. Inspect periodically and retighten to recommended torque. (A light application of spray paint over the cable and cable clips provides a visual indication of slippage.)

Recommendations for the minimum number of clips, torque, and dead-end turnback are given in table 6 . 
A-frame backstay cables are installed and tightened with the A-frame in a plumb position. Final sag adjustment should be made after the cable car is installed and several trips have been made across the cableway with a loaded car to stretch the cable and set bends and clips. One method to check sag easily is to paint a line on both A-frames at a distance down from the sheave corresponding to the proper unloaded sag and sight from one A-frame to the other with a hand level. This procedure is also applicable to structures where cable supports are at differing elevations.

It is necessary to mark the cableway to provide a width reference for discharge measurements. This is commonly done by stretching a tag line or steel tape between A-frames and painting marks at selected intervals with brightly colored paint. A convention of single marks at 5- or 10-foot intervals, double marks at $50 \mathrm{ft}$, and triple marks at $100 \mathrm{ft}$ is usually used.

\section{Installing Grounds}

\section{Grounding Rods}

Grounding rods can be installed for attachment to the main cable, backstay cables, and steel A-frames or other support structures. For cable grounding, drive a standard 10foot by 5/8-inch, copper-clad grounding rod into the earth under the main cable, streamward from the anchorage. Drive the grounding rod about 1 ft below ground level. Clamp a piece of 1/4- to 1/2-inch galvanized wire rope with galvanized cable clips to the main cable above all clamps and attachment hardware. With gentle bends, clamp this cable to all backstay cables and arc it toward the grounding rod. Just above the ground level, cut the galvanized wire rope and securely clamp it to a piece of No. 2 copper lightning-conductor cable. Clamp this cable to the grounding rod, using a commercial, bronze grounding clamp. (This procedure reduces damage to the main cable from electrochemical reaction of dissimilar metals.) All connection surfaces should be clean and free of corrosion and coatings. Drive a similar ground rod midway between the A-frame legs and under the A-frame. Solidly connect a No.2 copper lightning-conductor cable to each leg of the A-frame and to the grounding rod. Connect the two grounding rods with No. 2 copper lightning-connector cable. The grounding rods and connecting wire should be about $1 \mathrm{ft}$ below the surface of the earth. Drive the ground rods full length into solid earth. All bends in the grounding wires should be gradual with no bends less than 8 in. in radius. All cable and components must meet Lightning Protection Institute requirements. 


\section{Wire Grounds}

An alternative grounding system uses several 40- to 50foot lengths of wire buried at least 6 to 12 in. below ground and, preferably, below frost level. Running the wire from the main cable and the A-frames toward the river usually provides the best ground because of the likelihood of increased soil moisture. No. 2 copper lightning-protection cable should be used. Follow all connection procedures described for grounding rods. Extraneous metal objects such as wire fences or antennas should not be connected to cableway systems.

There is no effective means of protecting operating personnel from the hazards of lightning strikes. Use of cableways during periods of lightning storms is discouraged.

\section{CABLEWAYS CONFORMING TO CIRCULAR 17 SPECIFICATIONS}

Design criteria used in this manual differ slightly from those used in earlier cableway manuals. The type and strength of available cable materials have changed since USGS Circular 17 (Pierce, 1947) was prepared and heavier equipment is now being used.

Many of these earlier structures will be maintained in service for some time. Sag diagrams from Circular 17 are included herein and should be used for determining proper sag adjustments for cableways built in accordance with guidelines from Circular 17 (figs. 36 and 37 ).

Many existing cableways may be retrofitted with new higher-strength cable in the future. The heavier design loads recommended in this manual and the reduced sag and higherstrength characteristics of present cable may result in a larger tension force acting on the existing anchorage. Careful inspection and evaluation of existing anchorages and attachment hardware, cable supports, and footings are necessary to determine adequacy of these components to meet increased loads. Complete inspection is also necessary to ensure that strength-limiting deterioration has not occurred. In many cases replacement of entire systems will be necessary.

Inspection, evaluation, and redesign must be performed and documented using the guidelines described in this report.

\section{DOCUMENTATION}

After a cableway installation is complete, all vital dimensions must be recorded for inclusion in District files and Field Station Description (Form 9-197). Documentation should include the size and depth of the footings, the size of the anchors, the manufacturer and type of cable, and a diagram 


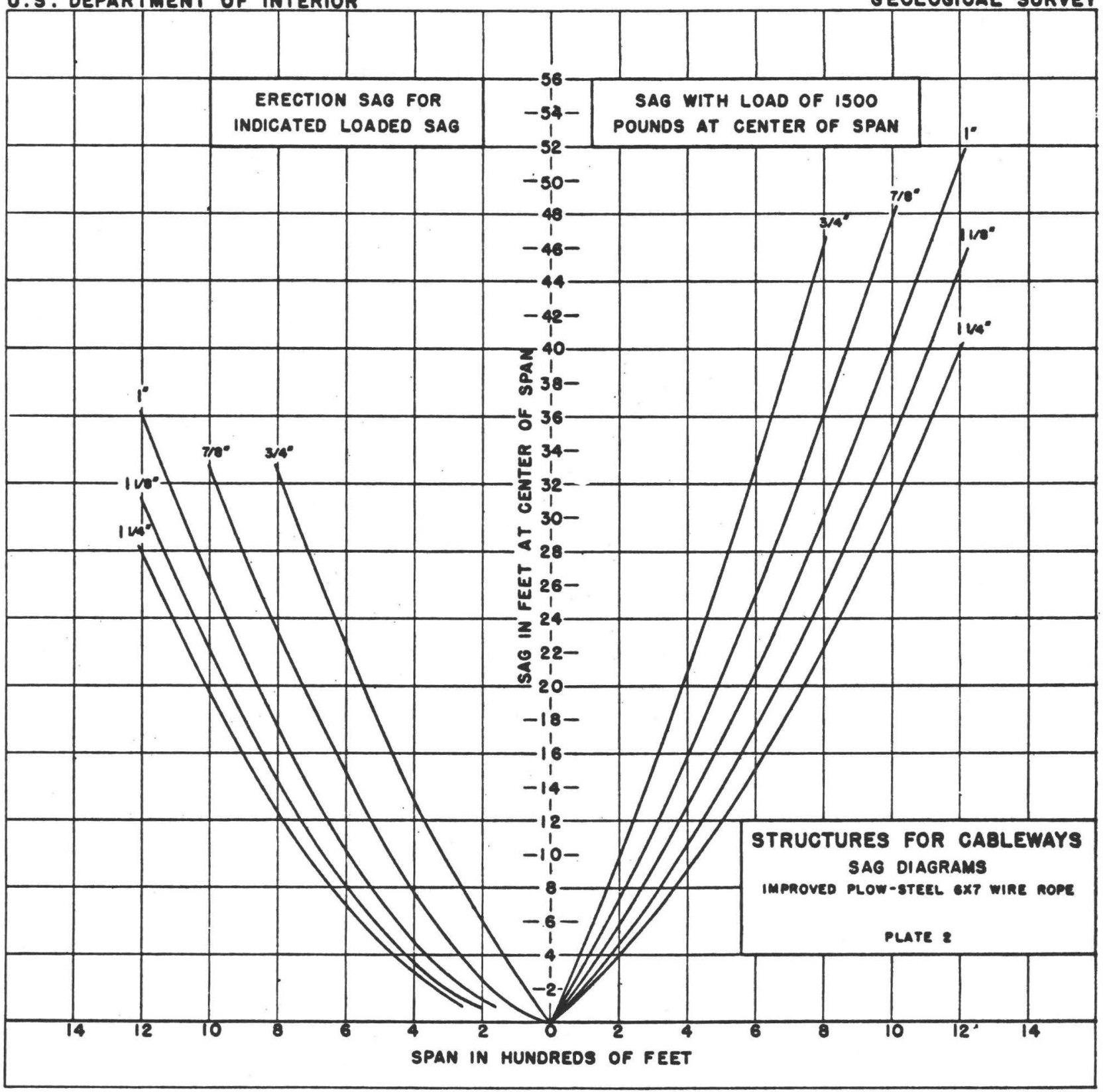

Figure 36.--Sag diagram for improved plow-steel 6 x 7 wire rope (cable). [From Pierce, 1947, p. 16a] 


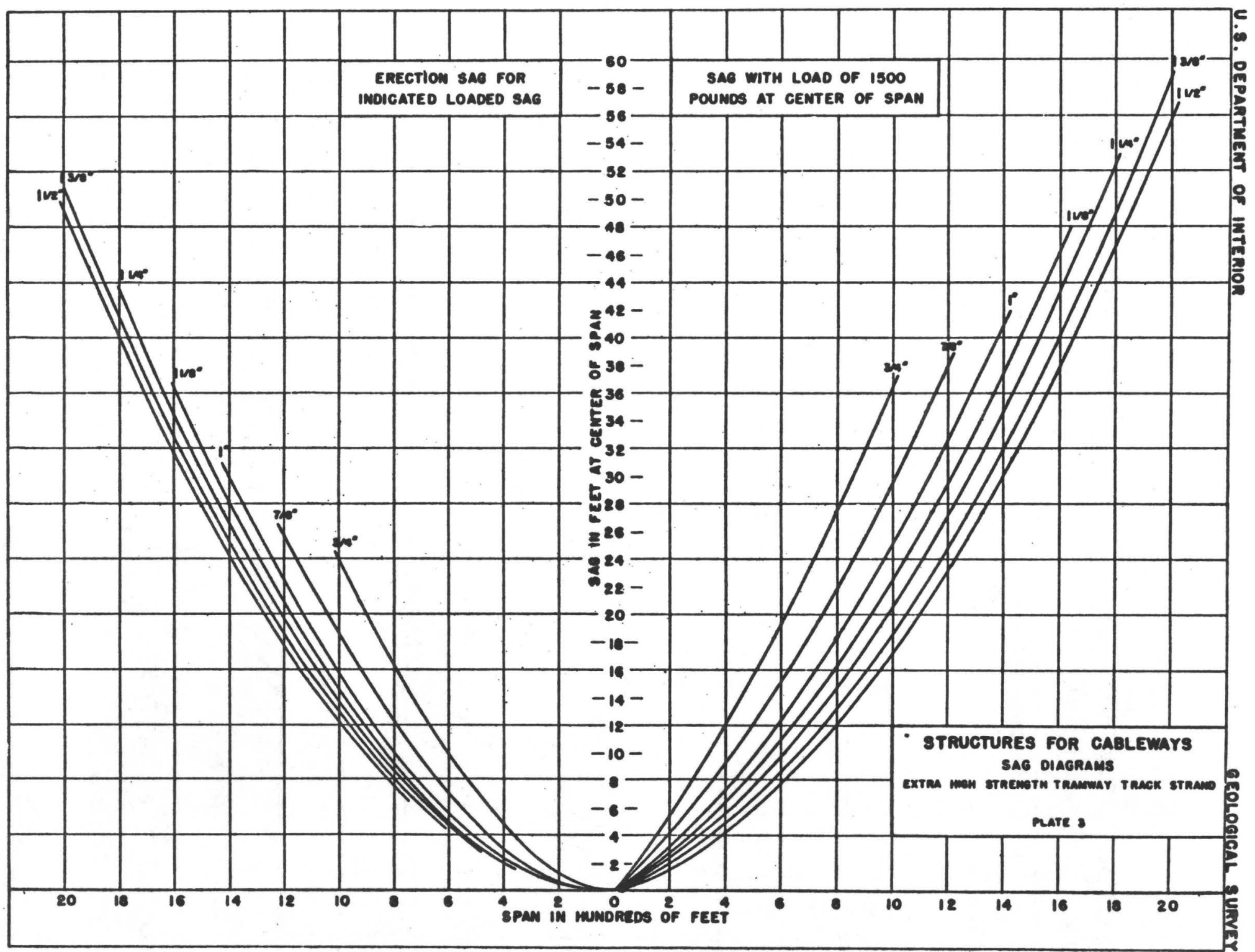

Figure 37.--Sag diagram for extra high strength tramway track strand of various diameters. [From Pierce, 1947, p. 16b] 
showing dimensions between components. A copy of the design information, including any special considerations, should always be retained. Any changes or repairs to the structure should be added as they are made.

As much information as possible should be obtained on existing structures. Careful field measurements of cable diameter and type, anchorage dimensions, and related information is important for evaluating the safety of old structures. Reliable information about existing anchors and footings is needed to determine whether they can safely be reused with new supports and (or) cables.

\section{SECURITY}

Cableways frequently are the target of vandals. This vandalism may involve breaking locks and using the cable cars to cross streams or just damaging the structure. Cable cars should always be locked when not in use. In most cases, a piece of chain about $4 \mathrm{ft}$ long wrapped around the A-frame or anchor and a standard or high security USGS padlock will be adequate. The preferred chain is 3/8- to 1/2-inch casehardened and rustproofed. It is nearly impossible to saw through case-hardened chain and the USGS high-security padlock. However, vandals may cut the chain with large bolt cutters. Several types of special locking devices and lock shields have been tried with some success. "Danger--Keep Off" warning signs should be attached to all cableways.

In some areas subject to frequent vandalism, enclosing the entire anchor, A-frame, and cable car with a heavy-duty, chain-link fence protects the Survey's property and minimizes potential liability for persons injured by misused equipment.

\section{INSPECTION AND MAINTENANCE}

Casual inspection and incomplete maintenance of a cableway structure may result in shortening its useful life and jeopardizing the safety of personnel using the system. Inspection personnel must have a knowledge of materials and forces acting on the systems and be properly trained in field inspection techniques. Maintenance personnel must also receive training in proper procedures. One of the major factors in deterioration of cableway systems is the improper selection of fabrication materials and subsequent preservation of components. Guidance on painting and preservation is given in appendix $\mathrm{C}$.

Past experience indicates that the majority of cableway system deficiencies are the footing to A-frame attachment, backstay system, and improperly installed cable clips. 
Every cableway system shall be inspected at least once each year, and new or modified structures should be inspected after the first several uses. The inspections shall be performed by a qualified person, and an inspection report, in approved WRD format, must be completed, signed, and submitted to appropriate District management. In cases where the safety of a cableway is in doubt, the structure should not be used until further testing proves it to be safe or repairs have been made. Field inspection of cableway systems is critical to the lives and health of field personnel. District management and field personnel must therefore make thorough inspection and maintenance of cableways a priority of the highest order. Inspection of a cableway system should include, at a minimum, items listed in the following sections.

\section{Anchers and Footings}

1. Carefully check the general condition of concrete and steel U-bar connection to concrete. Look for crack lines in concrete or evidence of movement where the Ubar enters concrete.

2. Inspect the general condition of rock anchors for any indications of deterioration or movement of U-bar or pin. Check for fracture or other failure of adjacent rock formation.

3. Check to see that connections are free of soil and debris. Check for indications of overstress, corrosion, or damage. Clean and paint if required. Previous guidance recommended that tar should be used to seal between U-bars and concrete. However, experience has since shown that moisture frequently penetrates between the tar and metal causing corrosion. Tar should be removed and metal components carefully inspected. If found to be safe, clean and paint; otherwise replace as necessary.

4. Check for movement of anchor or footings. Look for subsidence, heaving, or other signs of instability. Check dimensions between anchors and footings if instability is suspected.

5. Check for erosion or other disturbance of adjacent soil.

6. Trees used as anchors must be alive and healthy. Check bearing blocks for soundness and proper position. Root systems must not show signs of movement or damage.

Main Cable Supports

1. A-frames or I-beams must be plumb. Check bolts and hardware attaching A-frames to concrete footings for rust and signs of movement. 
2. All metal components must be rust free. Remove rust and paint as required. See appendix $C$.

3. Check wooden A-frames and walkways for rot or termite damage, especially at ends. Apply wood preservative as required.

4. Check points of contact between concrete and steel (or wood) for corrosion or rot.

5. Check sheave or saddle block for condition and proper contact with cable. Look for signs of corrosion or damage to cable at this point of contact.

6. Check ladders, walkways, platforms, and safety rails for stability and condition.

7. Check grounding of steel structures.

8. Trees used as cable supports must be alive and healthy. Check bearing blocks for soundness and proper position. Root systems must not show signs of movement or damage.

\section{Main Cable}

1. Check general condition of main cable. Note rust penetration and broken wires. Particularly note condition at the point where the main cable contacts the support (sheave or saddle block) and where it connects to the anchorage. Broken wires at these locations indicate serious deterioration and require immediate replacement or inspection by a specialist.

2. Replace wire rope or structural strand when one or more of the following occur:

a. The number of broken wires within a rope lay length, excluding filler wires, exceeds either (1) 5 percent of the total number of wires or (2) 15 percent of the total number of wires within any strand

b. On a regular lay rope, there are two or more broken wires in the valley between strands in one rope lay length

c. On a structural strand, there are more than three broken wires

d. There are two or more broken wires at any termination

e. The rope deterioration caused by corrosion exceeds that defined as moderate in the glossary herein 
f. There is loss of more than 10 percent of the rope strength as determined by non-destructive testing

g. There is any unexplained distortion

3. Check sag and adjust as required. If sag has changed frequently, find out why.

4. Check cable markings; repaint as needed.

\section{Backstay}

1. Check general condition of cable. Note rust or damage to cable. Replace if indicated based on same criteria applicable to the main cable.

2. Check for undersized cable; replace if necessary.

3. Check tension. It should be taut but not under great load.

4. Check attachment on support structure and anchor.

\section{Cable connections}

1. Check general condition of wire rope clips. Replace if rusted. Replace if improperly installed. Check for damage to wire rope if improperly installed. Check for slippage on cable. Check for loose clips. Tighten to proper torque.

2. Check sockets (bridge sockets or poured sockets) for corrosion, movement, or other signs of deterioration. Field repairs are not recommended. Report deficiencies; do not use structure pending replacement or inspection and approval by a specialist.

3. Check condition of turnbuckle. Apply grease to threads to prevent seizing and retard corrosion.

4. Check clips and fittings on backstay cables.

5. Check cable attachments to trees. Adjustments may be necessary to accommodate tree growth.

\section{Cable Car}

1. Check general condition. Grease sheaves if required.

2. Check for loose, missing, or corroded bolts. Replace as required.

3. Check brake system. Repair as required. 
4. Check condition of wood on wooden cars. Apply wood preservative or replace as needed. Check and clean drainholes.

5. Check condition of aluminum components of aluminum cars for deterioration or corrosion.

6. Check and oil locking system.

\section{Miscellaneous}

1. Check aircraft warning markers. Replace as required. Check all components of supporting cable and fittings, as described above.

2. Cut grass and brush adjacent to anchors and cable supports and under cable to water's edge. REMOVE DIRT OR DEBRIS IN CONTACT WITH OR CLOSE TO ANCHOR CONNECTION.

3. Remove overhanging branches or trees that might fall on structure.

4. Note any encroachment of activity in area that might damage structures.

5. Check condition and integrity of security fences or other protective devices.

6. Check for warning signs. Replace if necessary.

NOTE ANY UNCORRECTED DEFICIENCIES THAT MAY AFFECT THE SAFE USE OF THE CABLEWAY AND REPORT TO DISTRICT MANAGEMENT IMMEDIATELY.

In addition to making periodic safety inspections, field personnel should always look over the anchorages, turnbuckles, cable clips, and other system components for damage or vandalism prior to operating a cableway. The supporting and anchoring devices on the far side of the stream may be difficult or impossible to inspect before every use but should be visually checked from the cable car at the time of each discharge measurement. In wooded areas, trees may fall on the cable structure and thorough inspection before use is required. 
American Concrete Institute, 1984, ACI standard 318: Detroit, Michigan, $111 \mathrm{p}$.

American Hot Dip Galvanizers Association, 1989, Technical manual: Clarendon Hills, Illinois.

American Welding Society, 1990, AWS D1.1-90, Structural welding code--steel: Miami, Florida, $448 \mathrm{p}$.

American Wood-Preservers' Association, 1990, Book of standards: Stevensville, Maryland, 257 p.

ANSI, 1982, ANSI B77.1-1982, American national standard for passenger tramways--serial tramways and lifts, surface lifts and tows--safety requirements: New York, New York, $104 \mathrm{p}$.

ASTM, Annual book of ASTM standards, Designations A-36, $\mathrm{A}-123, \mathrm{~A}-153, \mathrm{~A}-165, \mathrm{~A}-325, \mathrm{~A}-384, \mathrm{~A}-385, \mathrm{~A}-386, \mathrm{~A}-475$, $\mathrm{A}-586, \mathrm{~A}-615, \mathrm{~A}-767, \mathrm{~A}-780, \mathrm{C}-94, \mathrm{C}-260, \mathrm{C}-494, \mathrm{D}-2555$, D-2899: Philadelphia, Pennsylvania.

Baumeister, Theodore, Avallone, Eugene A., and Baumeister, Theodore III, ed., 1978, Marks' standard handbook for mechanical engineers: New York, New York, McGraw-Hill, $1525 \mathrm{p}$.

Block, Roger R., 1987, The grounds for lightning and EMP protection: Polyphase Corporation, Gardnerville, Nevada, $108 \mathrm{p}$.

Concrete Reinforcing Steel Institute (CRSI), 1984, Concrete reinforcing steel handbook: Schaumburg, Illinois, $945 \mathrm{p}$.

Dunham, C.W., 1962, Foundations of structures: New York, New York, McGraw-Hill, 722 p.

Federal Aviation Administration, 1975, Federal Aviation Regulation, Part 77, Objects affecting navigation airspace, 1986. 23 p. and Advisory Circular 70/7460 - 1G, Obstruction marking and lighting: Washington, D.C., U.S. Department of Transportation, $55 \mathrm{p}$.

Industrial Press, 1979, Machinery's handbook: New York, New York, $484 \mathrm{p}$.

International Organization for Standardization (ISO), 1983, Cableway system for stream gauging, ISO 4375-1979, in ISO Handbook 16--Measurement of liquid flow in open channels: New York, New York, ANSI, p. 461-468. 
Knutson, R.K., 1987, BASIC desk-top computer program for the three dimensional static configuration of an extensible flexible cable in a uniform stream: David W. Taylor Naval Ship Research and Development Center Report \#DTNSRDC$87 / 029$.

Lightning Protection Institute, 1987, Standard Practice LPI175: Harvard, Illinois, $35 \mathrm{p}$.

Marocchi, D., 1974, manslated by Bonasso, S.G., 1983, Aerial tramways and ski lifts - theory and planning: Morgantown, West Virginia, Alpha Associates, $164 \mathrm{p}$.

Munger, C.R., 1984, Corrosion prevention by protective coatings: Houston, Texas,. National Association of Corrosion Engineers, $512 \mathrm{p}$.

Pierce, C.H., 1947, Structures for cableways: U.S. Geological Survey Circular 17, 63 p.

Rust-Oleum Corporation, 1988, Industrial coating systems: Vernon Hills, Illinois. $23 \mathrm{p}$.

Steel Structures Painting Council, 1985, Good painting practice, V. 1: Pittsburgh, Pennsylvania, 580 p.

Water Survey of Canada, 1984, Safety guide-construction and operations of streamgaging cableways; Ottawa, Ontario, Inland Waters Directorate Water Resources Branch, Environment Canada, $50 \mathrm{p}$.

Winter, George, and Nilson, A.H., 1979, Design of concrete structures: New York, New York, McGraw-Hill, 647 p.

Wire Rope Technical Board, 1981, Wire rope users manual: Stevensville, Maryland, $132 \mathrm{p}$. 


\section{GLOSSARY}

The following terms are defined as they apply to streamgaging cableway systems.

\section{A-frame}

Anchor

Area,

Metalic

Backstay

Breaking strength The ultimate load at which a tensile failure occurs in the sample of wire rope being tested. (Note: The term breaking strength is synonymous with actual strength.)

1) Minimum Acceptance strength is that strength which is $21 / 2$ percent lower than the catalog or nominal strength. This tolerance is used to offset variables that occur during sample preparation and actual physical test of a wire rope.

2) Nominal Strength is the published (catalog) strength calculated by a standard procedure that is accepted by the wire rope industry. The wire rope manufacturer designs wire rope to this strength, and the user should consider this strength when making design calculations.

\section{Bridge socket}

A wire rope or strand end termination made of forged or cast steel that is designed with baskets--having adjustable bolts--for securing rope ends. There are two styles: 1) the closed type has a U-bolt with or without a bearing block in the $U$ of the bolt, and 2) the open type has two eye-bolts and a pin. 
Bright Rope

Cable

Cableway

Catenary

Certification

Circumference

Clip

Concrete Anchor

Constructional stretch

Core

Corrosion
Wire rope fabricated from wires that are not coated.

A term loosely applied to wire rope, wire strand, and electrical conductors. In the context of a USGS streamgaging cableway, it refers to the system's main support rope for cable-car operation.

Aerial conveying system for transporting personnel and equipment along a suspended cable above a river.

A curve formed by a strand or wire rope when supported horizontally between two fixed points; for example, the main spans on a cableway.

Documentation provided by manufacturer that demonstrates that wire rope meets minimum acceptance strength.

Measured perimeter of a circle that circumscribes either the wires of a strand or the strands of a wire rope.

Fitting for clamping two parts of wire rope to each other.

A large block of concrete used to hold a cable in place under tension.

The stretch that occurs when the rope is tensioned--it is due to the helically laid wires and strands creating a constricting action that compresses the core and generally brings all of the rope's elements into close contact.

The axial member of a wire rope about which the strands are laid.

Chemical decomposition of the wires in a rope through the action of moisture, acids, alkalies, or other destructive agents.

1) Light Corrosion: Rust showing without pitting of the material. Strength loss less than 1 percent. 2) Mild Corrosion: Rust with minor pitting, less than 5 percent surface pitted. Strength loss less than 5 percent. 
Design Factor

Design Ioad

Diameter

Dog-leg

End Termination

Extra Extra

Improved

Plow steel Rope

Extra Improved Plow steel Rope

ractor of Safety
3) Moderate Corrosion: Rust showing with 10 to 30 percent of surface pitted. Strength loss less than or equal to 10 percent.

4) Severe Corrosion: Rust showing with 30 to 60 percent of the surface pitted. Strength loss exceeds 10 percent and possibly goes as high as 25 percent.

5) Extreme Corrosion: Rust showing with 100 percent of the surface pitted, no original surface remaining between pits. Strength loss in many cases will exceed 50 percent.

In a wire rope, the ratio of the nominal strength to the total working (design) load.

Nominal (catalog) strength divided by the Design Factor. Also known as Working Load.

A line segment that passes through the center of a circle and whose end points lie on the circle. As related to wire rope, it would be the diameter of a circle which circumscribes the wire rope.

Permanent bend or kink in a wire rope caused by improper use or handling.

The treatment at the end or ends of a length of wire rope, usually made by forming an eye or attaching a fitting, designed to be the permanent end termination on the wire rope that connects it to the load or anchor.

A specific wire rope grade.

A specific wire rope grade.

In the wire rope industry, term originally used to express the ratio of nominal strength to the total working load. The term is no longer used because it implies a permanent existence for this ratio when, in actuality, the rope strength begins to reduce the 
Fatigue

Fiber Core

Filler Wire

Fitting

Galvanized

Galvanized Rope

Galvanized Strand

Galvanized พire

Grade

Guy Iine

Improved Plow

Steel Rope

Independent พire

Rope Core (IWRC)

Inner พires

Iay moment it is placed in service. See Design Factor.

As applied to wire rope, term usually referring to the process of progressive failure resulting from the bending of individual wires. These fractures may and usually do occur at bending stresses well below the ultimate strength of the material; it is not an abnormality although it may be accelerated due to conditions in the rope such as corrosion.

Cord or rope of vegetable or synthetic fiber used as the axial member of a rope.

Small spacer wires within a strand which help position and support other wires. Also the name for the type of strand pattern utilizing filler wires.

Any functional accessory attached to a wire rope.

Zinc coating for corrosion resistance.

Wire rope made of galvanized wire.

Strand made of galvanized wire.

Zinc-coated wire.

Wire rope or strand classification by strength and (or) type of material, such as, Improved Plow Steel, Type 302

Stainless, Phosphor Bronze. It does not imply a strength of the basic wire used to meet the rope's nominal strength.

See Backstay.

A specific grade of wire rope.

A wire rope used as the axial member of a larger wire rope.

All wires of a strand except the outer or cover wires.

1) The manner in which the wires in a strand or the strands in a rope are 


\section{Iay, Types}

Lay Length

Messenger Cable

Modulus of

Elasticity helically laid or 2) the distance measured parallel to the axis of the rope (or strand) in which a strand (or wire) makes one complete helical convolution about the core (or center). In this connection, lay is also referred to as lay Length or Pitch.

1) Right Lay: The direction of strand or wire helix corresponding to that of a right-hand screw thread.

2) Left Lay: The direction of strand or wire helix corresponding to that of a left-hand screw thread.

3) Cross Lay: Rope or strand in which one or more operations are performed in opposite directions. A multiple operation product is described according to the direction of the outside layer.

4) Regular Lay: The type of rope wherein the lay of the wires in the strand is in the opposite direction to the lay of the strand in the rope. The crowns of the wires appear to be parallel to the axis of the rope.

5) Lang Lay: The type of rope in which the lay of the wires in the strand is in the same direction as the lay of the strand in the rope. The crowns of the wires appear to be at an angle to the axis of the rope.

6) Alternate Lay: Lay of a wire rope in which the strands are alternately regular and lang lay.

7) Alberts Lay: An old, rarely used term for lang lay.

8) Reverse Lay: Another term for alternate lay.

9) Spring Lay: Not definable as a unique lay; more properly, it refers to a specific wire rope construction.

\section{See Lay (2).}

Galvanized rope used as support for aircraft warning markers or other special purposes.

Mathematical quantity expressing the ratio, within the elastic limit, between a definite range of unit stress on a wire rope and the corresponding unit elongation. 
Nominal Strength

\author{
Prestressing \\ Prestretching
}

Rated Capacity

Regular Lay Rope See Lay, Types.

Reserve Strength

Reverse Lay
Right Lay
Safety Factor
Safe Working
Load

Sag

Seize

Seizing wire

shackle

Sheave values. Prestretching. outer wires.

See Lay, Types.

See Lay, Types. straight line. or other means.
Values calculated by standardized, industry-accepted procedures. Also known as Catalog Strength. Designers should base calculations on these

An incorrect reference to

Subjecting a wire rope or strand to tension prior to its intended application for an extent and over a period of time sufficient to remove most of the Constructional stretch.

The load that a new wire rope may handle under given operating conditions and at an assumed Design Factor.

The strength of a rope exclusive of the

\section{See Design Factor.}

Potentially misleading term, now in disfavor. Essentially, it refers to that portion of the nominal rope strength that can be applied either to move or to sustain a load. It is misleading because it is only valid when the rope is new and the equipment is in good condition. See Rated Capacity.

1) The sag of a rope in a spar, usually measured at mid-span as the distance from the chord joining the tops of the two supports, or 2) any deviation from a

To make a secure binding at the end of a wire rope or strand with Seizing Wire,

A wire for seizing. See Seize.

A U- or ancho-shaped fitting with pin.

A grooved pulley for wire rope. 
socket

strand

stress

stretch

structural strand

Thimble

Track Cable

Turnbuckle

U-bar

พire
A type of end termination that provides attachment to an anchor or load. The most common types are

1) Poured zinc (spelter): Molten zinc is used to bond the wire rope to the socket .

2) Poured resin: Thermo-set resin is used to bond the wire rope to the socket.

3) Swaged: Mechanical force is used to forge or press the socket tightly around the socket.

Sockets may be closed, having one extending ear or bail with a hole or opening for attachment, or open, having two extending ears or bails with a hole or opening for attachment. Usually two cables may be attached if one has a closed and the other has an open socket. See Bridge socket.

A plurality of round or shaped wires helically laid about an axis.

The force or resistance within any solid body against alteration of form; in the case of a solid wire, the load on the rope divided by the cross-section area of the wire.

The elongation of a wire rope under load.

A plurality of wires formed as a single strand, also known as Tramway Track Strand or Bridge Strand.

Grooved metal fitting to protect the eye or fastening loop of a wire rope.

On an aerial conveyor, it is the suspended wire rope or strand along which load carriers move.

A right and left screw link to tighten a cable.

A U-shaped iron bar embedded in concrete or rock to which a cable is attached.

1) Round: A single, continuous length of metal, with a circular cross-section that is cold-drawn from rod. 
2) Shaped: A single, continuous length of metal with a non-circular crosssection that is either cold-drawn or cold-rolled from rod.

Wire Rope

A plurality of wire strands helically laid about an axis. 
APPENDIX A.--NOTICE OF PROPOSED CONSTRUCTION OR ALTERATION 


\section{NOTICE OF PROPOSED CONSTRUCTION OR ALTERATION}

\subsection{Conetruction or etteration requiring notice.}

(a) Except as provided in 577.15. each sponsor who proposes any of the following construction or afteration shall notify the Administrator in the form and manner prescribed in $\$ 77.17$

(1) Any construction or alteration of more than 200 feet in height above the ground level at its site.

(2) Any construction or alteration of greater height than an imaginary surface extending outward and upward at one of the following slopes:

(i) 100 to 1 for a horizontal distance of 20,000 feet from the nearest point of the nearest runway of each airport specified in subparagraph (5) of this paragraph with at least one runway more than 3,200 feet in actual length, excluding heliports.

(ii) $\mathbf{5 0}$ to 1 for a horizontal distance of 10,000 feet from the nearest point of the nearest runway of each airport specified in subparagraph $(5)$ of this paragraph with its longest runway no more than 3,200 feet in actual length, excluding

(iii) 25 to 1 for a horizontal distance of 5,000 feet from the nearest point of the nearest landing and takeoff area of each heliport specified in subparagraph (5) of this paragraph

(3) Any highway, railroad, or other traverse way for mobile objects, of a height which, if adjusted upward 17 feet for an Interstate Highway that is part of the Nationa System of Military and Interstate Highways where overcrossings are designed for a minimum of 17 feet vertical distance. 15 feet for any other public roadway. 10 feet or the height of the highest mobile object that would normally traverse the road. Whichever is greater, for a private road. 23 feet for a railroad, and for a waterway or any other traverse way not previously mentioned, an amounit equal to the height of the highes mobile object that would normally traverse it, would exceed a standard of subparagraph (1) or (2) of this paragraph.

(4) When requested by the FAA. any construction or alteration that would be in an instrument approach area (defined in the FAA standards governing instrument approach procedures) and available information indicates it might exceed a standard of Subpart $\mathrm{C}$ of this part.

(5) Any construction or alteration on any of the following airports (including heliports):

(i) An airport that is available for public use and is listed in the Airport Directory of the current Airman's Information Manual or in either the Alaska or Pacific Airman's Guide and Char Supplement.

(ii) An airport under construction, that is the subject of a notice or proposa I on file with the Federal Aviation Administration, and except for military airports, it is clearly indicated that that airport will be available for public use.

(iii) An airport that is operated by an armed force of the United States.

(b) Each sponsor who proposes construction or alteration that is the subject of a notice under paragraph (a) of this section and is advised by an FAA regional office that a supplemental notice is required shall submit that notice on a prescribed form to be received by the FAA regional office at least 48 hours before the start of the construction or alteration.

(c) Each sponsor who undertakes construction or alteration that is the subject of a notice under paragraph (a) of this section shall, within 5 days after that construction or atteration reaches its greatest height, submit a supplemental notice on a prescribed form to the FAA regional office having jurisdiction over the area involved, if-

(1) The construction or alteration is more than 200 feet above the surface level of its site: of

(2) An FAA regional office advises him that submission of the form is required
\$77.15 Conetruction or eviertion not requiring notice.

No person is required to notity the Administrator for any of the following construction or alteration:

(a) Any object that would be shielded by existing structures of a permanent and ubstantial character or by natural terrain or topographic features of equal or greater height, and would be located in the congested area of a city, town, or settlement wher it is evident beyond all reasonable doubt that the structure sa shielded will not adversely affect safety in air navigation.

(b) Any antenna structure of 20 feet or less in height except one that would increase the height of another antenna structure.

(c) Any air navigation facility, airport visual approach or landing aid, aircraf arresting device, or meteorological device, of a type approved by the Administrator, or an appropriate military service on military airports, the location and height of which is fixed by its functional purpose.

(d) Any construction or alteration for which notice is required by any other FAA regulation.

\section{$\$ \pi 7.17$ Fom and the of notice.}

(a) Each person who is required to notity the Administrator under 577.13 (a) shall end one executed form set of FAA Form 7460-1, Notice of Proposed Construction or Alteration, to the Maneger, Air Tratfic Division, FAA Regional Office having jurisdiction over the area within which the construction or alteration will be located. Copies of FAA Form 760 , mav Administration and the regional offices.

(b) The notice required under $\$ 77.13$ (a) (1) through (4) must be submitted at least 30 days before the earlier of the following dates-

(1) The date the proposed construction or alteration is to begin

(2) The date an application for a construction permit is to be filed

However, a notice relating to proposed construction or alteration that is subject to the licensing requirements of the Federal Communications Act may be sent to the FAA a the same time the application for construction is filed with the Federal Communications Commission, or at any time belore that filing.

(c) A proposed structure or an alteration to an existing structure that exceeds 2,000 eet in height above the ground will be presumed to be a hazard to air navigation and to result in an inefficient utilization of airspace and the applicant has the burden of overcoming that presumption. Each notice submitted under the pertinent provisions of Part 77 proposing structure in excess of 2,000 feet above oround or an alieration directed to metin this burden. Only in exceptional cases, where the FAA concludes that a clear and compelling showing has been made that it would not result in an inefficient utilization of the airspace and would not result in a hazard to air navigation, will a determination of no hazard be issued.

(d) In the case of an emergency involving essential public services, public health, or public safety, that requires immediate construction or alteration, the 30 day requirement in paragraph (b) of this section does not apply and the notice may be sent by telephone, telegraph, or other expeditious means, with an executed FAA Form 7460 submitted within five days thereafter. Outside normal business hours, emergency notices by telephone or telegraph may be submitted to the nearesI FAA Flight Service Station.

(e) Each person who is required to notify the Administrator by paragraph (b) or (c) of 77.13, or both, shall send an executed copy of FAA Form 7460-2. Notice of Actur Construction or Alteration, to the Manager Air Traffic Division, FAA Regional Office heving jurisdiction over the area involved.

\section{ADDRESSES OF THE REGIONAL OFFICES AND SAN JUAN OFFICE}

\begin{tabular}{l}
\hline Alegicen Region \\
AK \\
Alaskan Regional Oftice \\
Air Traftic Division AAL-530 \\
701 "C" Street \\
Anchorage, AK 99513 \\
Mail Address: \\
701 "C" Street, Box 14
\end{tabular}

701 "C" Street, Box 14

Anchorage, AK 99513

Tole. 907-271-5892

\section{Northmed Mountin Region}

WA, OR, ITT, ID, WY, UT, CO

Northwest Mountain Regional Office Air Traffic Division ANM-530 17900 Pacific Hwy. South

C-68966

Seattie, WA 98168

Tel. $206-431-2530$

\section{Centrol Region \\ NE, IA, MO, KS}

Contral Regional Office

Air Traftic Division ACE-530

601 East 12th Street

Kansas City, MO 64106

Tel. 816-374-3408

\section{Enotem Recion \\ NY, PA, WN, VA, DC, MD, DE, NW}

Enetern Regional Oftice

Air Traffic Division AEA-530

JFK International Airport

Fitzgerald Federal Building

Jamaica, NY 11430

Tel. 718-917-1228

New Enciend Reglon

MA, NH, VT, RI, CT, ME

Now England Regional Office

Air Traffic Division ANE-530

12 New England Executive Park

Burlington, MA 01803

Tel. 617-273-7141

\section{Weetern-Pecilic Region}

HI, CA, NV, AZ, CU

Western-Pacific Regional Office

Air Traffic Division AWP-530

15000 Aviation Boulevard

Hawthorne, CA 90260

Mail Address:

AWP-530

P.O. Box 92007

Woridway Postal Center

Los Angeles, CA 90009

Tel. 213-297-1182

\section{Corthmed Region}

NM, TX, OK, AR, LA

Southweet Regional Office

Air Traffic Division ASW-530

400 Blue Mound Road

Fort Worth, TX 76106

Mail Address:

Fort Worth, TX 7610

T.l. 817-877-2640
Cormem Region

KY, TN, NC, SC, GA, AL, MS, FL

Southern Regional Otfice

Air Traftic Division ASO-530

3400 Norman Berry Drive

Eest Point, GA 30344

Mail Address:

Atlante GA 30320

Tel. 404-763-7646

\section{Cen duen Otilce \\ V. PA}

DOT/FAA

San Juan CERAP

ATTN: ML \& SO

GPO Section

San Juan, PR 00936

Tel. 809-791-1615
Great Lakes Regional Office

Air Traffic Division AGL-530

2300 East Devon Aven

Des Plaines, IL 60018
Tel. 312-694-7458 
APPENDIX B.--CABLEWAY DESIGN SUMMARY 


\section{CABLEWAY DESIGN SUMMARY}

District Office

Region

Station No. Name

Property Owner LB

RB

Signed Easement (attach)

Signed Easement

Y N Date

Y N Date

FAA notification Construction Permits

Highwater Access

DESIGN CRITERIA--Attach cross section of cableway station

Channel width, Normal

Bankful 100 yr flood

Elevation of: $50 \mathrm{yr}$ flood 100 yr flood Historical

Cableway span between supports Cable-car Type

Cableway Purpose

Design Load lbs (if <2250, justify)

DESIGN--Standard USGS design based on Cableway Design Manual-OFR

Soil Type A B Frost Depth ft Submergence. Probable $\mathrm{YN}$

Footings: LB

Footings: $\mathrm{RB}$ Dimensions Dimensions

Cable Support

Anchorage

$\begin{array}{lll}\mathrm{LB} & \\ \mathrm{LB} & \text { Angle } & \text { Size } \\ \mathrm{RB} & \mathrm{L}\end{array}$
Height Height D D CUYDS CUYDS

Main Cable

Cable Type Diam Termination

Backstay Wire Rope Type Diam Number

Turnbuckle Size U-bar Size No Clips

Unloaded Sag Distance (cable loaded sag) to $100 \mathrm{yr}$ elev

Walkways/Platforms

Other:

Deviations from standard design $\mathrm{Y} \mathrm{N}$; if $\mathrm{Y}$, attach design documentation Remarks:

Designed by Title Date

Checked by Title Date 
APPENDIX C.--PAINTING AND PRESERVATION GUIDELINES 


\section{Painting \& Preservation Guidelines}

A major cause of deterioration of metal cableway structures is failure to maintain proper protective paint coatings. A large part of this problem is lack of thorough cleaning and rust removal from metal components prior to recoating. Metal components must be sandblasted, wire brushed, scraped, and then washed to remove all loose material, grease, and soil, allowed to dry, and recoated with a two-coat paint system. Industrial enamels with oil- or alkyd-type bases are best suited to USGS field facilities. Dampness-tolerant primers, which are particularly well suited for field application, are available. These primers are formulated to bond firmly to bare or semi-bare metal and should be coated with a compatible top coat after a 24-hour drying time.

Preparation time will greatly exceed actual painting time. A properly applied two-coat system should last 5 or 6 years on field structures, whereas a quick cover over with improper preparation may fail in less than a year.

Touch-up or repair of damaged galvanized surfaces should be done with an organic zinc-rich paint formulated for this purpose. Badly weathered galvanized structures should be painted with one of several two-coat systems of paints developed for this purpose.

Wooden structures are best preserved by fabrication from pressure-treated lumber. Where this has not been done, field treatment with a copper-sulfate-type wood preservative, paying particular attention to the members' end-grain areas most susceptible to deterioration, is an acceptable alternative.

All coatings should be industrial quality products from reliable manufacturers. Most coatings should be applied by brush during temperatures from $40^{\circ} \mathrm{F}$ to $125^{\circ} \mathrm{F}$. 